\title{
Planejamentos experimentais em modelos de regressão linear
}

\section{Camila Serinoli}

\author{
Dissertação apresentada \\ ao \\ Instituto de Matemática e Estatística \\ da \\ Universidade de São Paulo \\ para \\ Obtenção do grau \\ de \\ Mestre em Ciências
}

Programa: Estatística

Orientadora: Profa. Dra. Silvia Nagib Elian

São Paulo - Fevereiro - 2009. 


\section{Planejamentos experimentais em modelos de regressão linear}

Este exemplar corresponde à relação final

da dissertação devidamente corrigida e defendida por Camila Serinoli e aprovada pela Comissão Julgadora.

São Paulo, Junho de 2009

Comissão Julgadora:

- Profa. Dra. Silvia Nagib Elian (orientadora) - IME-USP

- Profa. Dra. Elisete da Conceição Quintaneiro Aubin - IME-USP

- Prof. Dr. Juvencio Santos Nobre - UFC 
Agradeço a Deus,

por sempre estar

ao meu lado,

e por ter me ajudado

a realizar este sonho. 
Agradeço ao meu marido João Ricardo Tiusso que esteve presente durante todo o mestrado, me ajudando e me apoiando para eu conseguir mais esta conquista. 


\section{Agradecimentos}

Nunca devemos desanimar, a nossa decisão de como vencer determinará a nossa vitória em cada dificuldade que enfrentamos. Deus prova o seu amor a todas as pessoas que lutam para vencer as dificuldades da vida e sai vitorioso aquele que com fé em Deus buscou a saída certa e com confiança em Deus recebe a recompensa em dobro. Tudo passa, embora fiquem as lembranças que muitas vezes é bom recordar, pois a vida é ciclo de experiências que aprendemos na escola da vida. Para mim este trabalho foi muito importante e tenho orgulho porque lutei muito para chegar até aqui, passei por muitas dificuldades que com a ajuda de todos superei.

Primeiramente quero agradecer à minha orientadora Silvia Nagib Elian pelo apoio, carinho, compreensão e incentivo em todos os momentos.

Agradeço aos professores do Departamento de Estatística do Instituto de Matemática e Estatística da Universidade de São Paulo, com quem tive a grande satisfação em estudar.

Aos meus queridos Pais Airton Serinoli e Maria Aparecida Marques Barcellos Serinoli que sempre estiveram ao meu lado me dando força para vencer esta batalha.

As minhas irmãs Carla Serinoli e Daniela Serinoli que sempre me ajudam em tudo que preciso.

Aos meus amigos Adriana Possamai, Artur Lemonte, Aline Abdelmur, Filipe Zabala, Karen Elisa, Kátia Marques e Marcos Paulo que me ajudaram nas disciplinas e sempre estiveram ao meu lado nas dificuldades, com essas pessoas aprendi muito e levarei esse aprendizado para sempre.

Agradeço a todos que de alguma forma colaboraram com este trabalho. 


\section{Resumo}

Neste trabalho apresentamos os principais objetivos dos planejamentos experimentais em modelos de regressão. Na primeira parte do trabalho descrevemos os planejamentos com alavancagem constante, que permitem que todos os pontos amostrais exerçam a mesma influência nas estimativas dos parâmetros do modelo de regressão. Abordamos ainda outros tipos de planejamentos experimentais que obedecem a certos critérios como, por exemplo: G-

otimalidade, D-otimalidade e Planejamentos ortogonais. Finalizando o trabalho foi apresentada uma análise prática em que as principais medidas estudadas foram aplicadas a um conjunto de dados reais. 


\begin{abstract}
This work presents the main objectives of the sampling plans in regression models. The first part of the study describes the planning with constant leverage, enabling all sampling points exercise the same influence on the estimatives of the parameters of the regression model. We still discussed other types of experimental plans that meet certain criteria, such as G-optimality, D-optimality and Planning orthogonal. Finally the work presented a practical analysis where the main measures were applied to a set of real data.
\end{abstract}




\section{Sumário}

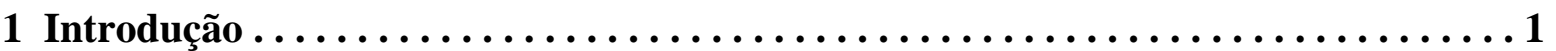

2 Objetivos dos Planejamentos Experimentais .................... 3

\section{Planejamento com alavancagem constante}

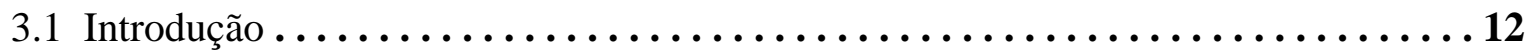

3.2 Planejamentos com alavancagem constante para a regressão linear múltipla . . . . 14

3.3 Métodos de construção de planejamentos com alavancagem constante . . . . . . 17

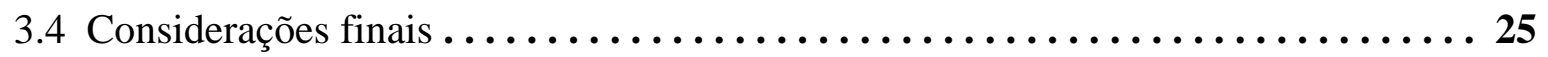

\section{Critérios de Otimalidade}

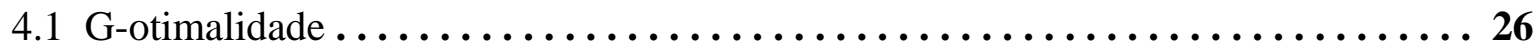

4.2 D-otimalidade para Regressão Linear ....................... 27

4.3 Algoritmos para construção de planejamento D-ótimo ............... 31

4.4 Métodos de obtenção de planejamentos D-ótimos ............... 33

4.5 Considerações finais $\ldots \ldots \ldots \ldots \ldots \ldots \ldots \ldots \ldots \ldots \ldots \ldots \ldots \ldots \ldots$

\section{Outras propriedades de Planejamentos Experimentais}

5.1 Planejamentos robustos com relação a um modelo $\ldots \ldots \ldots \ldots \ldots \ldots \ldots \ldots$

5.2 Planejamentos ortogonais $\ldots \ldots \ldots \ldots \ldots \ldots \ldots \ldots \ldots \ldots \ldots \ldots \ldots \ldots$

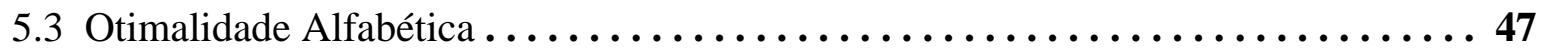

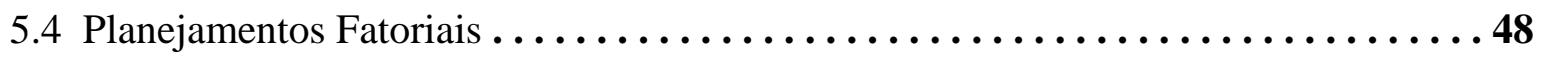

5.5 Planejamento de Superfície de Resposta ..................... 49

\section{Aplicação}

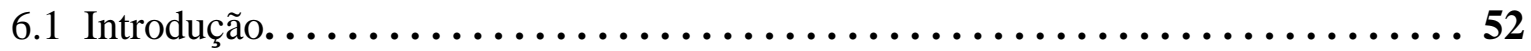

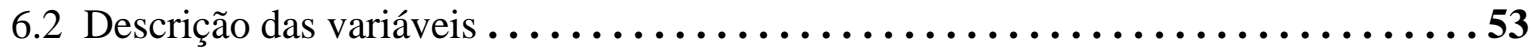

6.3 Análise dos Planejamentos . . . . . . . . . . . . . . . . . . . 56 
A Apêndice

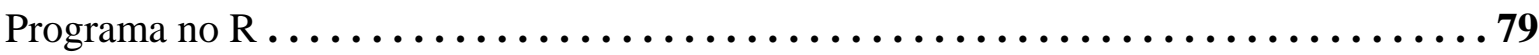

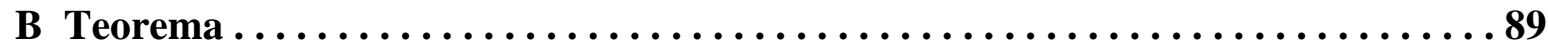

C Referências Bibliográficas ............................ 91 


\section{Capítulo 1}

\section{Introdução}

Análise de regressão: É uma técnica estatística usada para pesquisar e modelar o relacionamento existente entre as diversas variáveis de um processo.

As estratégias no planejamento de experimentos são:

- reconhecer, estabelecer e delimitar o problema;

- identificar os possíveis fatores que podem afetar o problema em estudo;

- verificar quais fatores que poderão ser mantidos fixos e, portanto, não terão os seus efeitos avaliados no estudo experimental;

- escolher um projeto experimental adequado, isto é, saber como combinar os níveis dos fatores de forma que se possa resolver o problema proposto com o menor custo possível;

- escolher a resposta adequada, ou seja, a variável y que mede adequadamente o resultado (a qualidade, o desempenho, etc) do processo e o planejamento de como será a análise dos dados do experimento.

No Capítulo 2 falamos de uma forma geral dos objetivos dos planejamentos experimentais, foi discutido que os valores dos regressores poderiam ser escolhidos através do uso de um planejamento experimental podendo assim evitar multicolinearidade ou minimizar a variância de certos estimadores. Comentamos sobre critérios desejáveis para um planejamento experimental. Descrevemos propriedades de 
planejamento que ajustam modelos da forma $Y=X \beta+\varepsilon$. Um comentário importante é que os $n$ valores da variável preditora não são necessariamente distintos, permitindo réplicas. Falamos sobre a matriz de projeção que é muito importante na identificação de observações influentes.

No Capítulo 3 apresentamos e discutimos os planejamentos com alavancagem constante que tem a vantagem de permitir que todos os pontos amostrais exerçam a mesma influência nas estimativas dos parâmetros do modelo de regressão. Foram apresentados exemplos de planejamentos com alavancagem constante e aplicação de algumas técnicas de construção de planejamento com alavancagem constante e foi utilizado o conhecido conjunto de dados "Stack loss".

No Capítulo 4 foi o momento em que escolhemos um planejamento experimental. Existem vários critérios de otimização que têm sido considerados importantes e assim foi destacado um grupo de critérios que é usualmente referido como “otimalidade alfabética”. Apresentamos uma breve discussão sobre algoritmos de construção de planejamentos D-ótimos e métodos de obtenção de planejamentos Dótimos, assim como planejamentos G-ótimos e seus métodos de obtenção.

No Capítulo 5 descrevemos vários outros critérios de escolha de planejamentos descritos na literatura, incluindo planejamentos robustos com relação a um modelo e também planejamentos ortogonais, além disso, vimos medidas de multicolinearidade e planejamentos de Superfície de Resposta.

No Capítulo 6 utilizamos um conjunto de dados e fizemos as aplicações nas partes importantes que estudamos no decorrer do trabalho. 


\section{Capítulo 2}

\section{Objetivos dos Planejamentos experimentais}

Muitos conjuntos de dados da regressão, senão a maioria, têm regressores que são variáveis aleatórias. Contudo, é freqüentemente possível selecionar os valores dos regressores, isto é, os valores dos regressores poderiam ser escolhidos através do uso de um planejamento experimental. Este poderia permitir que vários objetivos fossem atingidos, como, por exemplo, evitar a multicolinearidade ou minimizar a variância de certos estimadores. Existem vários outros objetivos que o uso de um planejamento experimental poderia satisfazer e isto será assunto do presente capítulo.

Consideremos o modelo linear geral $Y=X \beta+\varepsilon$ onde:

$\mathrm{Y}=\left[Y_{1}, \ldots, Y_{n}\right]^{T}$ é um vetor aleatório $\mathrm{n} \times 1$ de observações;

$\mathrm{X}=\left[x_{i j}\right]$ é uma matriz de dimensão $\mathrm{n} \mathrm{x}(\mathrm{p}+1)$ contendo os valores das $\mathrm{p}$ variáveis regressoras e uma coluna de uns;

$\beta=\left[\beta_{0}, \ldots, \beta_{p}\right]^{T}$ é um vetor $(\mathrm{p}+1) \times 1$ de parâmetros desconhecidos;

$\varepsilon=\left[\varepsilon_{1}, \ldots, \varepsilon_{n}\right]^{T}$ é um vetor aleatório $\mathrm{n} \times 1$ de erros.

De modo geral, critérios aparentemente desejáveis para um planejamento experimental são: 
a) Que todos os pontos exerçam igual influência na determinação das estimativas dos coeficientes de regressão.

b) Minimização de algumas funções (tais como a soma) das variâncias de estimadores.

c) O planejamento deveria permitir detectarmos a necessidade da inclusão de termos não lineares.

Segundo Box e Draper (1975), planejamentos para ajustar modelos de forma $Y=X \beta+\varepsilon$ podem levar em conta vários critérios, que descreveremos a seguir. Um destes é que o planejamento seja pouco sensível a observações discrepantes. Uma possível medida de tal sensibilidade é a soma de quadrados dos elementos da diagonal principal da matriz $X\left(X^{T} X\right)^{-1} X^{T}$.

As demais propriedades são:

i ) Gerar uma distribuição satisfatória de informação através de uma região de interesse $\mathrm{R}$.

ii) Assegurar que o valor ajustado em $\mathrm{x}, \hat{y}(x)$ seja tão próximo quanto possível do valor real em $\mathrm{x}, \mathrm{E}(\mathrm{y} \mid \mathrm{x})$.

iii) Fornecer a possibilidade de detectar falta de ajuste.

iv) Permitir que transformações sejam estimadas.

v) Permitir que os experimentos sejam realizados em blocos quando necessário.

vi) Permitir que planejamentos de ordem crescente sejam construídos seqüencialmente.

vii) Proporcionar uma estimativa interna da variância do erro.

viii) Ser insensível ou pouco sensível a observações discrepantes e a violação de suposições da teoria normal usual.

ix) Requerer um número mínimo de pontos experimentais.

x) Proporcionar padrões simples de distribuição dos dados que permitam apreciações visuais rápidas.

xi) Assegurar simplicidade de cálculo.

xii) Comportar-se bem na presença de erros no conjunto das variáveis preditoras.

xiii) Não requerer um número muito grande de níveis das variáveis preditoras.

xiv) Proporcionar uma posterior avaliação da suposição de igualdade de variâncias (homoscedasticidade). 
Ainda de acordo com Box e Draper (1975), é desejável que o estatístico aplicado tenha habilidade de perceber as necessidades especiais de uma dada situação e escolher o planejamento que permita encontrá-las. Para auxiliar nessa escolha, seria útil quando possível, ter medidas numéricas que expressem as propriedades desejáveis do experimento em relação aos vários critérios.

Draper e Smith (1981) analisam a situação em que temos somente uma variável preditora X e o modelo postulado é uma reta, de modo que as alternativas que seriam consideradas freqüentemente seriam polinômios de ordem superior em X, por exemplo, o quadrático $Y=\beta_{0}+\beta_{1} X+\beta_{11} X^{2}+\varepsilon$, o cúbico e assim por diante.

Vale ressaltar que o modelo de partida com o qual geralmente lidamos é $Y=\beta_{0}+\beta_{1} X+\varepsilon$ e todas as informações foram colocadas em uma perspectiva prática considerando o problema de escolha de uma estratégia experimental para o caso de uma variável preditora.

Supõe-se que um pesquisador quer coletar dados de uma variável resposta $\mathrm{Y}$ associados a $\mathrm{n}$ valores selecionados de uma variável preditora controlável para determinar uma relação entre a variável Y e a variável preditora.

Os n valores da variável preditora não são necessariamente distintos, portanto são permitidas réplicas. Nessas condições cabe avaliar:

1) Em qual intervalo de valores da variável preditora o pesquisador está realmente interessado? A decisão é freqüentemente difícil de ser tomada.

O intervalo deve ser amplo o suficiente para permitir inferência útil e uma vez que a decisão é tomada, o intervalo pode ser codificado para se tornar [-1,1], sem perda de generalidade. Em geral a transformação que permite tal codificação é dada por:

$$
X=\frac{\text { variável original }- \text { ponto médio do int ervalo original }}{\text { metade da amplitude doint ervalo original }}
$$

2) Que tipo de relação o pesquisador espera obter no intervalo selecionado (linear, quadrática ou outra)? 
Neste momento o pesquisador deverá utilizar seu próprio conhecimento e também consultar especialistas. Para fixar idéias, os autores admitem que o pesquisador acredita que a relação é provavelmente de $1^{\circ}$ grau, mas não está absolutamente certo.

3) Verificou-se que o modelo de $1^{\circ}$ grau é inadequado, qual modelo o pesquisador espera como alternativa?

Se sua crença inicial é que o modelo verdadeiro é uma reta, provavelmente, se isso não ocorrer, espera-se um modelo quadrático. Uma possibilidade remota é que o modelo verdadeiro seja cúbico.

4) O pesquisador deverá incorporar réplicas nos experimentos de modo que $\sigma^{2}$ possa ser estimado através do erro puro e dessa forma, as suposições usuais principalmente a de homoscedasticidade possam ser checadas.

5) Quantos dados experimentais são possíveis? Geralmente o pesquisador tem problemas de tempo, dinheiro, ou mesmo motivos práticos que dificultam a obtenção dos dados.

6) Quantas posições, isto é, diferentes valores de X, deveriam ser escolhidos e quantas observações devem ser obtidas para cada valor de X?

Um exemplo ilustrativo do problema encontra-se a seguir.

Vamos supor que o pesquisador decide que a relação de $1^{\circ}$ grau é a correta no intervalo $-1 \leq X \leq 1$ do seu preditor codificado, que teme uma alternativa quadrática, não conhece $\sigma^{2}$ e que $n=14$ observações são possíveis. Temos as seguintes questões: Em quais valores de $\mathrm{X}$ (por exemplo, quais posições) ele deveria realizar as coletas experimentais, quantas e com qual justificativa?

A Figura 2.1 mostra algumas das possibilidades que podem ser consideradas para uma amostra de tamanho 14, cada ponto representa uma observação e "pilhas" de pontos representam réplicas. 


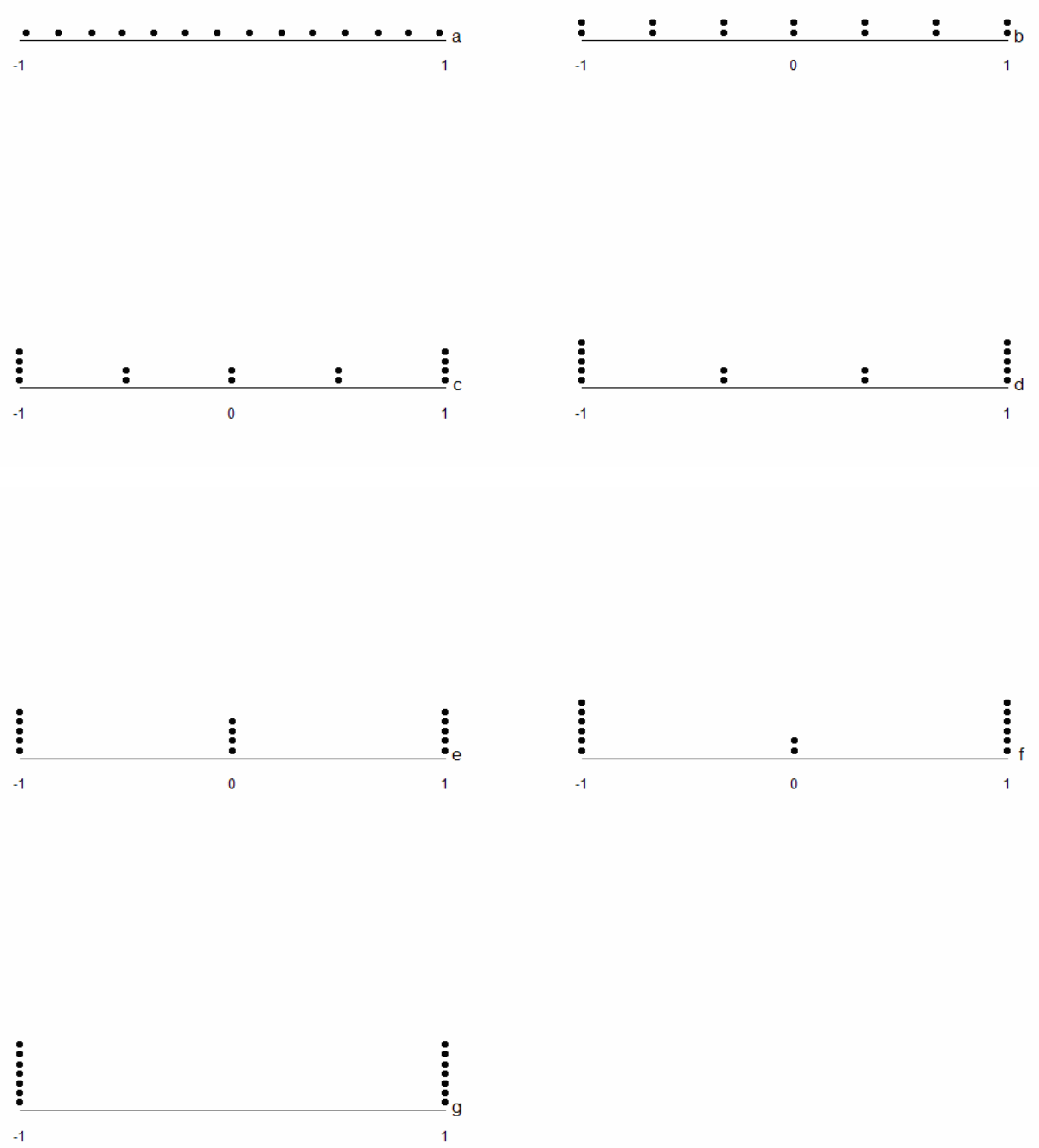

Figura 2.1: Algumas possíveis estratégias experimentais para obter dados para ajustar uma reta. (a) 14 posições (b) 7 posições (c) 5 posições (d) 4 posições (e) 3 posições (f) 3 posições (g) 2 posições

Draper e Smith (1981) analisam como cada um dos planejamentos presentes na Figura 2.1 preenche os requisitos desejáveis no ajuste do modelo de regressão linear simples $\mathrm{Y}=\beta_{0}+\beta_{1} X+\varepsilon$ com base em uma amostra de $\mathrm{n}=14$ observações independentes $\left(X_{i}, Y_{i}\right)$ em que $X_{i}$ é não aleatório e $Y_{i} \sim N\left(\beta_{0}+\beta_{1} X_{i}, \sigma^{2}\right)$. 
Cada planejamento tem em princípio 14 graus de liberdade. Dois deles são destinados à estimação dos parâmetros $\beta_{0}$ e $\beta_{1}$, restando 12 graus de liberdade, associados à soma de quadrados do resíduo(SQRes), para serem alocados entre falta de ajuste e erro puro.

Ajustado o modelo de regressão $Y=\beta_{0}+\beta_{1} X+\varepsilon$, na presença de réplicas, as somas de quadrados da falta de ajuste e do erro puro são dadas por:

$$
\mathrm{SQFA}=\sum_{i=1}^{k} n_{i}\left(\bar{y}_{i}-\hat{y}_{i}\right)^{2} \text { e SQEP }=\sum_{i=1}^{k} \sum_{j=1}^{n_{i}}\left(y_{i j}-\bar{y}_{i}\right)^{2}
$$

sendo que:

k: número de posições

$\bar{y}_{i}$ : média dos valores da variável Y associados ao i-ésimo valor $x_{i}$ da variável $\mathrm{X}$

$\hat{y}_{i}=\hat{\beta}_{0}+\hat{\beta}_{1} x_{i}$, estimador da média $\mathrm{E}\left(\mathrm{y} \mid x_{i}\right)=\beta_{0}+\beta_{1} x_{i}$

$\hat{\beta}_{0}$ e $\hat{\beta}_{1}$ estimadores de mínimos quadrados de $\beta_{0}$ e $\beta_{1}$

$n_{i}$ : número de observações associadas ao valor $x_{i}$ da variável $\mathrm{X}, \mathrm{i}=1,2, \ldots, \mathrm{k}$.

Além disso, a soma de quadrados do resíduo, SQRes, é definida como:

$$
S Q \operatorname{Re} s=\sum_{i=1}^{k} \sum_{j=1}^{n_{i}}\left(y_{i j}-\hat{y}_{i}\right)^{2}
$$

e verifica-se que SQRes = SQEP + SQFA.

A Tabela 2.1 corresponde à tabela de análise de variância associada ao teste de falta de ajustamento, que testa a hipótese nula $\mathrm{H}_{0}$ : $\mathrm{O}$ modelo é da forma $Y=\beta_{0}+\beta_{1} X+\varepsilon$ e rejeita essa hipótese se:

$$
\mathrm{F}_{F A}=\frac{\frac{S Q F A}{k-2}}{\frac{S Q E P}{n-k}} \geq F_{c, 1-\alpha}
$$

em que $F_{c, 1-\alpha}$ é o quantil de ordem 1- $\alpha$ da distribuição F com k-2 graus de liberdade no numerador e n-k graus de liberdade no denominador. 
Tabela 2.1: Tabela de análise de Variância para falta de ajustamento

\begin{tabular}{llllll}
\hline Fonte de Variação & GL & SQ & QM & F \\
\hline Falta de ajuste & & $\mathrm{k}-2$ & & SQFA & QMFA \\
$F_{F A}=\frac{Q M F A}{Q M E P}$ & & & & & \\
\hline Erro Puro & $\mathrm{n}-\mathrm{k}$ & SQEP & QMEP & \\
\hline Resíduo & $\mathrm{n}-2$ & SQRes & & \\
\hline
\end{tabular}

Já, a Tabela 2.2 apresenta algumas características associadas às sete estratégias representadas na Figura 2.1, e que são fundamentais para a escolha de uma delas.

Tabela 2.2: Características associadas às estratégias

\begin{tabular}{|c|c|c|c|c|c|c|c|}
\hline & (a) & (b) & (c) & (d) & (e) & (f) & (g) \\
\hline $\begin{array}{l}\text { (1)graus de liberdade } \\
\text { de falta de ajuste }\end{array}$ & 12 & 5 & 3 & 2 & 1 & 1 & 0 \\
\hline $\begin{array}{l}\text { (2)graus de liberdade } \\
\text { do erro puro }\end{array}$ & 0 & 7 & 9 & 10 & 11 & 11 & 12 \\
\hline $\begin{array}{l}\text { (3) } D P\left(\hat{\beta}_{1}\right) / \sigma \\
\mathbf{0 , 2 7}\end{array}$ & 0,43 & & 0,40 & 0,33 & 0,31 & 0,32 & 0,29 \\
\hline (4) $k$ & 14 & 7 & 5 & 4 & 3 & 3 & 2 \\
\hline
\end{tabular}

As linhas (1) e (2) da Tabela 2.2 exibem a partição dos graus de liberdade residuais em erro puro e falta de ajustamento para os vários planejamentos. A linha (3) fornece o valor de $\left\{\sum\left(X_{i}-\bar{X}\right)^{2}\right\}^{-\frac{1}{2}}$ o qual pela equação: $\operatorname{Var}\left(\hat{\beta}_{1}\right)=$ $\frac{\sigma^{2}}{\sum\left(X_{i}-\bar{X}\right)^{2}}=\frac{\sigma^{2}}{S_{x x}}$ é proporcional ao desvio-padrão de $\hat{\beta}_{1}$, quando é ajustada a reta $\hat{Y}=\hat{\beta}_{0}+\hat{\beta}_{1} X_{1}$. Já a linha (4) mostra o número de parâmetros que é possível ajustar em cada um dos planejamentos, sendo que podemos ajustar um polinômio de grau k-1 (com k parâmetros incluindo $\beta_{0}$ ) para um planejamento com k posições. Além disso, fixados 
n e $\sigma^{2}$, esta quantidade é proporcional a $\frac{k \sigma^{2}}{n}$ que é o tamanho médio de $\mathrm{V}(\hat{Y}(X))$, calculando a média sobre todos os pontos do planejamento, quando o polinômio de grau k-1 é ajustado.

Em outras palavras, verifica-se que:

$$
\frac{\sum_{i=1}^{n} V\left\{\hat{Y}\left(X_{i}\right)\right\}}{n}=\frac{k \sigma^{2}}{n} \text {. }
$$

Notemos que o número de graus de liberdade da soma de quadrados devido à falta de ajuste é igual ao número de posições de $\mathrm{X}$ menos o número de parâmetros no modelo postulado.

Da Tabela 2.2, observamos que a exigência de que $\sigma^{2}$ deva ser estimado via erro puro faz com que:

- (a) seja uma estratégia pobre. Se desejarmos testar a falta de ajuste, (g) também é automaticamente eliminada.

- Quanto à situação (b), é realmente necessário usar sete diferentes níveis se nossa alternativa mais provável é um modelo quadrático? Alem do mais, dentre os planejamentos restantes é o que apresenta maior valor de $\operatorname{DP}\left(\hat{\beta}_{1}\right) / \sigma$. Por esses motivos, (b) pode ser retirado de consideração.

- Dessa forma a melhor escolha claramente se encontra numa das alternativas (c), (d), (e) e (f), dependendo da preferência do pesquisador. A rigor, somente três níveis são estritamente necessários num teste de falta de ajuste do modelo de grau um contra uma alternativa quadrática, mas, neste caso existiria somente um grau de liberdade para falta de ajuste em (e) e (f).

- O planejamento (d) possui dois graus de liberdade para falta de ajuste, já o planejamento (c) talvez tenha um número excessivo de níveis. Então a escolha final se encontra entre (f) e (d) com (f) sendo levemente preferida se a alternativa quadrática é a única esperada. No entanto, o aspecto mais importante desta discussão não é a escolha específica de um planejamento, mas sim a eliminação imediata de planejamentos que poderiam em outros contextos ser considerados razoáveis. 
Nesta seção, apresentamos recomendações básicas e gerais para os planejamentos experimentais em modelos de regressão linear, com maior ênfase para o caso de uma única variável independente. Nos próximos capítulos, apresentaremos alguns planejamentos mais específicos. 


\section{Capítulo 3}

\section{Planejamentos com alavancagem constante}

\subsection{Introdução}

O objetivo desse capítulo é apresentar e discutir os planejamentos com alavancagem constante, que têm a vantagem de permitir que todos os pontos amostrais exerçam a mesma influência nas estimativas dos parâmetros do modelo de regressão.

Com esse objetivo vamos apresentar inicialmente uma introdução sobre a matriz de projeção, resíduos, ponto de alavanca e técnicas de diagnóstico.

O modelo de regressão clássico é definido por $Y=X \beta+\varepsilon$ em que: $\mathrm{Y}=\left[Y_{1}, \ldots, Y_{n}\right]^{T}$ é um vetor aleatório $\mathrm{n} \times 1$ de observações; $\mathrm{X}=\left[x_{i j}\right]$ é uma matriz de dimensão $\mathrm{n} \mathrm{x}(\mathrm{p}+1)$ contendo os valores das $\mathrm{p}$ variáveis regressoras e uma coluna de uns;

$\beta=\left[\beta_{0}, \ldots, \beta_{p}\right]^{T}$ é um vetor $(\mathrm{p}+1) \times 1$ de parâmetros desconhecidos;

$\varepsilon=\left[\varepsilon_{1}, \ldots, \varepsilon_{n}\right]^{T}$ é um vetor aleatório $\mathrm{n} \times 1$ de erros. 
Assumimos que $\varepsilon$ satisfaz as condições $\mathrm{E}(\varepsilon)=0$ e $\operatorname{Cov}[\varepsilon]=\sigma^{2} I_{n}$ em que $\sigma^{2}>0$ e $I_{n}$ representando a matriz identidade de ordem n e a matiz X, denominada matriz planejamento, conterá um vetor coluna de $1: X_{0}=1$. O restante das p colunas $X_{1}, \ldots, X_{p}$ são denominadas variáveis independentes (ou variáveis explicativas, preditoras ou regressoras). É conveniente ainda o uso da notação $X_{i}{ }^{T}$ para o i-ésimo caso ou linha da matriz de planejamento $\mathrm{X}$.

O método de mínimos quadrados admite como estimador $\hat{\beta}$ de $\beta$ o valor que minimiza o comprimento $\|\mathrm{e}\|=\left[e^{T} e\right]^{\frac{1}{2}}$ do vetor de resíduos definido por e $=\mathrm{Y}-\mathrm{X} \hat{\beta}$. Tal estimador é da forma $\hat{\beta}=\left(X^{T} X\right)^{-1} X^{T} Y$ e os valores ajustados do modelo são definidos por $\hat{Y}=X \hat{\beta}$. A matriz de projeção é definida em termos da matriz de planejamento por $H=X\left(X^{T} X\right)^{-1} X^{T}$ os valores ajustados $\hat{Y}$ dependem das observações y somente através de $H=\left[h_{i j}\right]$ devido ao fato que $\hat{Y}=X \hat{\beta}=H Y$.

Como vemos, os valores ajustados (estimados) podem ser obtidos como combinações lineares das observações da variável resposta $y_{i}$, com os coeficientes sendo os elementos da matriz H. Da mesma forma que os valores estimados, os resíduos também podem ser obtidos como combinação linear das observações $y_{i}$, isto é:

$$
e=Y-\hat{Y}=(I-H) Y \text {. }
$$

Temos que a matriz (I-H) é simétrica e idempotente. A derivação da matriz de variância e covariância do vetor dos resíduos é feita como segue: $e=(I-H) y$, logo $\operatorname{Var}(e)=(I-H) \operatorname{Var}(Y)(I-H)^{T}$. Porém, para o modelo proposto, temos que $\quad \operatorname{Var}(Y)=\operatorname{Var}(\varepsilon)=\sigma^{2} I \quad$ e $\quad$ também $\quad(I-H)^{T}=(I-H) . \quad$ Assim, $\operatorname{Var}(e)=\sigma^{2}(I-H) I(I-H)=\sigma^{2}(I-H)(I-H)=\sigma^{2}(I-H)$.

Os valores dos elementos $h_{i j}$ da matriz $\mathrm{H}$ podem ser interpretados como a intensidade da "alavancagem” exercida pelos valores observados $y_{j}$ sobre os valores ajustados $\left(\hat{y}_{i}\right)$. Portanto, a inspeção dos elementos da matriz $\mathrm{H}$ pode revelar pontos potencialmente influentes devido a sua localização no espaço das variáveis independentes. Geralmente, são pontos distantes do subespaço gerado pelas colunas de $\mathrm{X}$. 
Na detecção de pontos de alavancas sugere-se utilizar $\mathrm{h}=\operatorname{diag}(\mathrm{H})$ no modelo de regressão linear. Um ponto é considerado alavanca quando exerce uma forte influência no seu valor ajustado. Utiliza-se o critério de destacar observações maiores do que duas vezes a média dos $h_{i i}, \mathrm{i}=1,2, \ldots, \mathrm{n}$ que, no modelo com intercepto, devido ao fato que $\sum h_{i i}=p+1$, é dada por $\frac{p+1}{n}$, em que p é o número de variáveis explicativas.

Uma etapa importante na análise do ajuste do modelo de regressão é a verificação de possíveis afastamentos das suposições feitas, especialmente para a parte aleatória e para a parte sistemática.

A utilização de técnicas de diagnóstico permite a detecção de observações influentes, isto é, pontos que exercem um peso desproporcional nas estimativas dos parâmetros do modelo. Pontos de alavanca receberam esse nome por terem um peso desproporcional no próprio valor ajustado. Quando associados a resíduos grandes podem produzir um mau ajuste.

\subsection{Planejamentos com alavancagem constante para a Regressão Linear Múltipla}

Apresentaremos a seguir os métodos para construção de planejamentos com alavancagem constante na regressão linear propostos por Dollinger e Staudte (1990). Conforme comentado anteriormente, a matriz de projeção é extremamente usada como uma ferramenta de diagnóstico em regressão linear porque contém o valor da alavanca que avalia o efeito que as variáveis independentes exercem nos seus respectivos valores ajustados. Em alguns experimentos, observações com alta alavanca podem ser evitadas através de escolhas sensatas de planejamentos para as variáveis independentes. 
No entanto, os métodos de construção que serão descritos são aplicáveis somente em situações experimentais em que existe algum controle na escolha de valores para as variáveis independentes.

Lembrando que o i-ésimo valor ajustado no caso $x_{i}{ }^{T}$ é $\hat{y}_{i}=\sum_{j=1}^{n} h_{i j} y_{j}$, de modo que $\hat{y}_{i}$ se altera com peso $h_{i j}$ com respeito a uma alteração no j-ésimo valor observado $y_{j}$, então a j-ésima coluna $H_{j}$ da matriz de projeção dá a taxa de resposta do vetor de valores ajustados $\hat{y}$ para uma mudança no j-ésimo valor observado, isto é, $H_{j}=\frac{\partial \hat{y}}{\partial y_{j}}$.

$\mathrm{O}$ vetor $H_{j}$ será chamado de j-ésimo vetor alavanca. Em muitas análises de diagnóstico estudados, a atenção é focada somente nos elementos da diagonal de $\mathrm{H}$, embora todos componentes da j-ésima coluna sejam necessários para avaliar o efeito de uma observação errônea na previsão.

Uma justificativa para restringir atenção somente a elementos $h_{i i}$ da diagonal principal é a seguinte: o quadrado do comprimento de $H_{j},\left\|H_{j}\right\|^{2}$, associado ao jésimo vetor alavanca, fornece uma medida do efeito combinado da j-ésima observação em todos os valores ajustados e é chamado de j-ésima alavanca. Como H é simétrica e idempotente, segue que $\left\|H_{j}\right\|^{2}=h_{j j}$, de modo que a j-ésima alavanca é simplesmente o valor $h_{j j}$ da diagonal de $\mathrm{H}$.

Verifica-se que elementos da diagonal da matriz de projeção pertencem ao intervalo $\left[n^{-1}, 1\right]$ e seu valor médio é $\frac{p+1}{n}$ (segundo Dollinger e Staudte 1990). Verifica-se ainda que a matriz de projeção é invariante com respeito a transformações lineares não singulares, ou seja, se W=XA em que A é não singular, então $H_{w}=H_{x}$. Isto significa que mesmo que as variáveis explicativas sofram uma transformação linear, o método de mínimos quadrados fornecerá um estimador com posterior matriz de projeção dentro do mesmo subespaço.

Dollinger e Staudte (1990) utilizam a centralização das variáveis explicativas originais. A matriz $Z_{n \times p}$ das variáveis explicativas centralizadas é tal que seu elemento de ordem ij é definido por $Z_{i j}=x_{i j}-n^{-1} \sum_{i=1}^{n} x_{i j}$. Se $H_{z}=Z\left(Z^{T} Z\right)^{-1} Z^{T}$ é a matriz de projeção correspodente para Z, conforme demonstrado em Cook e Weiberg (1982, p.12) 
segue que o i-ésimo elemento da diagonal de $H_{z}$ é dado por $\left(H_{z}\right)_{i i}=\left(H_{x}\right)_{i i}-\frac{1}{n}=h_{i i}-\frac{1}{n}$. Se denotarmos a i-ésima linha de $\mathrm{Z}$ por $Z_{i}{ }^{T}$, temos que $\left(H_{Z}\right)_{i i}=Z_{i}^{T}\left(Z^{T} Z\right)^{-1} Z_{i}$, então do ponto de vista geométrico, o conjunto de vetores $\mathrm{Z}$ que geram alavancagem constante c no caso das variáveis centralizadas é dado por: $\xi_{Z}(c)=\left\{Z: Z^{T}\left(Z^{T} Z\right)^{-1} Z=c\right\}$.

Estritamente falando, o termo "alavanca” somente se aplica para vetores $Z_{i}{ }^{T}$ que se constituem em linhas da matriz Z. Desta forma, os contornos de alavancagem constante são elipsóides em $\mathfrak{R}^{p}$ centrados na origem. As direções e comprimentos dos eixos são determinados pela estrutura da matriz positiva definida $Z^{T} Z$, de modo que os eixos têm a direção dos vetores característicos de $Z^{T} Z$ e os comprimentos são proporcionais à raiz quadrada das raízes características correspondentes.

O planejamento X para o qual todos os pontos amostrais têm o mesmo valor da alavanca será denominado de planejamento com alavancagem constante. Para um planejamento de alavancagem constante, em que $\mathrm{X}$ tem $\mathrm{n}$ linhas e $\mathrm{p}+1$ colunas, $\left(H_{x}\right)_{i i}=\frac{p+1}{n}, \mathrm{i}=1,2, \ldots, \mathrm{n}$.

Para o correspondente planejamento centrado $\mathrm{Z},\left(H_{z}\right)_{i i}=\frac{p}{n}, \mathrm{i}=1,2, \ldots, \mathrm{n}$ e dessa forma todos os pontos de Z encontram-se no elipsóide $\xi_{z}\left(\frac{p}{n}\right)$.

Conforme comentado anteriormente, a grande vantagem de utilizarmos um planejamento com alavancagem constante é a inexistência de pontos com alavanca alta. Como uma observação para um ponto de alavanca alta pode ter um efeito desproporcional nos valores ajustados, a inexistência de tais pontos é freqüentemente desejável no planejamento de experimentos de regressão robusta. 


\subsection{Métodos de construção de planejamentos com alavancagem constante}

Nesta seção apresentaremos diferentes métodos de construção de planejamento com alavancagem constante para várias escolhas do tamanho amostral e número de variáveis independentes. Temos que as linhas da matriz de planejamento com alavancagem constante para p variáveis explicativas necessariamente encontra-se em um elipsóide em $\mathfrak{R}^{p}$. Por outro lado, a seleção dessa região elipsoidal para construir um planejamento com alavancagem constante deve ser baseada no intervalo desejado das variáveis explicativas a serem incluídas no experimento.

Para simplificar a análise, Dollinger e Staudte (1990) restringem a atenção para a matriz Z de variáveis explicativas centradas, já que um planejamento com alavancagem constante para as variáveis explicativas centradas pode ser transformado em um planejamento com alavancagem constante nas variáveis originais.

Além disso, os autores utilizam o conceito de planejamento escalar definido a seguir:

Definição 3.1: Um planejamento $Z, n \times$ p, é denominado planejamento escalar se a matriz $\mathrm{Z}^{T} \mathrm{Z}$ é múltipla da matriz identidade, ou seja, se $Z^{T} Z=\mathrm{m} I_{p}$.

São ainda considerados planejamentos experimentais com alavancagem constante cujos pontos pertencem a esferas centradas na origem. Destacamos que equações de elipsóides da forma $\mathrm{z}^{T} A^{-1} \mathrm{z}=\mathrm{k}$ se reduzem a equações de esferas centradas na origem para $A^{-1}=m I$, com I sendo a matriz identidade e m uma constante positiva. Além disso, como conseqüência da condição $\mathrm{z}^{T} A^{-1} \mathrm{z}=\mathrm{k}$ para $A^{-1}=m I$, verifica-se que se um planejamento amostral é tal que seus pontos pertencem à esfera centrada na origem, então todos os vetores formados pelas linhas de Z têm o mesmo comprimento. Adicionalmente, verifica-se que matrizes de planejamento $\mathrm{Z}$ associadas a 
planejamentos escalares possuem colunas ortogonais de mesmo comprimento, já que $Z^{T} Z=m I_{p}$.

Apresentaremos a seguir os seis primeiros itens do teorema proposto por Dollinger e Staudte (1990). As partes (i) e (ii) relacionam planejamentos com alavancagem constantes e escalares. O restante do teorema fornece métodos básicos para construção de planejamentos com alavancagem constante.

Teorema 3.1: Seja Z um planejamento centrado de modo que a soma dos elementos de cada coluna da matriz Z é zero. Nessas condições

(i) Se Z é um planejamento escalar n x p, então Z é um planejamento com alavancagem constante se e somente se as linhas de Z têm igual comprimento. Além disso, se as linhas de $Z$ se encontram em uma esfera de raio unitário, então $Z^{T} Z=\frac{n}{p} I_{p}$.

ii) Reciprocamente, se Z é um planejamento com alavancagem constante em uma esfera centrada na origem e se esta esfera é o único elipsóide em $\mathfrak{R}^{p}$, centrado na origem, que passa por todos os pontos (linhas) de Z, então Z é um planejamento escalar.

iii) Se $\mathrm{Z}$ é um planejamento escalar n x p e U é uma matriz ortogonal p x p, então ZU é um planejamento escalar. O resultado é também verdadeiro para planejamentos com alavancagem constante, já que estes são invariantes sob transformações não singulares.

iv) Sejam V e W planejamentos escalares $\mathrm{m} x \mathrm{p}$ e $\mathrm{n}$ x p na mesma esfera centrada na origem. Então, o planejamento combinado $Z^{T}=\left[V^{t} W^{t}\right]$ é um planejamento escalar com alavancagem constante $(m+n) \times p$ na mesma esfera.

v) Sejam $\mathrm{V}$ e $\mathrm{W}$ planejamentos com alavancagem constante $\mathrm{m}$ x $\mathrm{p}$ e $\mathrm{n}$ x $\mathrm{q}$ respectivamente, com alavancas $\frac{p}{m}$ e $\frac{q}{n}$ iguais. Então a matriz $Z=\left[\begin{array}{cc}V & 0 \\ 0 & W\end{array}\right]$ define um planejamento com alavancagem constante de dimensão $(m+n) \times(p+q)$. Se em adição $V$ e W são planejamentos escalares com alavancagem constante em uma esfera de mesmo raio, então Z é também um planejamento escalar com alavancagem constante. 
vi) Seja $W$ um planejamento escalar $\mathrm{m} x(\mathrm{p}-1) \operatorname{com} W^{T} W=k I_{p-1}$. Para cada linha $w_{i}{ }^{t}$ de W seja $c_{i}=\frac{p k}{m}-\left\|w_{i}^{T}\right\|^{2}$ para $\mathrm{i}=1,2, \ldots, \mathrm{m}$ e suponha que $c_{i} \geq 0$. Para cada $\mathrm{i}$, sejam os pontos $Z^{T}=\left[w_{i}{ }^{T}, \pm c_{i}{ }^{\frac{1}{2}}\right]$ pertencentes a $\mathfrak{R}^{p}$. A matriz resultante $\mathrm{Z}$, de dimensão $2 \mathrm{~m}$ $\mathrm{x}$ p, define um planejamento escalar com alavancagem constante na esfera de raio $\left(\frac{p k}{m}\right)^{\frac{1}{2}}$.

Apresentaremos a seguir alguns exemplos de planejamentos com alavancagem constante.

Exemplo 1: Na regressão linear simples $(\mathrm{p}=1)$ o único planejamento com alavancagem constante útil é aquele no qual o tamanho de amostra $n=2 m$ é par e os pontos são alocados eqüidistantes da origem. Se $h_{i i}$ são os elementos da diagonal principal da matriz de projeção $\mathrm{H}$, lembrando que no modelo de regressão linear simples $h_{i i}=\frac{1}{n}+\frac{\left(X_{i}-\bar{X}\right)^{2}}{\sum_{j=1}^{n}\left(X_{j}-\bar{X}\right)^{2}}$ será constante somente quando os $X_{i}$ são eqüidistantes de $\bar{X}$; e excluindo o caso trivial em que todos $X_{i}$ são iguais, isto ocorrerá somente quando existirem apenas dois valores distintos de $X_{i}$.

Se o intervalo de X é transformado para $(-1,1)$ e n é par, então o valor máximo de $h_{i i}$ é minimizado quando metade das observações são de $\mathrm{X}=-1$ e a outra metade é de $X=+1$. Tal fato é de interesse prático porque verifica-se que um intervalo de predição para Y pode ser escrito como $\hat{y} \pm t_{\alpha / 2} s \sqrt{1+h_{i i}}$.

Além disso, verifica-se que $\operatorname{Var}\left(\hat{\beta}_{1}\right)$ é minimizada quando temos $\frac{n}{2}$ pontos em cada um dos dois possíveis valores $X_{i}$, como torna-se aparente quando observamos que $\operatorname{Var}\left(\hat{\beta}_{1}\right)=\frac{\sigma^{2}}{\sum\left(X_{i}-\bar{X}\right)^{2}}$. No entanto tais planejamentos não permitem testes sobre a hipótese de linearidade já que não fornecem informação sobre a relação de y e x entre os 
dois valores extremos de $\mathrm{X}$. Assim, seria preferível que existissem pontos adicionais entre os dois valores de $\mathrm{X}$.

Isto poderia ser conseguido através de sutis modificações no planejamento de alavancagem constante de modo a facilitar a detecção de possível não linearidade, sem deixar de evitar pontos de alta alavanca.

Exemplo 2: Polígonos Regulares no plano.

Verifica-se que em $\mathfrak{R}^{2}$ existe um planejamento escalar para todo $n \geq 3$, cujos pontos são os vértices de um polígono regular centrado na origem. Por exemplo, para n=4 seja o quadrado de lado 4 com centro na origem, conforme Figura 3.1.

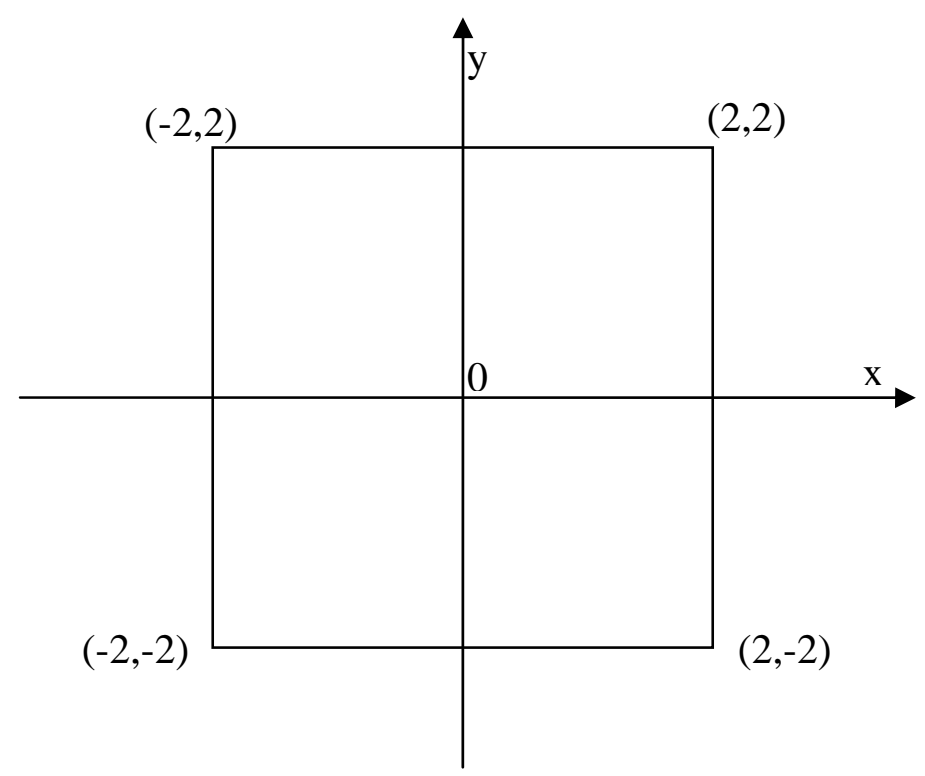

Figura 3.1: Quadrado centrado na origem

Neste caso,

$Z=\left[\begin{array}{rr}2 & 2 \\ -2 & 2 \\ -2 & -2 \\ 2 & -2\end{array}\right] \quad$ e $\quad Z^{T} Z=\left[\begin{array}{cc}16 & 0 \\ 0 & 16\end{array}\right]=m I_{2}$

para $m=16$. Portanto $Z$ é um planejamento escalar. Além disso, como suas linhas são de igual comprimento, pelo item (i) do Teorema 3.1, Z será um planejamento com alavancagem constante. 
Realmente,

$\mathrm{Z}\left(\mathrm{Z}^{\mathrm{T}} \mathrm{Z}\right)^{-1} \mathrm{Z}^{T}=$

$\frac{1}{16}\left[\begin{array}{rr}2 & 2 \\ -2 & 2 \\ -2 & -2 \\ 2 & -2\end{array}\right]\left[\begin{array}{rrrr}2 & -2 & -2 & 2 \\ 2 & 2 & -2 & -2\end{array}\right]=\frac{1}{16}\left[\begin{array}{rrrr}8 & 0 & -8 & 0 \\ 0 & 8 & 0 & -8 \\ -8 & 0 & 8 & 0 \\ 0 & -8 & 0 & 8\end{array}\right]$

de modo que $h_{i i}=\frac{1}{2}, \mathrm{i}=1,2,3,4$.

Para n=6 seja o hexágono com centro na origem, conforme Figura 3.2.

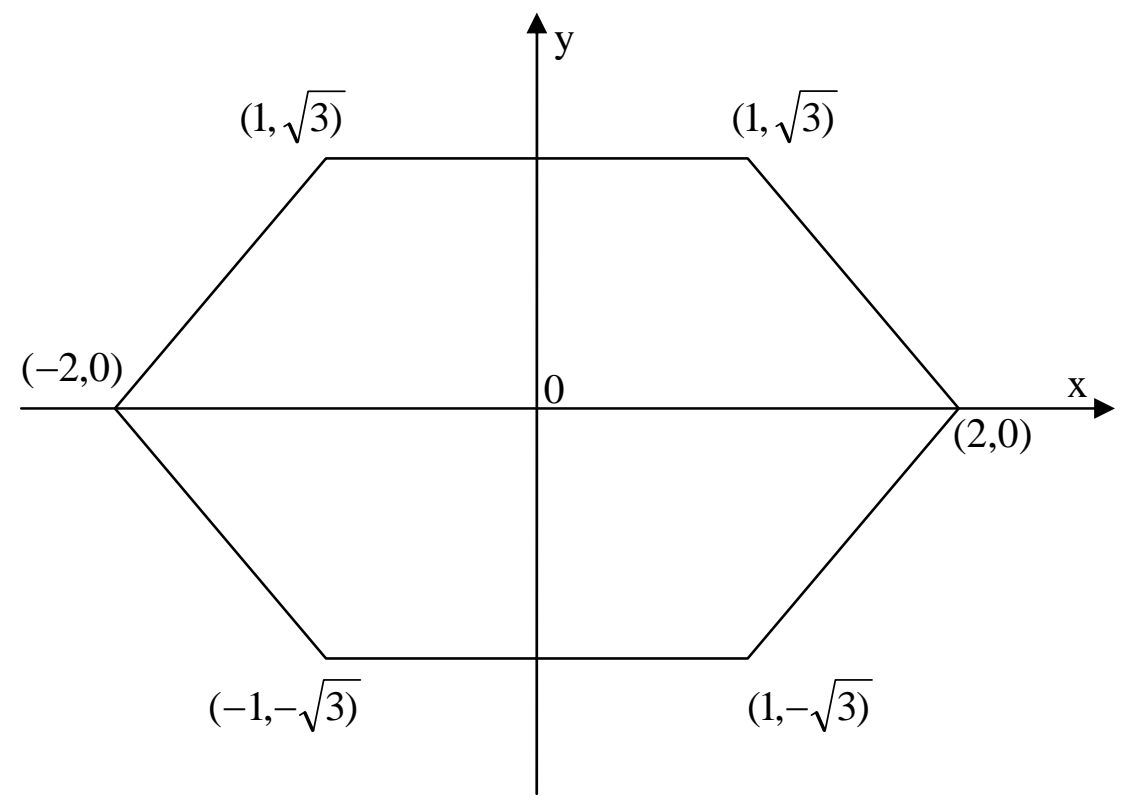

Figura 3.2: Hexágono centrado na origem

Neste caso,

$$
Z=\left[\begin{array}{rr}
1 & \sqrt{3} \\
-1 & \sqrt{3} \\
-2 & 0 \\
-1 & -\sqrt{3} \\
1 & -\sqrt{3} \\
2 & 0
\end{array}\right] \quad \text { e } \quad Z^{T} Z=\left[\begin{array}{cc}
12 & 0 \\
0 & 12
\end{array}\right]=m I_{2}
$$


para $m=12$. Portanto $Z$ é um planejamento escalar. Além disso, como suas linhas são de igual comprimento, pelo item (i) do Teorema 3.1, Z será um planejamento com alavancagem constante.

Realmente,

$\mathrm{Z}\left(\mathrm{Z}^{T} \mathrm{Z}\right)^{-1} \mathrm{Z}^{T}=\frac{1}{12}\left[\begin{array}{cc}1 & \sqrt{3} \\ -1 & \sqrt{3} \\ -2 & 0 \\ -1 & -\sqrt{3} \\ 1 & -\sqrt{3} \\ 2 & 0\end{array}\right]\left[\begin{array}{cccccc}1 & -1 & -2 & -1 & 1 & 2 \\ \sqrt{3} & \sqrt{3} & 0 & -\sqrt{3} & -\sqrt{3} & 0\end{array}\right]=$

$\frac{1}{12}\left[\begin{array}{rrrrrr}4 & 2 & -2 & -4 & -2 & 2 \\ 2 & 4 & 2 & -2 & -4 & -2 \\ -2 & 2 & 4 & 2 & -2 & -4 \\ -4 & -2 & 2 & 4 & 2 & -2 \\ -2 & -4 & -2 & 2 & 4 & 2 \\ 2 & -2 & -4 & -2 & 2 & 4\end{array}\right]$

de modo que $h_{i i}=\frac{1}{3}, \mathrm{i}=1,2, \ldots, 6$.

O próximo exemplo exibe o método de construção de planejamento denominado projeção inversa.

Exemplo 3: Planejamento de projeção inversa no plano.

O item (vi) do Teorema 3.1 permite a obtenção dos planejamentos que, devido à sua forma de construção, são denominados pelos autores de planejamentos de projeção inversa. Vamos supor que se deseja construir um planejamento escalar com alavancagem constante em $\mathfrak{R}^{2}$ sendo que uma das variáveis explicativas, $\mathrm{Z}_{1}$, admite apenas os $2 \mathrm{~m}$ valores $\pm a_{1}, \ldots, \pm a_{m}$.

Para isso, são escolhidos $4 \mathrm{~m}$ pontos da forma $\left(+a_{i}, \pm b_{i}\right),\left(-a_{i}, \pm b_{i}\right)$ e que devem estar em um círculo de raio r. O valor de r é determinado pela condição de que as 
colunas de Z têm igual comprimento (é usado o fato de que os valores $\pm a_{i}$ tem média 0 e então a variância desses valores é igual a $\left.\sigma_{a}^{2}=m^{-1} \sum_{i=1}^{m} a_{i}^{2}\right)$.

Temos que $\frac{\sum\left(a_{i}-\bar{a}\right)^{2}}{4 m}=\sigma_{a}^{2}$ e $\bar{a}=0$. Como as colunas de $\mathrm{Z}$ devem ter igual comprimento então $\sum 4 a_{i}{ }^{2}=\sum 4 b_{i}{ }^{2} \Rightarrow \frac{\sum 4\left(a_{i}-0\right)^{2}}{4 m}=\frac{\sum 4\left(b_{i}-0\right)^{2}}{4 m}=\sigma_{a}{ }^{2}=\sigma_{b}{ }^{2}$.

Para que os pontos ( $\pm a_{i}, \pm b_{i}$ ) pertençam ao círculo de centro na origem e raio $\mathrm{r}$, então $a_{i}{ }^{2}+b_{i}{ }^{2}=r^{2}$ e assim $\frac{a_{i}^{2}}{\sigma_{a}{ }^{2}}+\frac{b_{i}^{2}}{\sigma_{a}{ }^{2}}=\frac{r^{2}}{\sigma_{a}{ }^{2}}$.

Como conseqüência, temos que:

$$
\begin{aligned}
& \frac{\sum a_{i}{ }^{2}}{\sigma_{a}{ }^{2}}+\frac{\sum b_{i}{ }^{2}}{\sigma_{a}{ }^{2}}=\frac{m r^{2}}{\sigma_{a}{ }^{2}} \Rightarrow \frac{2 \sum a_{i}{ }^{2}}{\sigma_{a}{ }^{2}}=\frac{m r^{2}}{\sigma_{a}{ }^{2}} \\
& \Rightarrow \sum a_{i}{ }^{2}=\frac{m r^{2}}{2} \Rightarrow r^{2}=2 \frac{\sum a_{i}{ }^{2}}{m}=2 \sigma_{a}{ }^{2} \Rightarrow r^{2}=2 \sigma_{a}{ }^{2} .
\end{aligned}
$$

Da igualdade $a_{i}{ }^{2}+b_{i}{ }^{2}=r^{2}$ segue que $\left|a_{i}\right|^{2}<r^{2}, \mathrm{i}=1,2, \ldots, \mathrm{m}$, o que implica em $\max \left|a_{i}\right|<\mathrm{r}, \mathrm{i}=1,2, \ldots, \mathrm{m} \Rightarrow \max \left|a_{i}\right|<\sqrt{2} \sigma_{a}$. Assim, este método não permitirá escolhas arbitrárias dos $a_{i}$ 's e requer que não sejam incluídos pontos muito distantes da origem. Por outro lado, os valores de $a_{i}$ devem ser distantes o suficiente da origem, de modo a produzir $\sigma_{a}^{2}=\frac{r^{2}}{2}$.

Como ilustração, consideremos o planejamento gerado por pontos igualmente espaçados da forma $a_{i}=i, \mathrm{i}=1, \ldots, \mathrm{m}$. Verifica-se que neste caso $\sigma_{a}{ }^{2}=\frac{(m+1)(2 m+1)}{6}$ e a condição $\max _{i}\left|a_{i}\right| \leq \sqrt{2} \sigma_{a}$ é violada para a maior parte dos valores de m. Para solucionar o problema os autores sugerem omitir os pontos $\pm 1, \ldots, \pm j, \mathrm{j}<\mathrm{m}$, de modo que os pontos restantes satisfaçam às condições necessárias. Cálculos elementares mostram que em geral $j \approx \frac{m}{4}$ é pequeno, mas $j \approx \frac{2 m}{5}$ é relativamente grande. Por exemplo, se $\mathrm{j}=3$ e $\mathrm{m}=10$, o planejamento resultante é gerado pelos valores 
$a_{i}=4,5,6,7,8,9,10$. Neste caso, o planejamento teria 28 pontos e lembrando que $\mathrm{r}^{2}=2 \sigma_{a}{ }^{2}$, tais pontos encontram-se no círculo de raio $(106)^{\frac{1}{2}}=\sqrt{2 \sigma_{a}{ }^{2}}$.

Exemplo 4: Planejamento fatorial em p dimensões.

O planejamento fatorial $2^{p}$ tem linhas da forma $z^{T}=[ \pm 1, \ldots, \pm 1]$ e é um planejamento escalar com alavancagem constante. Tal planejamento será discutido no Capítulo 5.

Exemplo 5: Planejamento estrela de dimensão p

O planejamento estrela em $\mathfrak{R}^{p}$ tem $\mathrm{n}=2 \mathrm{p}$ pontos da forma $Z^{T}=[ \pm 1,0, \ldots, 0],[0, \pm 1,0, \ldots, 0], \ldots,[0, \ldots, 0, \pm 1]$. Verifica-se que é um planejamento escalar com alavancagem constante. Este planejamento, assim como o planejamento fatorial $2^{p}$, tem utilidade em Análise de Superfícies de Resposta.

Exemplo 6: Planejamento de Projeção Inversa em $\mathfrak{R}^{3}$

Este planejamento parte de um planejamento W, escalar em $\mathfrak{R}^{2}$. Se W é também um planejamento com alavancagem constante, então seus pontos encontram-se em um circulo e Z, a projeção inversa de W na esfera, terá todos seus pontos em dois planos paralelos na esfera. Para conseguir uma maior dispersão de pontos, constrói-se W a partir de planejamentos com alavancagem constante em círculos concêntricos. Por exemplo, o planejamento $\mathrm{W}$ a seguir é a união da origem, um planejamento com quatro pontos no circulo de raio 2 e um planejamento de seis pontos no círculo de raio 3.

$$
W^{T}=\left[\begin{array}{ccccccccccc}
0 & \sqrt{2} & -\sqrt{2} & -\sqrt{2} & \sqrt{2} & 3 & \frac{3}{2} & -\frac{3}{2} & -3 & -\frac{3}{2} & \frac{3}{2} \\
0 & \sqrt{2} & \sqrt{2} & -\sqrt{2} & -\sqrt{2} & 0 & \frac{3 \sqrt{3}}{2} & \frac{3 \sqrt{3}}{2} & 0 & -\frac{3 \sqrt{3}}{2} & -\frac{3 \sqrt{3}}{2}
\end{array}\right]
$$

Verifica-se facilmente que $W$ é escalar, pois $W^{T} W=35 I_{2}$. Neste caso, $m=11$, $\mathrm{p}=3$ e $\mathrm{k}=35$ e dessa forma a desigualdade $c_{i}=\frac{p k}{m}-\left\|w_{i}{ }^{T}\right\|^{2} \geq 0$ em (vi) do Teorema 3.1 
é satisfeito porque $\frac{p k}{m}=\frac{3(35)}{11}>9$. Como conseqüência, o planejamento escalar com alavancagem constante resultante tem 22 pontos na esfera de raio $(105 / 11)^{\frac{1}{2}}$.

\subsection{Considerações Finais}

A desejabilidade de planejamento com alavancagem constante deve ser equilibrada com a necessidade de execução do teste para falta de ajuste ou ainda com a existência de outros critérios de otimalidade.

Uma desvantagem do planejamento com alavancagem constante é que os pontos são localizados na superfície de um elipsóide e assim não há informação sobre o comportamento da variável resposta no interior desta região. Neste caso a hipótese de linearidade do modelo não pode ser testada. Se este teste for necessário, planejamentos que incluam pontos dentro e fora do elipsóide de alavancagem constante podem ser construídos. Se um teste de falta de ajuste for desejável, serão necessárias repetições dos mesmos pontos para se obter a estimativa do erro puro.

Tal planejamento pode ser construído selecionando vários diferentes planejamentos com alavancagem constante na esfera de raio unitário e então os transferindo para elipsóides concêntricos (cada um tendo um diferente valor de alavancagem constante), na região desejada para as variáveis explicativas. 


\section{Capitulo 4}

\section{Critérios de Otimalidade}

$\mathrm{Na}$ escolha de um planejamento experimental, existem vários critérios de otimização que têm sido considerados importantes. Destacaremos neste capítulo um grupo de critérios que, por terem sido designados por uma letra única, são usualmente referidos como critérios de “otimalidade alfabética”. Descreveremos a seguir alguns deles.

\subsection{G-otimalidade}

O termo G-otimalidade foi utilizado por Kiefer e Wolfowitz (1959), mas o critério aparentemente foi proposto por Smith (1918). Este critério é também chamado 
de critério minimax porque minimiza o valor máximo de $\operatorname{Var}\left(\hat{Y}_{x}\right)$ com relação a todos vetores x na região experimental para todos os planejamentos experimentais possíveis.

Lembrando que $\operatorname{Var}\left(\hat{Y}_{i}\right)=\sigma^{2} x_{i}^{T}\left(X^{T} X\right)^{-1} x_{i}=\sigma^{2} h_{i i}$ onde $x_{i}$ é a i-ésima linha da matriz de planejamento $\mathrm{X}$, verificamos que para um planejamento com alavancagem constante, $\operatorname{Var}\left(\hat{Y}_{x}\right)$ será constante para todo $x_{i}$.

Conforme discutido no Capítulo 3, um planejamento escalar com alavancagem constante com matriz de planejamento com linhas de comprimento um terá valores de alavanca $h_{i i}=\frac{k}{n} \mathrm{i}=1, \ldots, \mathrm{n}$ com $\mathrm{k}$ representando o número de regressores. Box e Draper (1987) demonstram que, para uma matriz de planejamento (não necessariamente centralizada), $\mathrm{n} \frac{\operatorname{Var}\left(\hat{Y}_{i}\right)}{\sigma^{2}}=k$ sob a G-otimalidade, com $\mathrm{k}$ representando o número de parâmetros do modelo de regressão. Então, a alavanca deve ser constante em um planejamento G-Ótimo, desde que $\operatorname{Var}\left(\hat{Y}_{x}\right)$ não depende de i. Reciprocamente, um planejamento com alavancagem constante será também G-Ótimo, já que o critério de G-otimalidade está simultaneamente satisfeito. Portanto, existe uma equivalência entre os planejamentos com alavancagem constante e planejamentos G-ótimos.

\subsection{D-otimalidade para regressão linear}

Um planejamento é denominado D-ótimo se o determinante de $X^{T} X$ é maximizado para uma dada região experimental. Esta característica é desejada principalmente porque tal planejamento minimiza “o volume do elipsóide de confiança” para os parâmetros do modelo de regressão (isto se refere à construção de uma região de confiança para mais de um parâmetro de regressão). 
Como discutido por Dollinger e Staudle (1990), um planejamento escalar com alavancagem constante que é construído em uma dada região elipsoidal será D-ótimo. $\mathrm{Na}$ verdade, isto vale somente para planejamentos escalares com alavancagem constante. Já, o inverso não é verdadeiro e será discutido a seguir.

Para os autores, se removermos fatores de escala tomando $\left\|x_{i}\right\|^{2}=n, \mathrm{i}=1, \ldots, \mathrm{k}$ (com k=número de regressores) a D-otimalidade é obtida quando o planejamento é ortogonal. Isto pode ser mostrado para $\mathrm{k}=2$, pois, neste caso, excluindo-se a coluna de uns da matriz X, temos:

$$
X^{T} X=\left[\begin{array}{lc}
n & \sum_{j=1}^{n} X_{1 j} X_{2 j} \\
\sum_{j=1}^{n} X_{1 j} X_{2 j} & n
\end{array}\right]
$$

para os dados codificados como $X_{i j}=\frac{\left(X_{i j}{ }^{*}-\bar{X}_{i}^{*}\right)}{f} \operatorname{com} \mathrm{f}=\sqrt{\frac{\sum\left(X_{i j}{ }^{*}-\bar{X}_{i}{ }^{*}\right)^{2}}{n}}$ e $X_{i j}{ }^{*}$ denotando o valor original. Desde que $\left|X^{T} X\right|=n^{2}-r^{2}$, em que $\mathrm{r}=\sum X_{1} X_{2}$, temos que o determinante de $X^{T} X$ é máximo quando $\mathrm{r}=0$, isto é, quando o planejamento é ortogonal.

Como um planejamento ortogonal não é necessariamente um planejamento com alavancagem constante, verifica-se então que a D-otimalidade não implica em planejamento com alavancagem constante. No entanto, a D-otimalidade pode ser obtida se o planejamento é um planejamento escalar (em particular se $X^{T} X=n I$ ).

Por outro lado, desde que um planejamento G-ótimo tem alavancagem constante e planejamentos com alavancagem constante não são necessariamente D-ótimos, segue que G-otimalidade e D-otimalidade não são equivalentes.

St. John e Draper (1975) analisaram a D-otimalidade para o modelo de regressão linear com as suposições e a região de planejamentos descritos a seguir:

$$
y_{i}=f^{T}\left(x_{i}\right) \beta+\varepsilon \quad \mathrm{i}=1, \ldots, \mathrm{n}
$$

o qual pode ser expresso em notação matricial como:

$$
\mathrm{Y}=X \beta+\varepsilon \text {, }
$$

em que o vetor y é um vetor de observações $\mathrm{n}$ x 1 ; X é uma matriz $\mathrm{n}$ x p, com i-ésima linha contendo $f^{T}\left(x_{i}\right)$; $x_{i}$ é um vetor q $x 1$ de variáveis preditoras, $f^{T}\left(x_{i}\right)$ é um vetor de funções das variáveis preditoras que desejamos incluir no modelo; $\beta$ é um 
vetor $\mathrm{p} \times 1$ de parâmetros desconhecidos; $\varepsilon$ é um vetor $\mathrm{n} \times 1$ de variáveis aleatórias independentes e identicamente distribuídas com média zero e variância $\sigma^{2}$. A região experimental é denotada por $\chi$ e assumimos que $\chi$ é compacta e que as funções $f_{i}\left(x_{i}\right)$ são contínuas em $\chi$.

Utilizam-se ainda os estimadores de mínimos quadrados dos parâmetros presentes no vetor $\beta$, dados por:

$$
\hat{\beta}=\left(X^{T} X\right)^{-1} X^{T} Y
$$

e a matriz de variância e covariância de $\hat{\beta}: \mathrm{V}(\hat{\beta})=\sigma^{2}\left(X^{T} X\right)^{-1}$.

Para $\mathrm{x} \in \chi$, a resposta predita é:

$$
\hat{y}(x)=f^{T}(x) \hat{\beta}
$$

com variância

$$
v(\hat{y}(x))=\sigma^{2} f^{T}(x)\left(X^{T} X\right)^{-1} f(x)
$$

Conforme comentado anteriormente, o problema de planejamento consiste em selecionar vetores $x_{i}, \mathrm{i}=1, \ldots, \mathrm{n}$ de $\chi$ tal que o planejamento definido pelos $\mathrm{n}$ vetores é ótimo segundo algum critério.

Wald (1943) propôs o critério de maximizar o determinante de $X^{T} X$ como uma maneira de maximizar o poder do teste F para hipóteses lineares dos parâmetros em modelos de análise de variância com efeito fixo. Posteriormente, Kiefer e Wolfowitz(1959) chamaram este critério de D-otimalidade e estenderam seu uso aos modelos de regressão em geral.

Apresentaremos a seguir dois resultados principais introduzidos por St. John e Draper (1975), que relacionam o conceito de medida de planejamento e um teorema de equivalência geral.

De acordo com os autores, um planejamento pode ser visto como uma medida $\xi$ em $\chi$. Suponha que dispomos de um planejamento contendo $\mathrm{n}$ pontos com $n_{i}$ observações na posição $x_{i}\left(\operatorname{com} \sum n_{i}=n\right)$.

Seja $\xi$ uma medida de probabilidade em $\chi$ tal que $\xi\left(x_{j}\right)=0$ se não há observações no ponto $x_{j}$ e $\xi\left(x_{i}\right)=\frac{n_{i}}{n}$ se há $n_{i}>0$ observações com valores $x_{i}$. Para um planejamento discreto com n pontos, $\xi$ assume apenas valores múltiplos de $\frac{1}{n}$ e 
define um planejamento exato em $\chi$. Removendo a restrição de que $\xi$ seja múltiplo de $\frac{1}{n}$, podemos estender esta idéia para uma medida de planejamento que satisfaz em geral, às condições:

$$
\begin{aligned}
& \xi(x) \geq 0, x \in \chi \\
& \int_{\chi} \xi(d x)=1 .
\end{aligned}
$$

Com respeito ao modelo (4.1), que possui p variáveis explicativas, é possível definir uma matriz análoga a $X^{T} X$ para o planejamento $\xi$ como:

$$
m_{i j}(\xi)=\int_{\chi} f_{i}(x) f_{j}(x) \xi(d x) \quad \mathrm{i}, \mathrm{j}=1, \ldots, \mathrm{p}
$$

e $M(\xi)=\left[m_{i j}(\xi)\right]$ é a correspondente matriz com elemento $m_{i j}(\xi)$ na posição ij. Dessa forma, $m_{i j}(\xi)$ pode ser vista como um valor esperado do produto $f_{i}(x) f_{j}(x)$ com relação à medida $\xi$.

Nota-se ainda que para um planejamento exato, $\mathrm{nM}(\xi)=X^{T} X$. Similarmente, uma generalização da função variância (4.2) é dada por:

$$
\mathrm{d}(\mathrm{x}, \xi)=f^{T}(x) M^{-1}(\xi) f(x) .
$$

Introduzidos esses conceitos, apresentaremos a seguir a definição de Dotimalidade.

Definição 4.1: O planejamento $\xi^{*}$ é D-ótimo se e somente se $\mathrm{M}\left(\xi^{*}\right)$ é não singular e $\max _{\xi} \operatorname{det}(M(\xi))=\operatorname{det}\left(M\left(\xi^{*}\right)\right)$.

De acordo com essa definição, o planejamento $\xi^{*}$ será ótimo se, dentre todos os planejamentos com medida de probabilidade $\xi$, maximizar o determinante da matriz $\mathrm{M}(\xi)$. 
Snee (1985) destaca que o método de planejamento que maximiza $\left|X^{T} X\right|$ baseia-se no pressuposto de que o modelo estipulado está correto e esta verificação pode exigir muitas réplicas.

Por ouro lado para a obtenção de planejamentos D e G ótimos é necessária à existência de um conjunto de pontos iniciais e os algoritmos utilizados produzem planejamentos D ou G ótimos relativos ao conjunto de pontos estipulados. Consequentemente, o planejamento resultante deve maximizar $\left|X^{T} X\right|$ ou minimizar $\operatorname{Var}\left(\hat{Y}_{x}\right)$ e pode não ser ortogonal. Apresentaremos a seguir uma breve discussão sobre algoritmos de construção de planejamentos D-ótimos.

\subsection{Algoritmos para construção de planejamentos D-ótimos}

De acordo com St John e Draper (1975), os primeiros autores a desenvolveram algoritmos para a obtenção de planejamentos D-ótimos foram Fedorov (1969a, 1969b, 1972) e Fedorov e Dubova (1968).

O algoritmo de Fedorov, na sua forma mais simples, encontra-se descrito em St. John e Draper (1975).

Seja $\xi_{n}$ um planejamento não degenerado $\left(\operatorname{det}\left(\mathrm{M}\left(\xi_{n}\right)\right)>0\right)$ de n pontos em $\chi \mathrm{e}$ seja $\mathrm{i}=\mathrm{n}$.

Os passos do algoritmo são como segue:

1) Calcular $\mathrm{M}\left(\xi_{i}\right)$ e $\mathrm{M}^{-1}\left(\xi_{i}\right)$.

2) Encontrar $x_{i}$, tal que $\max _{x} d\left(x, \xi_{i}\right)=d\left(x_{i}, \xi_{i}\right)$.

3) Definir $\alpha_{i}=\frac{d\left(x_{i}, \xi_{i}\right)-p}{p\left(d\left(x_{i}, \xi_{i}\right)-1\right)}$ como a medida de probabilidade no ponto $x_{i}$

4) Seja $\xi_{i+1}=\left(1-\alpha_{i}\right) \xi_{i}+\alpha_{i} \varepsilon_{x_{i}}$ a nova medida de planejamento (em que $\varepsilon_{x_{i}}$ associa medida 1 ao ponto $x_{i}$ ). 
5) Repetir os passos 1 a 4 até $d\left(x_{i}, \xi_{i}\right)$ estar suficientemente próximo de p.

Desta forma, o procedimento consiste em:

i) Selecionar qualquer planejamento inicial não degenerado,

ii) Calcular a matriz de dispersão,

iii) Encontrar o ponto de variância máxima e acrescentá-lo ao planejamento com medida proporcional à sua variância.

iv) Recalcular a medida de planejamento.

O autor provou também que para $\mathrm{i} \rightarrow \infty$ a seqüência de planejamentos definidos pelos passos 1 a 5 converge para o planejamento D-ótimo $\xi^{*}$.

O valor de $\alpha_{i}$ dado em (4.3) maximiza o aumento no valor do determinante a cada passo da seqüência. Entretanto, Fedorov (1972) estabelece que qualquer seqüência de $\alpha_{i}, \quad \alpha_{i}$ satisfaz:

$$
\sum_{i=1}^{\infty} \alpha_{i}=\infty \text { e } \lim _{i \rightarrow \infty} \alpha_{i}=0
$$

e garante a convergência para o planejamento D-ótimo $\xi^{*}$.

Wynn (1970) provou a convergência de um algoritmo similar, mas com $\alpha_{i}=\frac{1}{(i+1)}$, isto é, com todos os pontos no planejamento seqüencial tendo igual peso. Obviamente, tal escolha de $\alpha$, satisfaz (4.4).

Apesar da existência do algoritmo de Fedorov, D-otimalidade não é sempre um critério fácil para implementar. Alguns autores comentam que criar um planejamento exato a partir de uma medida de probabilidade pode requerer um número extremamente grande de repetições.

Uma solução seria utilizar planejamentos com n fixo, obtidos a partir de algoritmos que fornecessem n pontos experimentais com $\left|X^{T} X\right|$ máximo.

Com esse objetivo, seja $\xi(\mathrm{n})$ um planejamento exato com n pontos e $X_{n}$ a matriz de planejamento correspondente. A matriz de informação para estes $n$ pontos experimentais é definida como $\mathrm{nM}(\xi(\mathrm{n}))=X_{n}{ }^{T} X_{n}$ e admitindo sem perda de generalidade $\sigma^{2}=1$ a função de variância da resposta predita fica $v(\hat{y}(x))=f^{T}(x)\left(X_{n}{ }^{T} X_{n}\right)^{-1} f(x)$. 
Nestas condições, utilizam-se planejamentos $D_{n}$ ótimos, definidos a seguir.

Definição 4.2: O planejamento $\xi^{*}(n)$ é $D_{n}$-ótimo se e somente se sua matriz de planejamento $X_{n}^{*}$ é tal que $X_{n}{ }^{* T} X_{n}{ }^{*}$ é não singular e o valor $\operatorname{de} \operatorname{det}\left(X_{n}{ }^{* T} X_{n}{ }^{*}\right)$ é o valor máximo para todos os possíveis planejamentos $\xi(n)$.

Vários autores têm obtido planejamentos $D_{n}$-ótimos para modelos específicos usando métodos de programação matemática para maximizar $\left|X_{n}{ }^{T} X_{n}\right|$. Entretanto, algoritmos computacionais para construção de planejamentos envolvem otimização com respeito às np variáveis e podem fornecer soluções que não são ótimas.

Na próxima seção, apresentaremos alguns métodos de obtenção de planejamentos D-ótimos.

\subsection{Métodos de obtenção de planejamentos D-ótimos}

Consideremos novamente o modelo $y=X \beta+\varepsilon$ e o vetor de estimativas de $\beta$ dado por $\hat{\beta}=\left(X^{T} X\right)^{-1} X^{T} y$.

Apresentaremos a seguir o procedimento proposto por Dykstra (1971), que consiste em acrescentar dados aos já existentes, com o objetivo de maximizar $\left|X^{T} X\right|$.

Sejam $\mathrm{A}=X^{T} X$ em que $\mathrm{X}$ é uma matriz $\mathrm{n} \mathrm{x}$ p de posto completo e A é matriz $\mathrm{p}$ x p positiva definida. Adicionalmente, seja $x_{0}$ um vetor coluna p x 1 de modo que $x_{0}{ }^{T}$ é um ponto candidato a se tornar a linha $n+1$ da matriz X. Deseja-se então calcular o determinante de $X^{T} X$ para $\mathrm{n}+1$ pontos amostrais, quando $x_{0}$ é acrescentado aos pontos originais. Para simplificar, assumimos que $\mathrm{X}$ contém todas as colunas de variáveis explicativas necessárias ao modelo, incluindo uma coluna de 1's para o termo constante. Com esse objetivo, será utilizado o resultado relativo a matrizes inversas, 


$$
\left(\mathrm{A}+x_{0} x_{0}{ }^{T}\right)^{-1}=A^{-1}-\frac{A^{-1} x_{0} x_{0}{ }^{T} A^{-1}}{1+x_{0}{ }^{T} A^{-1} x_{0}}
$$

Multiplicando (4.5) à direita por $\mathrm{A}$ e substituindo $\mathrm{A}$ por $\left(\mathrm{A}+x_{0} x_{0}{ }^{T}\right)-x_{0} x_{0}{ }^{T}$ no lado esquerdo dessa igualdade obtém-se:

$$
\mathrm{I}-\left(\mathrm{A}+x_{0} x_{0}{ }^{T}\right)^{-1} x_{0} x_{0}{ }^{T}=\mathrm{I}-\frac{A^{-1} x_{0} x_{0}{ }^{T}}{1+x_{0}{ }^{T} A^{-1} x_{0}} .
$$

Após simplificações e lembrando que $\left|A^{-1}\right|=\frac{1}{|A|}$ e $|\mathrm{AB}|=|\mathrm{A}||\mathrm{B}|$, finalmente obtemos $\frac{\left|A+x_{0} x_{0}{ }^{T}\right|}{|A|}=1+x_{0}{ }^{T} A^{-1} x_{0}$.

Então, para maximizar $\left|A+x_{0} x_{0}{ }^{T}\right|$ com $|\mathrm{A}|$ fixado, devemos maximizar $x_{0}{ }^{T} A^{-1} x_{0}$. Como $\operatorname{Var}\left(\hat{y} \mid x_{0}\right)=\sigma^{2} x_{0}{ }^{T}\left(X^{T} X\right)^{-1} x_{0}$, verifica-se que $\left|X^{T} X\right|$ é maximizado tomando como próximo ponto amostral $x_{0}$ aquele em que $\operatorname{Var}\left(\hat{y} \mid x_{0}\right)$ é a maior possível.

Como conseqüência, uma maneira para definir o $(n+1)$-ésimo elemento é avaliar $\operatorname{Var}\left(\hat{y} \mid x_{0}\right)$ para todos os possíveis pontos candidatos, escolhendo aquele que fornece o maior valor de $\operatorname{Var}\left(\hat{y} \mid x_{0}\right)$.

Na escolha dos pontos, o grau do modelo deve ser levado em conta. Assim, para um modelo de $1^{\mathrm{a}}$ ordem, o procedimento é selecionar pontos nos extremos do espaço experimental e somente pontos extremos precisam ser especificados como candidatos. Para um modelo de $2^{\circ}$ grau, deve-se incluir um ponto central em adição aos pontos extremos. Um modelo cúbico deve ter valores de X em quatro níveis e assim por diante.

A aproximação que é recomendada por Dykstra (1971) consiste nos passos seguintes:

1) Determinar $\left(X^{T} X\right)^{-1}$ com base nas n observações;

2) Determinar $\operatorname{Var}(\hat{y})$ para cada ponto candidato;

3) Escolher como próximo ponto amostral aquele para o qual $\operatorname{Var}(\hat{y})$ é máxima. 
Para ilustrar o procedimento, o autor utiliza os dados da Tabela 4.1 nos dois exemplos descritos a seguir. No primeiro, utilizou-se o modelo $y=\beta_{0}+\beta_{1} X_{1}+\beta_{2} X_{2}+\beta_{3} X_{3}+\varepsilon$ sendo que havia interesse nas variáveis explicativas nos intervalos:

$$
\begin{aligned}
& -7 \leq X_{1} \leq 6 \\
& -7 \leq X_{2} \leq 7 \\
& -5 \leq X_{3} \leq 12 .
\end{aligned}
$$

Tabela 4.1: Dados ilustrativos, $n=20$, três variáveis explicativas

\begin{tabular}{lrrrrrrr}
\hline \multirow{2}{*}{ Observação } & $X_{1}$ & $X_{2}$ & $X_{3}$ & Observação & $X_{1}$ & $X_{2}$ & $X_{3}$ \\
\hline 1 & $-6,389$ & $-5,330$ & 6,0437 & 11 & $-1,593$ & $-3,957$ & 0,1869 \\
2 & $-6,179$ & $-5,549$ & 9,0819 & 12 & $-1,338$ & $-2,613$ & $-0,3136$ \\
3 & $-4,533$ & $-5,717$ & 7,6283 & 13 & $-0,787$ & $-2,487$ & $-2,7032$ \\
4 & $-5,293$ & $-6,492$ & 7,8131 & 14 & $-1,649$ & $-1,077$ & $-2,1917$ \\
5 & $-4,004$ & $-6,464$ & 3,0976 & 15 & 2,075 & 1,719 & $-2,2917$ \\
6 & $-2,631$ & $-5,320$ & 5,4978 & 16 & 2,224 & 0,946 & $-2,8516$ \\
7 & $-3,012$ & $-4,080$ & 1,0688 & 17 & 2,382 & 3,879 & $-4,2335$ \\
8 & $-2,864$ & $-4,583$ & 4,5822 & 18 & 3,350 & 3,510 & $-4,8033$ \\
9 & $-0,979$ & $-2,887$ & 1,0250 & 19 & 3,384 & 6,383 & $-2,5554$ \\
10 & $-0,420$ & $-4,094$ & 2,2669 & 20 & 5,984 & 6,499 & $-2,120$ \\
\hline
\end{tabular}

Fonte: Gaylor and Merril (1968).

Foram considerados como possíveis pontos a serem acrescentados, as combinações dos valores extremos de $X_{1}, X_{2}$ e $X_{3}$. A Tabela 4.2 apresenta esses pontos, o valor de $\frac{\operatorname{Var}(\hat{y})}{\sigma^{2}}$ para cada um deles e a razão $\frac{\left|X^{T} X\right|_{n+1}}{\left|X^{T} X\right|_{20}}$ em que a razão é considerada acréscimo no quociente. 
Tabela 4.2: $\frac{\operatorname{Var}(\hat{y})}{\sigma^{2}}$ para pontos adicionais, modelo de primeira ordem $\operatorname{com} \mathbf{p}=\mathbf{3} \mathbf{e}$ $\mathbf{n}=\mathbf{2 0}$

\begin{tabular}{ccccccccccc}
\hline & $x_{1}:$ & 6 & -7 & -7 & 6 & 6 & -7 & -7 & 6 & \\
& $x_{2}:$ & 7 & -7 & -7 & -7 & 7 & 7 & 7 & -7 & $\frac{\left.|X|^{T} X\right|_{n+1}}{\left|X^{T} X\right|_{20}}$ \\
& & & & & & & & & & \\
$\mathrm{n}$ & $x_{3}:$ & -5 & 12 & -5 & -5 & 12 & 12 & -5 & 12 & \\
\hline 20 & & 0,30 & 0,48 & 1,92 & 3,12 & 3,94 & 4,84 & 5,63 & $6,11^{*}$ & 7,11 \\
21 & & 0,30 & 0,46 & 0,89 & 1,81 & 2,40 & $3,99 *$ & 1,36 & 0,86 & 35,45 \\
22 & 0,27 & 0,23 & 0,61 & 0,49 & $1,06 *$ & 0,80 & 0,73 & 0,84 & 73,10 \\
23 & 0,24 & 0,23 & 0,37 & 0,48 & 0,52 & 0,67 & $0,69 *$ & 0,63 & 123,65 \\
24 & 0,23 & 0,23 & 0,33 & 0,43 & 0,50 & $0,56 *$ & 0,41 & 0,45 & 193,10 \\
25 & 0,23 & 0,21 & 0,32 & 0,32 & $0,45 *$ & 0,36 & 0,37 & 0,44 & 280,13 \\
26 & 0,22 & 0,21 & 0,26 & 0,32 & 0,31 & 0,34 & 0,36 & $0,39 *$ & 388,54 \\
27 & 0,22 & 0,20 & 0,25 & 0,30 & 0,28 & $0,33^{*}$ & 0,29 & 0,28 & 516,84 \\
\hline
\end{tabular}

Fonte: Gaylor and Merril (1968).

* O elemento que está assinalado com * é o máximo valor de $\operatorname{Var}(\hat{y})$, que define o ponto amostral a ser selecionado.

De acordo com o descrito na Tabela 4.2, o ponto $(6,-7,12)$, produziu o máximo valor de $\operatorname{Var}(\hat{y})$ na primeira etapa do processo. Introduzido no modelo, o tamanho de amostra passou a ser $n=21$, fornecendo a segunda linha da tabela. Nessa segunda etapa, o ponto selecionado foi $(-7,7,12)$, por maximizar $\operatorname{Var}(\hat{Y})$, e assim, o processo foi repetido por mais seis passos.

O segundo exemplo considerado utiliza as duas primeiras variáveis da Tabela 4.1 no modelo $y=\beta_{0}+\beta_{1} X_{1}+\beta_{2} X_{2}+\beta_{11} X_{1}{ }^{2}+\beta_{12} X_{1} X_{2}+\beta_{22} X_{2}{ }^{2}+\varepsilon$.

Os pontos listados na Tabela 4.3 incluem os quatro extremos definidos pelas variáveis $X_{1}$ e $X_{2}$; um ponto central ( $\left.X_{1}=-0,5, X_{2}=0\right)$ e quatro pontos axiais definidos por $\left(\left(X_{1}+0,5\right) / 6,5\right)^{2}+\left(X_{2} / 7\right)^{2}=2$ que é a equação de uma elipse de centro $(-0,5,0)$ e eixo maior paralelo ao eixo das ordenadas. Verifica-se que na região de interesse os oito pontos extremos são eqüidistantes do centro do espaço experimental. Os resultados associados à inclusão de seis pontos adicionais são apresentados na Tabela 4.3. 
Tabela 4.3: $\frac{\operatorname{Var}(\hat{y})}{\sigma^{2}}$ para pontos adicionais, modelo de segunda ordem $\operatorname{com} \mathbf{p}=\mathbf{2}$ $\mathbf{e} \mathbf{n}=\mathbf{2 0}$

\begin{tabular}{|c|c|c|c|c|c|c|c|c|c|c|}
\hline$x_{1}:$ & $-0,5$ & -7 & 6 & $-0,5$ & 8,69 & $-0,5$ & $-9,69$ & 6 & -7 & \\
\hline n $\quad x_{2}:$ & 0,0 & -7 & 7 & $-9,9$ & 0,0 & 9,9 & 0,0 & -7 & 7 & $\frac{\left|X^{T} X\right|_{n+1}}{\left|X^{T} X\right|_{20}}$ \\
\hline 20 & 0,28 & 0,5 & 0,78 & 23,28 & 39,10 & 63,45 & 82,07 & 119,45 & $237,73^{*}$ & $2,38 \times 10^{2}$ \\
\hline 21 & 0,28 & 0,5 & 0,73 & 6,53 & 15,05 & 5,56 & 5,14 & $16,13^{*}$ & 1,00 & $4,09 \times 10^{3}$ \\
\hline 22 & 0,16 & 0,49 & 0,65 & 3,82 & 4,76 & 4,85 & $4,97 *$ & 0,94 & 0,97 & $2,44 \times 10^{4}$ \\
\hline 23 & 0,15 & 0,41 & 0,65 & 1,38 & 1,85 & $2,10^{*}$ & 0,83 & 0,94 & 0,93 & $7,57 \times 10^{4}$ \\
\hline 24 & 0,15 & 0,41 & 0,61 & 0,95 & $1,31^{*}$ & 0,68 & 0,68 & 0,93 & 0,63 & $1,75 \times 10^{5}$ \\
\hline 25 & 0,15 & 0,41 & 0,48 & 0,93* & 0,57 & 0,60 & 0,61 & 0,75 & 0,62 & $3,39 \times 10^{5}$ \\
\hline
\end{tabular}

\section{Fonte: Gaylor and Merril (1968).}

Nesta seção, apresentamos até o momento um método de maximização de $\left|X^{T} X\right|$ baseado na inclusão de uma observação de cada vez.

Suponhamos agora que um planejamento inicial de n observações foi executado e há recursos disponíveis para incluir m observações adicionais. Trabalhos anteriores foram limitados quase exclusivamente à adição de um ponto de cada vez ao planejamento inicial. Evans (1979) discute o problema da escolha de m pontos adicionais.

A abordagem adaptada no referido trabalho é diferente de outros trabalhos em dois aspectos importantes:

1) Deseja-se que $\left|X^{T} X\right|$ sejam tão grandes quanto possível após a inclusão de m pontos ao planejamento original.

2) Deseja-se avaliar a possibilidade de adicionar $r$ pontos simultaneamente no planejamento inicial com $r=1,2, \ldots, \mathrm{m}$.

Ambos os quesitos mencionados podem ser satisfeitos através do uso de um procedimento de busca simplex e um método computacional para aumento de $\left|X^{T} X\right|$. 
Evans (1979) tem como objetivo principal demonstrar a grande vantagem do uso do procedimento de busca simplex para acrescentar pontos a planejamentos experimentais satisfazendo a alguns critérios de planejamento e em particular ao critério de D-otimalidade.

Foi utilizado o modelo (4.1), com a suposição de que $\sigma^{2}=1$, sem perda de generalidade.

De acordo com o autor, o uso do critério de D-otimalidade justificava-se devido a suas propriedades, tais como:

1) Fornecer uma região de confiança para os parâmetros com menor volume no espaço paramétrico.

2) Minimizar a variância generalizada do vetor $\hat{\beta}$ dos estimadores dos parâmetros.

3) Ser invariante a transformações lineares na escala dos parâmetros

4) Minimizar a máxima variância de qualquer previsor (da função de regressão experimental) ao longo do espaço experimental.

No entanto, a obtenção desse tipo de planejamento pode ser trabalhosa devido à dificuldade de maximizar $\operatorname{det}\left(X^{T} X\right)$. Mitchell[13] mostra que se um planejamento inicial $X_{0}$ é aumentado com pontos de planejamento adicionais de modo que o novo planejamento é dado por:

$$
X_{1}=\left[\begin{array}{l}
X_{0} \\
A^{T}
\end{array}\right]
$$

em que as linhas de $A^{T}$ correspondem aos pontos experimentais adicionais, então:

$$
\left|X_{1}^{T} X_{1}\right|=\left|X_{0}^{T} X_{0} \| I+A^{T} V_{0} A\right|
$$

$\operatorname{com} V_{0}=\left(X_{0}^{T} X_{0}\right)^{-1}$.

Usando esta relação, pode-se facilmente determinar a alteração em $\left|X^{T} X\right|$ quando adicionarmos qualquer número de observações.

A pesquisa simplex desenvolvida começa com $\mathrm{k}+1$ ensaios organizados sob a forma de um simplex regular, sendo k o número de variáveis independentes. 
Usando $L_{i}$ e $H_{i}$ para representar, respectivamente, as baixas e altas escolhas para variável i onde i $=1, \ldots, \mathrm{k}$, uma possível forma de planejamento simplex seria

$\begin{array}{cccc}L_{1} & L_{2} & \ldots & L_{k} \\ H_{1} & L_{2} & \ldots & L_{k} \\ L_{1} & H_{2} & \ldots & L_{k} \\ \cdot & \cdot & & \cdot \\ \cdot & \cdot & & \cdot \\ \cdot & \cdot & & \cdot \\ L_{1} & L_{2} & & H_{k} .\end{array}$

Os k+1 resultados são classificados de melhor para pior. O pior deles é, então, rejeitado. Em seguida, um cálculo simples, indica onde o próximo teste deve ser tomado para substituir o elemento rejeitado. Este procedimento é repetido sequencialmente, mantendo $\mathrm{k}+1$ pontos em todas as fases do processo.

Os k+1 ensaios formam um simplex em k dimensões, que em duas dimensões é um triangulo eqüilátero.

Qualquer procedimento de “pesquisas simplex” pode ser usado para encontrar planejamentos experimentais ótimos. Suas vantagens reais vêm do aumento do planejamento inicial com pontos do planejamento extra para conseguir “otimalidade”.

O problema básico é que, dado um planejamento inicial, deseja-se encontrar o “melhor” conjunto de m pontos o qual, se adicionado no planejamento, produz o beneficio máximo com respeito ao critério de planejamento considerado no caso, $\left|X^{T} X\right|$.

Uma das principais vantagens da pesquisa simplex é a capacidade que a mesma apresenta para adicionar mais de um ponto de cada vez a um planejamento inicial, a fim de maximizar $\left|X^{T} X\right|$.

Se for desejado adicionar dois pontos simultaneamente no planejamento, a dimensão do espaço a ser pesquisado pelo simplex é duplicada.

As dimensões acrescentadas representam as coordenadas do segundo ponto a ser adicionado. Do mesmo modo, aumentado a dimensão do espaço do planejamento por m vezes, m pontos podem ser adicionados simultaneamente a um planejamento já existente.

A vantagem de poder adicionar um conjunto de $\mathrm{m}$ pontos é que o conjunto acrescentado de m pontos não depende somente do planejamento inicial, mas também 
da inter-relação desses m pontos mutuamente. No caso da D-otimalidade, isto é óbvio devido à relação $\left|X_{1}^{T} X_{1}\right|=\left|X_{0}{ }^{T} X_{0} \| I+A^{T} V_{0} A\right|$

Neste caso, o procedimento de pesquisa vai procurar $A^{T}$, a matriz $\mathrm{m} \mathrm{x} \mathrm{p} \mathrm{de}$ pontos do planejamento para ser adicionado a planejamento inicial $X_{0}$. Note que se assumir que existem $\mathrm{k}$ variáveis controláveis, então a matriz $\mathrm{X}$ é $\mathrm{n}$ x p onde $\mathrm{p}$ é maior ou igual a k. O valor de p poderá ser maior do que $\mathrm{k}$ devido as colunas adicionais em $\mathrm{X}$ que representariam o termo constante e/ou produtos cruzados. A matriz $A^{T}$ contém $\mathrm{k}$ posições para os m pontos adicionais, mas deve ser completada de modo a acomodar o termo constante e os produtos cruzados do modelo considerado. Assim, para adicionar m pontos simultaneamente deve ser efetuada uma busca em um espaço mk dimensional.

O procedimento de pesquisa simplex é idealmente criado para acrescentar m pontos de uma vez, já que o acréscimo na dimensão do espaço a ser pesquisado não exigirá modificações no programa básico.

O uso de recursos adicionais ao procedimento básico aumentará a velocidade de convergência para o melhor conjunto de $\mathrm{m}$ pontos sem aumentar a dificuldade computacional associada ao acréscimo de mais de um ponto. 


\subsection{Considerações Finais}

Evans (1979) apresenta uma melhora do procedimento simplex básico, adequada para os casos em que as quantidades $\mathrm{m}$ e $\mathrm{k}$ são muito grandes, já que, para m e k moderados, o procedimento funciona bem.

Mais recentemente, Heredia Lanager et al. (2003) discutem os principais algoritmos na obtenção de planejamentos D-ótimos, alguns deles apresentados nas seções anteriores. Adicionalmente, os autores propõem o uso de “algoritmos genéticos” na obtenção de planejamentos D-ótimos.

Tal abordagem difere das demais por não necessitar da utilização de um conjunto de pontos “candidatos” a compor o planejamento. Além disso, tem a vantagem de ser mais eficiente quando a região experimental é sujeita a muitas restrições. O algoritmo é baseado na idéia de combinar diferentes pedaços de informação relevantes ao problema de modo a obter novas e melhores soluções, que são refinados e usados novamente, até que algum critério de convergência seja satisfeito. A busca da melhor solução é feita combinando, selecionando e alterando soluções já existentes.

Segundo o critério de D-otimalidade, temos que maximizar $\left|X^{T} X\right|$ que é equivalente a minimizar a variância generalizada de $\hat{\beta}$. Dentre os planejamentos estudados como alavanca constante, D-ótimo e G-ótimo pode-se dizer que o D-ótimo é preferível já que minimiza uma medida global e também, já que ponto de alavanca não é necessariamente influente. 


\section{Capítulo 5}

\section{Outras Propriedades de Planejamentos Experimentais}

Complementando as análises apresentadas nos capítulos anteriores, descreveremos brevemente vários outros critérios de escolha de planejamentos presentes na literatura.

\section{1 - Planejamentos Robustos com relação a um modelo}

De acordo com Ryan (1997), Box e Draper (1959) foi o primeiro trabalho a considerar o problema da má especificação do modelo na escolha do planejamento amostral. Os autores criticam o uso dos critérios de otimalidade comuns por pressuporem que o modelo proposto é o correto, argumentam que um critério mais apropriado para comparar planejamentos experimentais seria a média do erro quadrático médio (J) em uma região de interesse R, que estaria contida na região experimental total 


$$
\mathrm{J}=\left(\frac{n}{\sigma^{2} \Omega}\right) \int_{R} E\left\{[\hat{g}(x)-g(x)]^{2}\right\} d x,
$$

em que temos que $\mathrm{g}(\mathrm{x})$ é a função resposta verdadeira, $\hat{g}(x)$ é a respectiva estimativa de mínimos quadrados de $\mathrm{g}(\mathrm{x})$ e $\Omega=\int_{R} d x$. Esta expressão pode ser decomposta como a soma de um componente de viés e um componente de variância respectivamente dados por:

$$
\mathrm{J}=\left(\frac{n}{\sigma^{2} \Omega}\right)\left(\int_{R}[E(\hat{g}(x))-g(x)]^{2} d x+\int_{R} \operatorname{var}\{\hat{g}(x)\} d x\right)
$$

Box e Draper (1959) analisaram o efeito de assumir o modelo de regressão polinomial de primeiro grau quando o modelo verdadeiro é um polinômio de segundo grau. Verificaram que planejamentos que minimizam a média do erro quadrático médio são semelhantes aos que minimizam o componente de viés, mas são bastante diferentes daqueles que minimizam a componente da variância. Assim, planejamentos de "mínimo viés” diferiam significativamente daqueles obtidos pelos critérios tradicionais de otimalidade, que de modo geral consideram somente funções de variância.

Lauter (1974) considerou o problema geral do planejamento ótimo quando a forma da função resposta verdadeira é desconhecida. Neste trabalho, foi proposta uma extensão dos critérios de otimalidade usuais, que são baseados em um particular modelo, para uma classe mais ampla de modelos. A medida de otimalidade adotada seria obtida como uma média ponderada das medidas calculadas para todos os modelos da classe. O planejamento resultante não é, em geral, ótimo para qualquer um dos modelos, mas deveria ser neste caso razoavelmente eficaz para todos os modelos considerados prováveis.

Atkinson (1972) propôs um critério para o planejamento de regressão linear que tem o objetivo de simultaneamente estimar parâmetros do modelo e testar a adequação do mesmo. $\mathrm{O}$ autor considerou modelos da forma $Y_{i}=f_{1}\left(x_{i}\right)^{T} \beta_{1}+f_{2}\left(x_{i}\right)^{T} \beta_{2}+\varepsilon_{i}$ em que $f_{1}\left(x_{i}\right)$ corresponde ao modelo assumido por tentativa e $f_{2}\left(x_{i}\right)$ corresponde aos termos adicionais. Por exemplo, $f_{1}$ pode ser um polinômio de primeiro grau e $f_{2}$ uma função contendo termos quadráticos.

Várias outras situações similares são possíveis e encontram-se descritas na Seção 5.2 de Steinberg e Hunter (1984). 


\subsection{Planejamentos ortogonais}

De acordo com Box e Draper (1987), os trabalhos de R.A Fisher e F. Yates mostram que a ortogonalidade entre as variáveis preditoras já era considerada uma importante característica de um planejamento há muitos anos. O assunto é muito extenso e, para efeito de complementação dos capítulos anteriores, descreveremos apenas a abordagem apresentada em Box e Draper (1987), realizada dentro do contexto de planejamentos ótimos.

Por simplicidade, consideremos um modelo de regressão linear com apenas duas variáveis explicativas $X_{1}$ e $X_{2}$, n observações, da forma $Y_{i}=\beta_{0}+\beta_{1} \tilde{X}_{1 i}+\beta_{2} \tilde{X}_{2 i}+\varepsilon_{i}$ em que $\tilde{X}_{1 i}=X_{1 i}-\bar{X}_{1}$ e $\tilde{X}_{2 i}=X_{2 i}-\bar{X}_{2}$. Como $\tilde{X}_{1 i}$ e $\tilde{X}_{2 i}$ são variáveis centralizadas, $\overline{\widetilde{X}}_{1 i}=\widetilde{\widetilde{X}}_{2 i}=0$ e o coeficiente de correlação entre ambas é dado por:

$$
\mathrm{r}=\frac{\sum_{i=1}^{n} \tilde{X}_{1 i} \tilde{X}_{2 i}}{\left\{\sum_{i=1}^{n} \tilde{X}_{1 i}{ }^{2} \sum_{i=1}^{n} \tilde{X}_{2 i}{ }^{2}\right\}^{\frac{1}{2}}}=\frac{\tilde{X}_{1}{ }^{T} \tilde{X}_{2}}{\sqrt{\tilde{X}_{1}{ }^{T} \tilde{X}_{1}} \sqrt{\tilde{X}_{2}{ }^{T} \tilde{X}_{2}}}=\cos \theta
$$

para $\tilde{X}_{1}^{T}=\left(\tilde{X}_{11}, \tilde{X}_{12} \ldots \tilde{X}_{1 n}\right), \tilde{X}_{2}{ }^{T}=\left(\tilde{X}_{21}, \tilde{X}_{22} \ldots \tilde{X}_{2 n}\right)$ e $\theta$ é o ângulo formado por $\tilde{X}_{1}$ e $\tilde{X}_{2}$

Denotando $\hat{\beta}_{0}=\bar{y}, \hat{\beta}_{1}, \hat{\beta}_{2}$ os estimadores $\beta_{0}, \beta_{1}, \beta_{2}$, respectivamente, é possível mostrar que as variâncias e covariâncias destes estimadores são:

$$
\begin{aligned}
& \operatorname{Var}\left(\hat{\beta}_{0}\right)=\frac{\sigma^{2}}{n}, \\
& \operatorname{Var}\left(\hat{\beta}_{1}\right)=\left\{\frac{1}{\left(1-\cos ^{2} \theta\right) S_{1}^{2}}\right\} \frac{\sigma^{2}}{n}, \\
& \operatorname{Var}\left(\hat{\beta}_{2}\right)=\left\{\frac{1}{\left(1-\cos ^{2} \theta\right) S_{2}^{2}}\right\} \frac{\sigma^{2}}{n},
\end{aligned}
$$




$$
\begin{aligned}
& \operatorname{cov}\left(\hat{\beta}_{0}, \hat{\beta}_{1}\right)=0, \\
& \operatorname{cov}\left(\hat{\beta}_{0}, \hat{\beta}_{2}\right)=0, \\
& \operatorname{cov}\left(\hat{\beta}_{1}, \hat{\beta}_{2}\right)=\left\{\frac{-\cos \theta}{\left(1-\cos ^{2} \theta\right) S_{1} S_{2}}\right\} \frac{\sigma^{2}}{n}
\end{aligned}
$$

em que $S_{1}{ }^{2}=n^{-1} \sum \tilde{X}_{1 u}{ }^{2}, S_{2}{ }^{2}=n^{-1} \sum \tilde{X}_{2 u}{ }^{2}$.

Assim, para $\operatorname{Var}(\varepsilon)=\sigma^{2}$ constante e tamanho de amostra fixo n, consideremos o problema de planejar um experimento em que $\operatorname{Var}\left(\hat{\beta}_{j}\right), \mathrm{j}=0,1,2$, seja a menor possível. Claramente $\operatorname{Var}\left(\hat{\beta}_{0}\right)$ será inalterado pela escolha do planejamento porque $\frac{\sigma^{2}}{n}$ é fixado na definição de nosso problema.

Observa-se que $S_{1}$ e $S_{2}$ são medidas de dispersão dos pontos do planejamento na direção dos vetores $\tilde{X}_{1}$ e $\tilde{X}_{2}$ e sendo $\theta$ o ângulo entre os vetores $\tilde{X}_{1}=\left(\tilde{X}_{11}, \tilde{X}_{12}, \ldots, \tilde{X}_{1 n}\right)^{T}$ e $\tilde{X}_{2}=\left(\tilde{X}_{21}, \tilde{X}_{22}, \ldots, \tilde{X}_{2 n}\right)^{T}$, então $-1 \leq \cos \theta \leq 1$.

Desta forma, podemos tornar $\operatorname{Var}\left(\hat{\beta}_{1}\right)$ e $\operatorname{Var}\left(\hat{\beta}_{2}\right)$ tão pequenas quanto possível escolhendo as alternativas a seguir:

(a) $S_{1}{ }^{2}$ e $S_{2}{ }^{2}$ tão grande quanto possível ou

(b) $\cos ^{2} \theta$ tão pequeno quanto possível.

Na prática, é preciso escolher os fatores de escala $S_{1}$ e $S_{2}$ juntamente com as medidas de posição $\bar{X}_{1}$ e $\bar{X}_{2}$ a fim de que o planejamento estenda-se sobre a região de interesse.

Feito isto, adicionalmente, o planejamento deve ser selecionado de modo que $\cos \theta=0$. Dessa forma, dados $S_{1}$ e $S_{2}, \operatorname{Var}\left(\hat{\beta}_{1}\right)$ e $\operatorname{Var}\left(\hat{\beta}_{2}\right)$ serão tão pequenas quanto possível.

A condição de que $\cos \theta=0$ implica que os vetores do planejamento ndimensional $\tilde{X}_{1}$ e $\tilde{X}_{2}$ formem um ângulo de 90 graus, isto é, sejam ortogonais uns aos outros. Desde que $S_{1}$ e $S_{2}$ são, por suposição, maiores que zero, a condição é obtida tomando $\sum \tilde{X}_{1 i} \tilde{X}_{2 i}=0$. 
Como $\cos \theta$ é uma medida de correlação entre $X_{1}$ e $X_{2}$, a ortogonalidade implica que os regressores $X_{1}$ e $X_{2}$ são não correlacionados. Além disso, - $\cos \theta$ é o coeficiente de correlação entre os estimadores $\hat{\beta}_{1}$ e $\hat{\beta}_{2}$, então, a escolha de um planejamento ortogonal assegura que estes estimadores são não correlacionados, ou seja, $\beta_{1}, \beta_{2}$ são parâmetros ortogonais.

Ao contrário, a multicolinearidade, que se constitui na existência de relações lineares entra as variáveis preditoras do modelo de regressão, é um sério problema.

Deve-se ter em mente que uma região experimental restrita frequentemente resulta na existência de correlação entre as variáveis preditoras. Neste caso, verifica-se que embora os parâmetros $\beta_{0}, \beta_{1}, \ldots, \beta_{k}$ possam ser mal estimados, ainda assim, o modelo pode ser satisfatório para previsão dentro da região de interesse. O fator de inflação de variância, medida facilmente obtida nos pacotes computacionais, é de extremo auxílio na detecção de multicolinearidade. Este fator de inflação é definida como:

$$
\mathrm{FIV}=\frac{1}{1-R_{j}^{2}}
$$

em que $R_{j}^{2}$ é o coeficiente de correlação múltipla da regressão de $X_{j}$ em função das demais variáveis explicativas presentes no modelo.

Os planejamentos escalares apresentados no Capítulo 3 são ortogonais. No estudo realizado naquele capítulo procurava-se construir planejamentos escalares dentro de esferas de raio unitário, com a propriedade adicional de possuir alavancagem constante. De acordo com Ryan(1997, pag 458), como ortogonalidade é um quesito desejável, seria preferível construir planejamentos com alavancagem constante, ortogonais (ou próximos dos ortogonais) na região experimental desejada e não apenas na esfera de raio unitário. 


\subsection{Otimalidade Alfabética}

Além dos critérios D e G-otimalidade estudados no capítulo anterior, na literatura são apresentados outros critérios de otimalidade alfabética, utilizados em menor frequência. Destacamos:

A-otimalidade: Um planejamento é denominado A-ótimo se $\operatorname{tr}\left(X^{T} X\right)^{-1}$ é minimizado, sendo que tr denota traço da matriz. Lembrando que $\operatorname{Var}\left(\hat{\beta}_{j}\right)=a_{j j} \sigma^{2}$ para $a_{j j}$, j-ésimo elemento da diagonal de $\left(X^{T} X\right)^{-1}$, tal planejamento minimiza $\sum_{j=0}^{k} \operatorname{Var}\left(\hat{\beta}_{j}\right)$.

E-otimalidade: Um planejamento é denominado E-ótimo se o máximo autovalor de $\left(X^{T} X\right)^{-1}$ é minimizado. Lembrando que se $\lambda_{1}, \lambda_{2}, \ldots, \lambda_{k+1}$ são os $\mathrm{k}+1$ autovalores de $\left(X^{T} X\right)^{-1}$ então $\sum_{j=1}^{k+1} \lambda_{j}=\operatorname{tr}\left(X^{T} X\right)^{-1}$, de acordo com este critério, estaria sendo minimizada a maior parcela de $\sum_{j=0}^{k} \operatorname{Var}\left(\hat{\beta}_{j}\right)$.

$I_{\lambda}$-otimalidade: Um planejamento é $I_{\lambda}$-ótimo se $\int_{\chi} d x \lambda(d x)$ é minimizada em que $\lambda$ é uma medida de probabilidade no espaço de variáveis preditoras. Este critério, que alguns denominam de variância média integrada, também pertence à classe geral do critério L-otimalidade, discutido por Fedorov (1972).

L-otimalidade: Um planejamento é denominado L-ótimo se minimiza: $L(D)=\int_{\chi}[f(x)]^{T} D[f(x)] d(x)$ para $\mathrm{f}(\mathrm{x})$ função vetorial da i-ésima linha da matriz $\mathrm{X}$ e D uma matriz de dispersão, por exemplo, $\mathrm{D}=\left(X^{T} X\right)^{-1}$.

C-otimalidade: Neste caso, deseja-se estimar combinações lineares de $\beta$, da forma $C^{T} \beta$, com mínima variância. Desta forma, o critério a ser minimizado é $\operatorname{Var}\left(C^{T} \hat{\beta}\right)=C^{T}\left(X^{T} X\right)^{-1} C$. 


\subsection{Planejamentos Fatoriais}

Planejamentos fatoriais são amplamente utilizados em experimentos que envolvem vários fatores, quando é necessário estudar o efeito conjunto dos mesmos em uma resposta.

Um planejamento fatorial com $\mathrm{k}$ fatores é obtido fixando-se $n_{1}$ níveis do fator 1 , $n_{2}$ níveis do fator $2 \ldots n_{k}$ níveis do fator $\mathrm{k}$ e então, selecionando $\mathrm{n}=n_{1} \times n_{2} \times \ldots \times n_{k}$ réplicas obtidas tomando todas as possíveis combinações dos níveis mencionados.

Este tipo de planejamento possui inúmeras vantagens dentre as quais se destacam a alta eficiência das estimativas, já que em geral, produzem estimadores com variâncias menores que outros tipos de planejamentos com a mesma função.

Apresenta ainda a vantagem adicional do estudo simultâneo de vários fatores ao invés da análise de um fator de cada vez. Dois casos particulares importante são aqueles em que cada um dos $\mathrm{k}$ fatores possuem dois níveis (planejamento $2^{k}$ ) ou três níveis (planejamentos $3^{k}$ ).

Nos planejamentos $2^{k}$, os níveis podem ser quantitativos, por exemplo, dois valores de temperatura, pressão ou instante de tempo, ou qualitativos, como duas máquinas, dois operadores, níveis alto e baixo de um fator ou ainda presença e ausência do fator. Este planejamento é particularmente útil em estágios iniciais de uma pesquisa experimental, quando muitos fatores devem ser investigados. Devido ao fato de se dispor somente de dois níveis para cada fator, uma suposição básica deste tipo de planejamento é que a resposta seja aproximadamente linear no espaço onde os fatores foram selecionados. 


\subsection{Planejamento de Superfície de Resposta}

A metodologia de superfície resposta foi desenvolvida por Box (Box and Wilson 1951, Box 1954 e Box and Youle 1975) para análises em indústrias químicas. Esta metodologia explora modelos empíricos simples como polinômios de baixo grau, para aproximar a variável resposta e um conjunto de variáveis explicativas em uma região de interesse. A técnica consiste em uma coleção de procedimentos estatísticos que analisam a influência de variáveis explicativas em uma variável resposta com o objetivo de otimizá-la. Como o exemplo, consideremos a situação em que se deseja determinar a temperatura $\left(x_{1}\right)$ e pressão $\left(x_{2}\right)$ que maximizam a produção de um processo. Neste caso, a resposta y será uma função dos níveis de temperatura e pressão na forma:

$y=f\left(x_{1}, x_{2}\right)+\varepsilon$. Se $\mathrm{E}(\mathrm{y})=\eta=\mathrm{f}\left(x_{1}, x_{2}\right)$, então a superfície $\eta=\mathrm{f}\left(x_{1}, x_{2}\right)$ é chamada superfície resposta. Na maioria dos casos, a forma da relação entre y e $x_{1}, x_{2}$ é desconhecida e o primeiro passo é encontrar uma relação funcional adequada.

Uma constatação importante é que variáveis experimentais nas Ciências, Química, Física e Engenharia são freqüentemente quantitativas (contínuas).

Tem-se que as variáveis em experimentos de agricultura são frequentemente qualitativas (categóricas). Isto sugere o uso de planejamentos rotacionais, propostos por Box e Hunter (1957), que seriam aqueles para os quais a variância das previsões das respostas é constante na extremidade esférica na região de interesse.

Desde sua introdução no começo dos anos 50, a metodologia de superfície de resposta se tornou um conjunto de conceitos e técnicas. Uma das aplicações dos métodos de superfície de resposta foi para melhorar o desempenho de processos industriais existentes, sistematicamente variando variáveis do processo e coletando dados enquanto os processos operam, sem perturbar a produção normal. Um possível objetivo seria o de determinar condições ótimas de operação do sistema, ou determinar a região do espaço de variáveis explicativas nas quais as especificações de operação estão satisfeitas.

O uso de método de superfície de resposta para melhoria de processos é conhecido como operação evolucionária (EVOP). EVOP é uma estratégia de 
gerenciamento agressiva nas quais melhores maneiras de operar um processo são ativamente procuradas ao invés de acidentalmente descobertas. Spendley, Hext e Himsworth (1962) propuseram um esquema de planejamento alternativo conhecido como EVOP Simples, no qual k variáveis de processo são colocados em um simplex com k +1 vértices. Hahn e Dershowitz (1974) discutiram alguns dos problemas práticos que deveriam ser considerados no uso do EVOP. De acordo com Montgomery (1984), o procedimento consistiria em introduzir sistematicamente pequenas mudanças nos níveis das variáveis explicativas utilizadas. Muitas vezes, um planejamento $2^{k}$ é empregado com esse objetivo. Admite-se que estas mudanças são pequenas a ponto de não causar alterações sérias na produção ou na qualidade do processo, mas suficientes para detectar eventuais melhoras. Os dados são coletados para as variáveis respostas de interesse em cada ponto do planejamento $2^{k}$.

Muitos dos trabalhos estatísticos em planejamento de superfície resposta têm interesse no uso da teoria de planejamento ótimo.

Nas séries de artigos de Galil e Kiefer (1977a, b, 1979) foram obtidos planejamentos ótimos para modelos de superfície resposta polinomial quadrático e cúbico quando o domínio das variáveis preditoras é assumido um cubo ou esfera $\mathrm{k}$ dimensional. Planejamentos foram derivados para uma família de critérios otimizados que inclue A-, D- e E-otimalidade. Um dos maiores argumentos contra o uso da teoria de planejamentos ótimos é a necessidade de especificar um modelo para a função resposta, devido ao fato de que planejamentos ótimos são frequentemente sensíveis à forma do modelo. No entanto, esta preocupação estimulou muitas pesquisas para atingir planejamentos experimentais que sejam robustos à escolha do modelo.

Uma suposição comum é que a região de experimentação é um corpo geométrico simples, tal como um híper cubo, uma híper esfera ou pode ser transformado para tal região centrando e escalando variáveis preditoras. Uma das características dos planejamentos ótimos encontrados nos trabalhos mencionadas é que muitas observações experimentais são colocadas nos limites extremos da região.

Box (1982) observou que em muitos experimentos de superfície resposta, a região de experimentações possíveis não é precisamente conhecida. Além do mais, como os pontos do planejamento são afastados um dos outros, o efeito do viés em qualquer modelo de aproximação simples parece tornar-se cada vez mais severo. Desta forma, a tendência dos planejamentos ótimos de concentrar muitas observações nos 
extremos da região de planejamentos é vista com preocupação, especialmente no contexto de experimento de superfície resposta. Neste sentido, Draper (1982) discutiu vários métodos para escolher o número de pontos centrais em planejamentos para modelos com superfície de resposta quadrática.

Montgomery (1984) sugere o uso de planejamentos fatoriais do tipo $2^{k}$ com codificação do tipo \pm 1 , como por exemplo, para $\mathrm{k}=3$, o modelo seria da forma $y=\beta_{0}+\beta_{1} x_{1}+\beta_{2} x_{2}+\beta_{3} x_{3}+\varepsilon$, com matriz de planejamento $\mathrm{X}$ dada por:

$X=\left[\begin{array}{rrrr}1 & -1 & -1 & -1 \\ 1 & -1 & -1 & 1 \\ 1 & -1 & 1 & -1 \\ 1 & -1 & 1 & 1 \\ 1 & 1 & -1 & -1 \\ 1 & 1 & -1 & 1 \\ 1 & 1 & 1 & -1 \\ 1 & 1 & 1 & 1\end{array}\right]$

que produz um planejamento ortogonal. Como os planejamentos do tipo $2^{k}$ não possibilitam a estimação de $\sigma^{2}$, é comum a inclusão de observações centrais, ou seja, pontos com $x_{j}=0$, para $\mathrm{j}=1,2, \ldots, \mathrm{k}$. Verifica-se que o acréscimo desses pontos centrais não altera a ortogonalidade do planejamento, nem influencia os valores de $\hat{\beta}_{j}$, $\mathrm{j}=1,2, \ldots, \mathrm{k}$.

O autor sugere ainda planejamentos ortogonais do tipo simplex. Neste contexto, um simplex é uma figura $\mathrm{k}$ dimensional com $\mathrm{k}+1$ vértices. Para $\mathrm{k}=2$, o planejamento simplex é um triângulo eqüilátero e para $\mathrm{k}=3$ um tetraedro regular. Planejamentos desse tipo foram analisados no Capítulo 3. Para ajuste de modelos do segundo grau, algumas possibilidades de planejamentos são também sugeridas. 


\section{Capítulo 6}

\section{Aplicação}

\subsection{Introdução}

Temos como objetivo neste capítulo aplicar a teoria apresentada nos capítulos anteriores a um conjunto de dados. Foi utilizado um subconjunto do conjunto de dados obtido no Centro de Estatística Aplicada (CEA) do Instituto de Matemática e Estatística da Universidade de São Paulo (IME-USP).

Os dados referentes ao relatório de análise estatística (RAE-CEA-9710 André, Elian e Bruscato, 1997) são provenientes da área farmacológica. Neste trabalho investiga-se o efeito de diversos tipos de anestésicos locais sobre o coração de ratos, sendo que anestésicos são usados na prática médica e odontológica para inibir a dor, permitindo, assim, a realização de procedimentos cirúrgicos. O alvo dos anestésicos locais são os tecidos excitáveis do organismo. Os anestésicos locais impedem a transmissão dos impulsos elétricos nestes tecidos, bloqueando (reversivelmente) os canais iônicos responsáveis pela transferência de carga positiva através da membrana celular. 
O interesse deste estudo consistia em verificar quais características físicoquímicas da molécula de determinada droga influenciam mais em sua potência tóxica. Para isto, foram utilizados setenta e dois ratos, homogêneos entre si, divididos em quatorze grupos, contendo de três a oito ratos. Cada grupo foi submetido a uma droga diferente e foi calculada a potência tóxica, variável obtida após a realização de um experimento descrito no referido relatório. Na análise da relação entre as variáveis foi utilizado um modelo de regressão linear múltipla.

O objetivo do capítulo presente é selecionar o melhor planejamento das variáveis explicativas associada a esse conjunto de dados, conforme as técnicas descritas nos capítulos anteriores.

\subsection{Descrição das variáveis}

$\mathrm{Na}$ presente aplicação utilizamos quatro variáveis independentes das dez analisadas no projeto, cada uma delas relativa ao grupo de efeito a que se refere.

A variável do grupo do efeito estérico mede um comprimento relacionado ao grupamento substituinte.

- B4 : largura do grupo substituinte a partir do eixo da ligação, perpendiculares a ele (medidas em Ângstron).

A variável do grupo do efeito eletrônico mede o efeito de dispersão de carga em torno do anel benzênico.

- SIGMA : constante de Hammet .

A variável do grupo do efeito hidrofóbico mede quanto as moléculas da droga misturam-se na água. 
- $\log$ PAPP : logaritmo do coeficiente de partição óleo-água medido (adimensional);

A variável do grupo de outros efeitos é:

- MR4 : refratividade molar (adimensional).

A variável resposta é:

- POTÊNCIA : $\log \left(\mathrm{DE}_{30}\right)$, onde $\mathrm{DE}_{30}$ é a dose de droga necessária para ocorrer uma redução de 30\% na freqüência do átrio em relação ao controle (adimensional). 
A Tabela 6.1 apresenta os valores dessas variáveis consideradas na aplicação. Utilizamos inicialmente quatorze diferentes combinações de valores das variáveis explicativas, sendo que, associados a cada combinação, havia três valores da variável resposta, perfazendo quatorze réplicas de tamanho três e amostra de tamanho 42.

Tabela 6.1: Dados da aplicação

\begin{tabular}{cccccccc}
\hline Grupo & B4 & SIGMA & LogPAPP & MR4 & \multicolumn{3}{c}{ Potência } \\
\hline 1 & 1,00 & 0,00 & 0,83 & 0,103 & 3,27 & 3,27 & 3,35 \\
2 & 2,04 & $-0,17$ & 1,54 & 0,565 & 3,91 & 3,77 & 3,73 \\
3 & 2,97 & $-0,15$ & 1,95 & 1,030 & 3,74 & 3,87 & 3,62 \\
4 & 3,49 & $-0,13$ & 2,45 & 1,496 & 3,92 & 3,78 & 3,57 \\
5 & 4,42 & $-0,16$ & 2,89 & 1,969 & 4,60 & 4,17 & 4,21 \\
& & & & & & & \\
6 & 2,87 & $-0,27$ & 1,01 & 0,787 & 3,93 & 3,75 & 3,61 \\
7 & 4,79 & $-0,32$ & 2,63 & 2,166 & 4,11 & 4,25 & 4,02 \\
8 & 2,93 & 0,50 & 0,48 & 1,118 & 3,18 & 2,57 & 2,91 \\
9 & 1,80 & 0,23 & 1,63 & 0,603 & 3,29 & 4,05 & 3,75 \\
10 & 1,60 & 0,66 & 0,36 & 0,633 & 2,65 & 2,55 & 2,88 \\
& & & & & & & \\
11 & 5,87 & $-0,16$ & 4,00 & 2,887 & 3,96 & 3,93 & 4,11 \\
12 & 6,23 & $-0,32$ & 3,80 & 3,090 & 4,28 & 4,19 & 4,20 \\
13 & 3,15 & 0,72 & $-0,70$ & 1,349 & 2,41 & 2,53 & 2,59 \\
14 & 2,61 & 0,54 & 1,87 & 0,502 & 3,18 & 3,61 & 3,53 \\
$\bar{x}$ & 3,26 & 0,069 & 1,78 & 1,307 & & & \\
\hline
\end{tabular}




\subsection{Análise dos Planejamentos}

Com o objetivo de selecionar o melhor planejamento nas variáveis explicativas SIGMA, LogPAPP, MR4 e B4, calcularemos a seguir as quantidades $\operatorname{DP}(\hat{\beta}) / \sigma$, $\operatorname{Traço}\left(X^{T} X\right)^{-1}$ e $\left|\left(X^{T} X\right)\right|$, descritos anteriormente.

Devido à multicolinearidade existente entre as variáveis explicativas, foram ainda analisados os fatores de inflação de variância, associados a cada variável, $\operatorname{FIV}\left(X_{j}\right), \mathrm{j}=1,2, \ldots, \mathrm{k}$.

Lembramos que $\operatorname{Var}\left(\hat{\beta}_{j}\right)=a_{j j} \sigma^{2}$, para $\quad a_{j j}$ elemento de ordem $\mathrm{j}$ da diagonal de $\left(X^{T} X\right)^{-1}$ e, portanto, nessas condições, $\operatorname{Traço}\left(X^{T} X\right)^{-1}=\sum_{j=0}^{k} \frac{\operatorname{Var}\left(\hat{\beta}_{j}\right)}{\sigma^{2}}$, com k número de variáveis explicativas do modelo.

As Tabelas 6.2 a 6.8 apresentam estes valores considerando-se uma variável independente, duas variáveis independentes (SIGMA e LogPAPP), três variáveis independentes (SIGMA, LogPAPP, MR4) e quatro variáveis independentes (SIGMA, LogPAPP, MR4 e B4), com réplicas de tamanho dois e três.

Os cálculos foram feitos no software R, com exceção do FIV(Fator de Inflação da Variância), que foi calculado no Minitab.

Não há interesse nos valores de FIV para modelos com uma variável independente. 
Tabela 6.2: Variável independente SIGMA( $\left.X_{1}\right)$, réplicas de tamanho 2 e 3

\begin{tabular}{lcc}
\hline & réplica de tamanho 2 & réplica de tamanho 3 \\
\hline $\operatorname{DP}\left(\hat{\beta}_{0}\right) / \sigma$ & 0,1923 & 0,1570 \\
$\operatorname{DP}\left(\hat{\beta}_{1}\right) / \sigma$ & 0,5159 & 0,4212 \\
$\operatorname{Traço~}\left(X^{T} X\right)^{-1}$ & 0,3032 & 0,2021 \\
$\left|\left(X^{T} X\right)\right|$ & 105,1956 & 236,69 \\
$\operatorname{VIF}\left(X_{1}\right)$ & 1 & 1 \\
\hline
\end{tabular}

Tabela 6.3: Variável independente $\operatorname{LogPAPP}\left(X_{2}\right)$, réplicas de tamanho 2 e 3

\begin{tabular}{lcc}
\hline & réplica de tamanho 2 & réplica de tamanho 3 \\
\hline $\operatorname{DP}\left(\hat{\beta}_{0}\right) / \sigma$ & 0,3224 & 0,2632 \\
$\operatorname{DP}\left(\hat{\beta}_{1}\right) / \sigma$ & 0,1689 & 0,1207 \\
$\operatorname{Traço~}\left(X^{T} X\right)^{-1}$ & 0,1258 & 0,0839 \\
$\left|\left(X^{T} X\right)\right|$ & 1281,2 & 2882,8 \\
$\operatorname{VIF}\left(X_{2}\right)$ & 1 & 1 \\
\hline
\end{tabular}

Tabela 6.4: Variável independente $\operatorname{MR} 4\left(X_{3}\right)$, réplicas de tamanho 2 e 3

\begin{tabular}{lcc}
\hline & réplica de tamanho 2 & réplica de tamanho 3 \\
\hline $\operatorname{DP}\left(\hat{\beta}_{0}\right) / \sigma$ & 0,3381 & 0,2760 \\
$\operatorname{DP}\left(\hat{\beta}_{1}\right) / \sigma$ & 0,2145 & 0,1751 \\
$\operatorname{Traço}\left(X^{T} X\right)^{-1}$ & 0,1603 & 0,1069 \\
$\left|\left(X^{T} X\right)\right|$ & 608,7 & 1369,6 \\
$\operatorname{VIF}\left(X_{3}\right)$ & 1 & 1 \\
\hline
\end{tabular}

Tabela 6.5: Variável independente B4( $\left.X_{4}\right)$, réplicas de tamanho 2 e 3

\begin{tabular}{lcc}
\hline & réplica de tamanho 2 & réplica de tamanho 3 \\
\hline $\operatorname{DP}\left(\hat{\beta}_{0}\right) / \sigma$ & 0,4524 & 0,3694 \\
$\operatorname{DP}\left(\hat{\beta}_{1}\right) / \sigma$ & 0,1257 & 0,1027 \\
$\operatorname{Traço~}\left(X^{T} X\right)^{-1}$ & 0,2205 & 0,1469 \\
$\left|\left(X^{T} X\right)\right|$ & 1771,5 & 3985,9 \\
$\operatorname{VIF}\left(X_{4}\right)$ & 1 & 1 \\
\hline
\end{tabular}


Tabela 6.6: Variáveis independentes SIGMA e $\operatorname{LogPAPP}\left(X_{1}\right.$ e $\left.X_{2}\right)$, réplicas de tamanho 2 e 3

\begin{tabular}{lcc}
\hline & réplica de tamanho 2 & réplica de tamanho 3 \\
\hline $\operatorname{DP}\left(\hat{\beta}_{0}\right) / \sigma$ & 0,4508 & 0,3680 \\
$\operatorname{DP}\left(\hat{\beta}_{1}\right) / \sigma$ & 0,7337 & 0,5991 \\
$\operatorname{DP}\left(\hat{\beta}_{2}\right) / \sigma$ & 0,2102 & 0,1717 \\
$\operatorname{Traço~}\left(X^{T} X\right)^{-1}$ & 0,7857 & 0,5237 \\
$\left|\left(X^{T} X\right)\right|$ & $2.380,07$ & $8.032,72$ \\
$\operatorname{VIF}\left(X_{1}\right)$ & 2,0 & 2,0 \\
$\operatorname{VIF}\left(X_{2}\right)$ & 2,0 & 2,0 \\
\hline
\end{tabular}

Tabela 6.7: Variáveis independentes SIGMA, LogPAPP e MR4 $\left(X_{1}, X_{2}\right.$ e $\left.X_{3}\right)$, réplicas de tamanho 2 e 3

\begin{tabular}{lcc}
\hline & réplica de tamanho 2 & réplica de tamanho 3 \\
\hline $\operatorname{DP}\left(\hat{\beta}_{0}\right) / \sigma$ & 0,4589 & 0,3747 \\
$\operatorname{DP}\left(\hat{\beta}_{1}\right) / \sigma$ & 0,7417 & 0,6056 \\
$\operatorname{DP}\left(\hat{\beta}_{2}\right) / \sigma$ & 0,2778 & 0,2268 \\
$\operatorname{DP}\left(\hat{\beta}_{3}\right) / \sigma$ & 0,3171 & 0,2589 \\
$\operatorname{Traço}\left(X^{T} X\right)^{-1}$ & 0,9384 & 0,6256 \\
$\left|\left(X^{T} X\right)\right|$ & $23.671,36$ & $119.836,3$ \\
$\operatorname{VIF}\left(X_{1}\right)$ & 2,1 & 2,1 \\
$\operatorname{VIF}\left(X_{2}\right)$ & 3,5 & 3,5 \\
$\operatorname{VIF}\left(X_{3}\right)$ & 2,2 & 2,2 \\
\hline
\end{tabular}


Tabela 6.8: Variáveis independentes SIGMA, LogPAPP, MR4 e B4 ( $X_{1}, X_{2}, X_{3}$ e $\left.X_{4}\right)$, réplicas de tamanho 2 e 3

\begin{tabular}{lll}
\hline & réplica de tamanho 2 & réplica de tamanho 3 \\
\hline $\operatorname{DP}\left(\hat{\beta}_{0}\right) / \sigma$ & 0,8641 & 0,7056 \\
$\operatorname{DP}\left(\hat{\beta}_{1}\right) / \sigma$ & 0,6805 & 0,5556 \\
$\operatorname{DP}\left(\hat{\beta}_{2}\right) / \sigma$ & 0,7442 & 0,6076 \\
$\operatorname{DP}\left(\hat{\beta}_{3}\right) / \sigma$ & 0,2847 & 0,2324 \\
$\operatorname{DP}\left(\hat{\beta}_{4}\right) / \sigma$ & 1,10 & 0,9044 \\
$\operatorname{Traço~}\left(X^{T} X\right)^{-1}$ & 3,0715 & 2,0476 \\
$\left|\left(X^{T} X\right)\right|$ & $51.120,43$ & $388.195,8$ \\
$\operatorname{VIF}\left(X_{1}\right)$ & 29,3 & 29,3 \\
$\operatorname{VIF}\left(X_{2}\right)$ & 2,1 & 2,1 \\
$\operatorname{VIF}\left(X_{3}\right)$ & 3,7 & 3,7 \\
$\operatorname{VIF}\left(X_{4}\right)$ & 26,7 & 26,7 \\
\hline
\end{tabular}

De modo geral, as propriedades desejáveis de um planejamento são: baixos valores de $\operatorname{DP}\left(\hat{\beta}_{j}\right) / \sigma$, Traço $\left(X^{T} X\right)^{-1}, \operatorname{VIF}\left(X_{j}\right)$ e alto valor de $\left|X^{T} X\right|$.

Segundo esse critério, com base na análise das Tabelas 6.2 a 6.8, observarmos que, fixadas as variáveis independentes, planejamentos com réplicas de tamanho três são superiores aos de tamanho dois. Além disso, dentre os planejamentos com uma variável explicativa, os melhores foram os que envolviam a variável explicativa LogPAPP e a variável explicativa B4. O ajuste do modelo com quatro variáveis se mostrou inadequado devido aos altos valores do fator de inflação de variância obtidos. A literatura considera problemática a situação em que $\operatorname{FIV}\left(X_{j}\right) \geq 5$.

Por outro lado, do ponto de vista das medidas consideradas, planejamentos com maior número de variáveis explicativas são inferiores, o que é esperado já que são mais suscetíveis à multicolinearidade e de modo geral, por envolverem mais parâmetros, implicam em maior variância global.

As Tabelas 6.9 a 6.15 apresentam as mesmas medidas considerando-se uma variável independente, duas variáveis independentes (SIGMA e LogPAPP), três variáveis independentes (SIGMA, LogPAPP, MR4) e quatro variáveis independentes (SIGMA, LogPAPP, MR4 e B4), com réplicas de tamanho três, sendo que o cálculo foi 
realizado tirando um ponto de cada réplica. Tal fato implica que, se $n_{i}$ é o tamanho da iésima réplica, então $n_{i}=3$ para todas as réplicas e apenas para uma $n_{i}=2$. Dessa forma, foram feitas ao todo 14 retiradas.

Tabela 6.9: Variável SIGMA, réplica de tamanho três, retirado um ponto de cada réplica

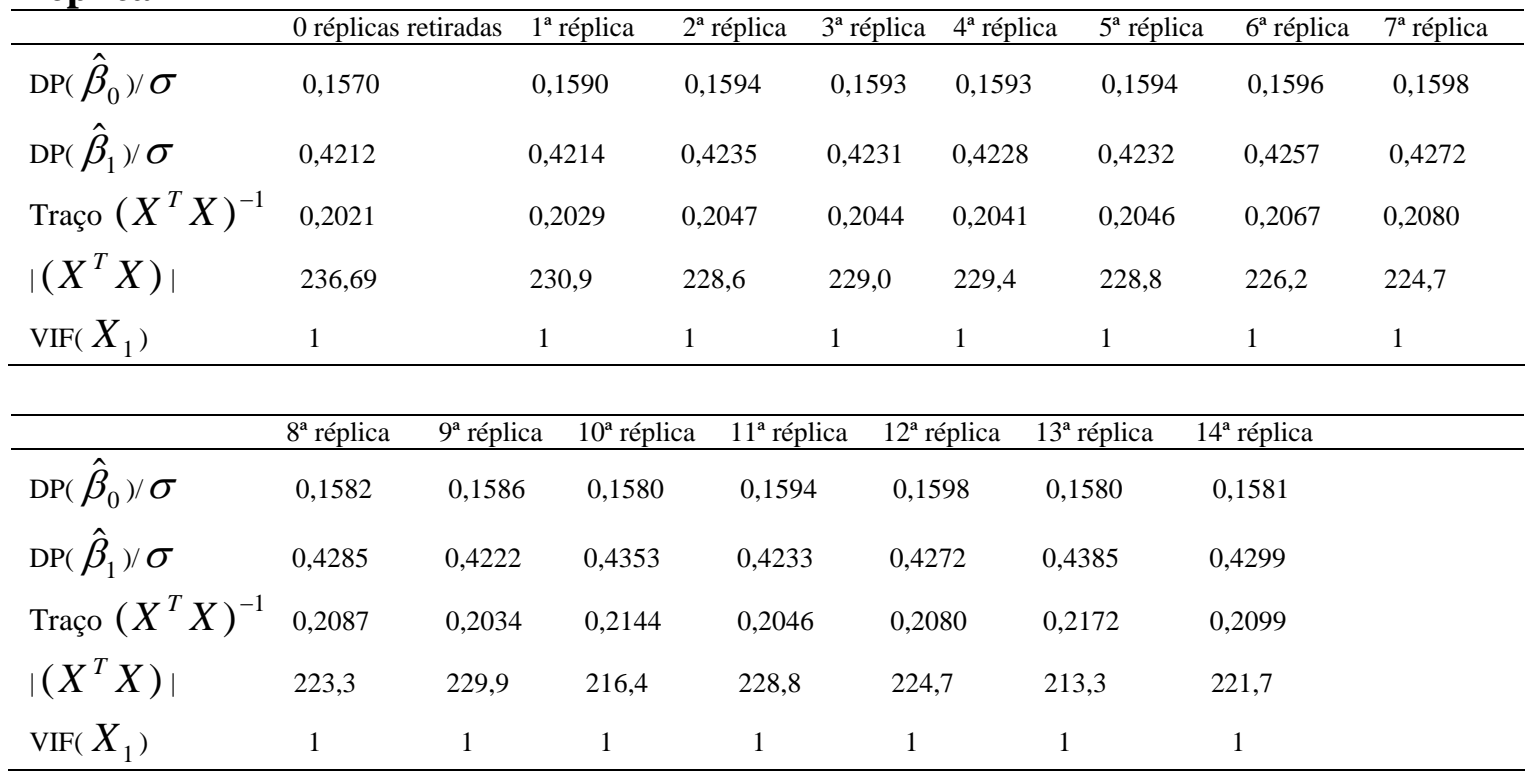


A primeira coluna dessa tabela apresenta, para efeito de comparação, os valores das medidas quando nenhum ponto é retirado.

Tabela 6.10: Variável LogPAPP, réplica de tamanho três, retirado um ponto de cada réplica

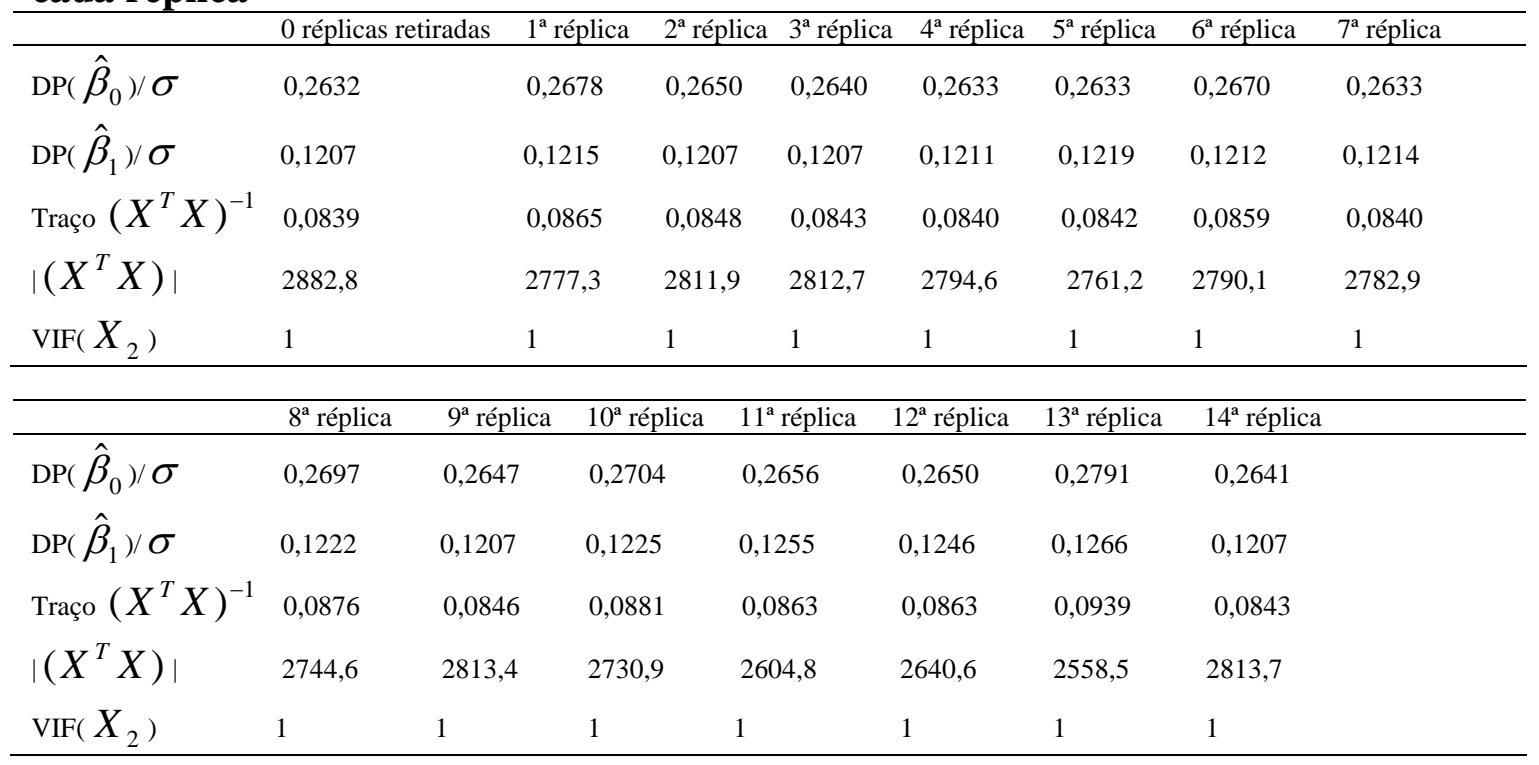

Tabela 6.11: Variável MR4, réplica de tamanho três, retirado um ponto de cada réplica

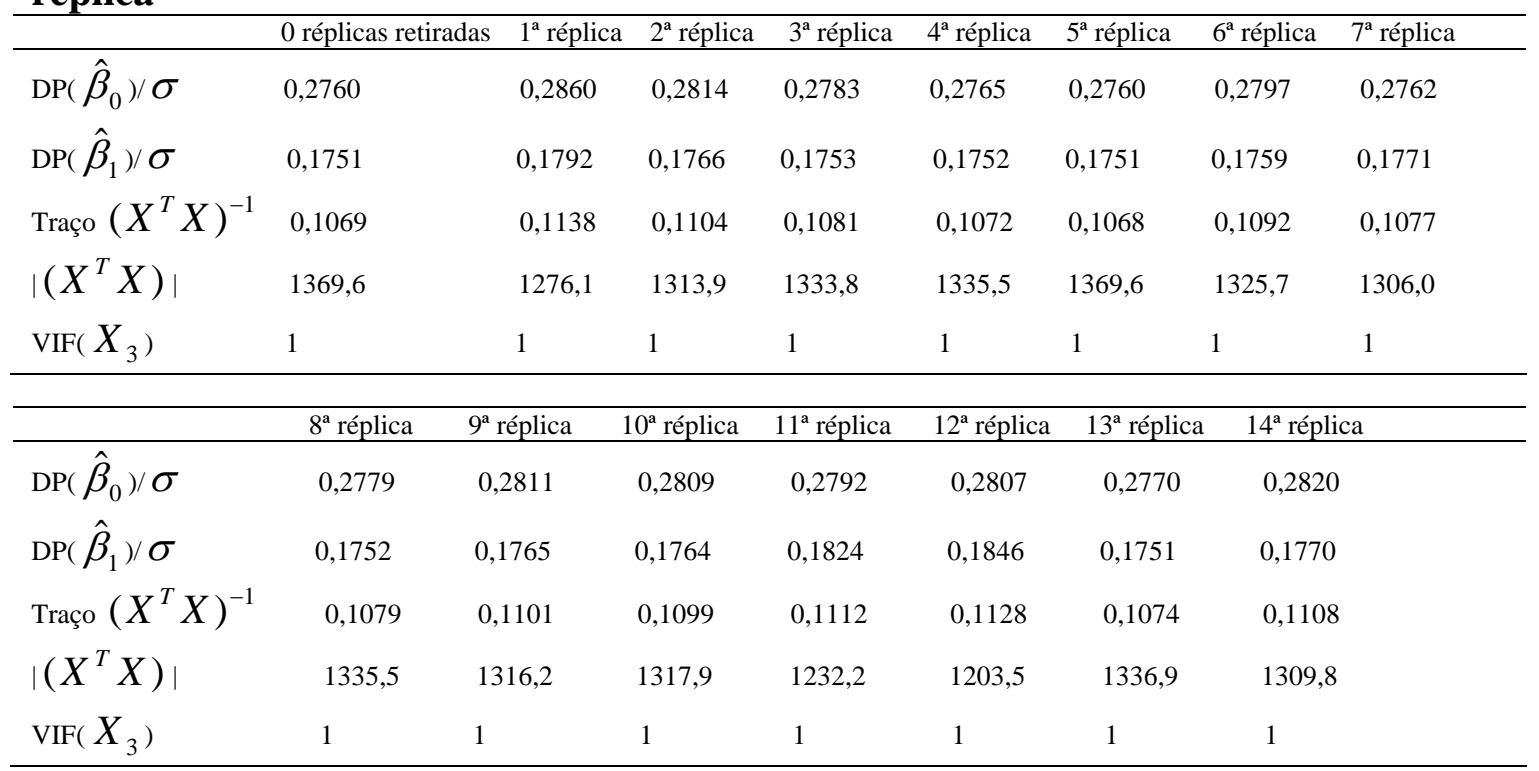


Tabela 6.12: Variável B4, réplica de tamanho três, retirado um ponto de cada réplica

\begin{tabular}{|c|c|c|c|c|c|c|c|c|c|}
\hline & \multicolumn{2}{|c|}{0 réplicas retiradas } & $1^{a}$ réplica & $2^{\mathrm{a}}$ réplica & $3^{\text {a }}$ réplica & $4^{\mathrm{a}}$ réplica & $5^{\text {a }}$ réplica & $6^{\mathrm{a}}$ réplica & $7^{\mathrm{a}}$ réplica \\
\hline $\mathrm{DP}\left(\boldsymbol{\beta}_{0}\right) / \sigma$ & 0,3694 & & 0,3843 & 0,3755 & 0,3709 & 0,3697 & 0,3697 & 0,3713 & 0,3705 \\
\hline $\mathrm{DP}\left(\hat{\beta}_{1}\right) / \sigma$ & 0,1027 & & 0,1056 & 0,1035 & 0,1027 & 0,1027 & 0,1034 & 0,1027 & 0,1040 \\
\hline Traço $\left(X^{T} X\right)^{-1}$ & 0,1469 & & 0,1589 & 0,1517 & 0,1482 & 0,1472 & 0,1474 & 0,1484 & 0,1481 \\
\hline $\mid(X$ & 3985,9 & & 3674,7 & 3827,5 & 3887,2 & 3888,9 & 3835,4 & 3884,3 & 3793,9 \\
\hline $\operatorname{VIF}\left(X_{4}\right)$ & 1 & & 1 & 1 & 1 & 1 & 1 & 1 & 1 \\
\hline & $8^{\mathrm{a}}$ réplica & \multicolumn{2}{|c|}{$9^{a}$ réplica } & $10^{a}$ réplica & $11^{\mathrm{a}}$ réplica & $12^{a}$ réplica & $13^{\mathrm{a}}$ réplica & \multicolumn{2}{|c|}{$14^{\mathrm{a}}$ réplica } \\
\hline $\mathrm{DP}\left(\hat{\beta}_{0}\right) / \sigma$ & 0,3711 & \multicolumn{2}{|c|}{0,3772} & 0,3787 & 0,3758 & 0,3786 & 0,3704 & \multicolumn{2}{|c|}{0,3724} \\
\hline $\operatorname{DP}\left(\hat{\beta}_{1}\right) / \sigma$ & 0,1027 & \multicolumn{2}{|c|}{0,1039} & 0,1042 & 0,1066 & 0,1079 & 0,1027 & \multicolumn{2}{|c|}{0,1029} \\
\hline Traço $\left(X^{T} X\right)^{-1}$ & 0,1483 & \multicolumn{2}{|c|}{0,1530} & 0,1543 & 0,1526 & 0,1549 & 0,1478 & \multicolumn{2}{|c|}{0,1492} \\
\hline$\left|\left(X^{T} X\right)\right|$ & 3886,2 & \multicolumn{2}{|c|}{3800,3} & 3773,9 & 3606,9 & 3522,8 & 3890,4 & \multicolumn{2}{|c|}{3872,7} \\
\hline $\operatorname{VIF}\left(X_{4}\right)$ & 1 & \multicolumn{2}{|l|}{1} & 1 & 1 & 1 & 1 & \multicolumn{2}{|l|}{1} \\
\hline
\end{tabular}

Observamos que, de modo geral, para todas as variáveis explicativas, a retirada de uma observação provocou uma piora no planejamento.

Considerando os valores dessas variáveis, apresentados na Tabela 6.1, observamos que:

- Para a Variável SIGMA, de acordo com a Tabela 6.9, a retirada dos pontos extremos 0.32 e 0,72 , que se encontram na $7^{\mathrm{a}}$ e $13^{\mathrm{a}}$ réplica respectivamente resultam nos piores planejamentos. Quando retiramos pontos extremos, é natural que isso aconteça, já que $\operatorname{Var}\left(\hat{\beta}_{1}\right)=\frac{\sigma^{2}}{\sum\left(x_{i}-\bar{x}\right)^{2}}$. A retirada de pontos extremos diminui o valor de $\sum\left(x_{i}-\bar{x}\right)^{2}$, aumentando $\operatorname{Var}\left(\hat{\beta}_{1}\right)$.

Por outro lado, na retirada de um ponto da $1^{\mathrm{a}}$ réplica, para a qual $\mathrm{x}=0$, obtem-se o máximo de $\left|X^{T} X\right|$ e o mínimo de $\operatorname{tr}\left(X^{T} X\right)^{-1}$.

Observa-se que este valor de x é o mais próximo de $\bar{x}=0,069$, o que evidencia o fato que a remoção de valores centrais da variável explicativa não apresenta efeito negativo nas características do planejamento. 
- Os valores extremos da variável LogPAPP são -0,70 e 4,00, que se encontram na $13^{\mathrm{a}}$ e $11^{\mathrm{a}}$ réplica respectivamente. Analisando a Tabela 6.10, percebemos que a retirada de um ponto dessas réplicas produz o menor valor de $\left|X^{T} X\right|$ e assim, o pior planejamento segundo esse critério. Por outro lado, a remoção do ponto $x=1,87$ (14 $4^{\mathrm{a}}$ réplica), que é um ponto central, já que $\bar{x}=1,767$, gera um valor de $\left|X^{T} X\right|$ maior que os obtidos na remoção de pontos nas demais réplicas.

- Para a variável MR4, os pontos extremos são 0,103 e 3,090, $1^{\mathrm{a}}$ e $12^{\mathrm{a}}$ réplicas respectivamente. De acordo com a Tabela 6.11, a retirada desses valores provoca sensíveis reduções em $\left|X^{T} X\right|$ e acréscimos em $\operatorname{tr}\left(X^{T} X\right)^{-1}$. Destaca-se ainda o ponto $\mathrm{x}=2,887$ ( $11^{\mathrm{a}}$ réplica) que, por ser muito próximo de 3,090, produz efeito semelhantes.

- Na Tabela 6.12, observa-se um comportamento semelhante para a variável B4 com relação aos pontos extremos 1,0 e 6,23 e o ponto $x=5,87$, muito próximo do valor extremo.

Analisando-se as Tabelas 6.13 a 6.15, que apresentam as mesmas informações para modelos com mais do que uma variável explicativa, observamos uma sensível redução de $\left|X^{T} X\right|$ e um moderado aumento em $\operatorname{tr}\left(X^{T} X\right)^{-1}$ quando da retirada de pontos em qualquer réplica. Há uma pequena alteração nos valores dos fatores de inflação da variância, tanto para mais quanto para menos, mas que não podem ser considerados importantes.

O modelo com quatro variáveis explicativas apresenta um alto valor de FIV, para todas as situações analisadas. É evidente que tal modelo, por apresentar alta multicolinearidade, deveria ser evitado ou utilizado com cautela em uma situação prática.

Comparando-se as retiradas efetuadas nas diferentes réplicas, observamos que a maior redução em $\left|X^{T} X\right|$ ocorre na $6^{\text {a }}$ e $13^{\mathrm{a}}$ réplica para o modelo com variáveis SIGMA e LogPAPP, na $13^{\mathrm{a}}$ réplica para o modelo com três variáveis independentes e na $14^{\mathrm{a}}$ réplica para o modelo com quatro variáveis independentes. No caso em que o número de variáveis independentes é maior ou igual a três, a determinação de pontos extremos se torna mais difícil, a menos que gráficos multidimensionais sejam disponíveis. Uma forma alternativa de determinar tais observações é o cálculo da alavanca $h_{i i}$ associada a cada uma delas. Tal cálculo será apresentado e analisado no final do capítulo e a partir de tabelas e gráficos podemos notar que as réplicas 
mencionadas são as que possuem maior valor de alavanca e, portanto, contem pontos extremos.

Dessa forma, também para o caso multidimensional (mais que duas variáveis independentes), a retirada de pontos extremos provoca um sensível decréscimo em $\left|X^{T} X\right|$.

Destacamos ainda que, no caso de várias variáveis independentes, a análise de $\left|X^{T} X\right|$, ou de $\operatorname{tr}\left(X^{T} X\right)^{-1}$ é extremamente vantajosa, pois esses elementos se comportam como uma medida resumo das várias outras medidas presentes nas tabelas.

Tabela 6.13: Variáveis SIGMA e LogPAPP, réplicas de tamanho três, retirado um ponto de cada réplica

\begin{tabular}{|c|c|c|c|c|c|c|c|c|c|c|}
\hline & 0 réplica & $1^{\text {a }}$ réplica & $2^{\mathrm{a}}$ réplica & \multicolumn{2}{|c|}{$3^{\mathrm{a}}$ réplica } & \multicolumn{2}{|c|}{$4^{\mathrm{a}}$ réplica } & $5^{\text {a }}$ réplica & a $\quad 6^{\text {a }}$ réplica & $7^{\mathrm{a}}$ réplica \\
\hline $\operatorname{DP}\left(\hat{\beta}_{0}\right) / \sigma$ & 0,3680 & 0,3791 & 0,3757 & \multicolumn{2}{|c|}{0,3712} & \multicolumn{2}{|c|}{0,3684} & 0,3681 & 0,3893 & 0,3697 \\
\hline $\mathrm{DP}\left(\hat{\beta}_{1}\right) / \sigma$ & 0,5991 & 0,6068 & 0,6083 & \multicolumn{2}{|c|}{0,6028} & \multicolumn{2}{|c|}{0,5995} & 0,5991 & 0,6281 & 0,6042 \\
\hline $\operatorname{DP}\left(\hat{\beta}_{2}\right) / \sigma$ & 0,1717 & 0,1749 & 0,1734 & \multicolumn{2}{|c|}{0,1720} & \multicolumn{2}{|c|}{0,1717} & 0,1725 & 0,1788 & 0,1717 \\
\hline Traço $\left(X^{T} X\right)^{-1}$ & 0,5237 & 0,5425 & 0,5413 & \multicolumn{2}{|c|}{0,5307} & \multicolumn{2}{|c|}{0,5246} & 0,5241 & 0,5781 & 0,5312 \\
\hline$\left|\left(X^{T} X\right)\right|$ & $8.032,7$ & 7543,5 & 7600,4 & \multicolumn{2}{|c|}{7742,0} & \multicolumn{2}{|c|}{7776,5} & 7693,9 & 7072,2 & 7622,9 \\
\hline $\operatorname{VIF}\left(X_{1}\right)$ & 2,0 & 2,1 & 2,1 & \multicolumn{2}{|l|}{2,0} & \multicolumn{2}{|l|}{2,0} & 2,0 & 2,0 & 2,0 \\
\hline $\operatorname{VIF}\left(X_{2}\right)$ & 2,0 & 2,1 & 2,1 & 2,0 & & 2,0 & & 2,0 & 2,0 & 2,0 \\
\hline & $8^{\mathrm{a}}$ réplic & $9^{\mathrm{a}}$ rép & $10^{\mathrm{a} r}$ & lica & $11^{\mathrm{a} r}$ & lica & $12^{\mathrm{a}}$ & éplica & $13^{\mathrm{a}}$ réplica & $14^{\mathrm{a}}$ réplica \\
\hline $\operatorname{DP}\left(\hat{\beta}_{0}\right) / \sigma$ & 0,3694 & 0,368 & 0,36 & & 0,37 & & 0,3 & 696 & 0,3744 & 0,3726 \\
\hline $\mathrm{DP}\left(\hat{\beta}_{1}\right) / \sigma$ & 0,6023 & 0,6010 & 0,60 & & 0,60 & & 0,5 & 991 & 0,6017 & 0,6276 \\
\hline $\operatorname{DP}\left(\hat{\beta}_{2}\right) / \sigma$ & 0,1718 & 0,1718 & 0,17 & & 0,17 & & 0,1 & 748 & 0,1737 & 0,1762 \\
\hline Traço $\left(X^{T} X\right)^{-1}$ & 0,5287 & 0,526 & 0,53 & & 0,53 & & 0,5 & 261 & 0,5325 & 0,5637 \\
\hline$\left|\left(X^{T} X\right)\right|$ & 7565,8 & 7788,4 & 7343 & & 7111 & & 735 & 6,1 & 7065,9 & 7143,3 \\
\hline $\operatorname{VIF}\left(X_{1}\right)$ & 2,0 & 2,0 & 2,0 & & 2,0 & & 2,0 & & 1,9 & 2,1 \\
\hline $\operatorname{VIF}\left(X_{2}\right)$ & 2,0 & 2,0 & 2,0 & & 2,0 & & 2,0 & & 1,9 & 2,1 \\
\hline
\end{tabular}


Tabela 6.14: Variáveis SIGMA, LogPAPP e MR4, réplicas de tamanho três, retirado um ponto de cada réplica

\begin{tabular}{|c|c|c|c|c|c|c|c|c|c|c|}
\hline & 0 réplica & $1^{a}$ réplica & \multirow{2}{*}{$\begin{array}{l}2^{\mathrm{a}} \text { réplica } \\
0,3845\end{array}$} & $3^{\mathrm{a}}$ réplica & $4^{\mathrm{a}}$ réplica & \multicolumn{2}{|c|}{$5^{\mathrm{a}}$ réplica } & \multicolumn{2}{|c|}{$6^{\mathrm{a}}$ réplica } & $7^{\mathrm{a}}$ réplica \\
\hline $\operatorname{DP}\left(\hat{\beta}_{0}\right) / \sigma$ & 0,3747 & 0,3889 & & 0,3785 & 0,3751 & \multicolumn{2}{|c|}{0,3747} & \multicolumn{2}{|c|}{0,3955} & 0,3756 \\
\hline $\mathrm{DP}\left(\hat{\beta}_{1}\right) / \sigma$ & 0,6056 & 0,6112 & 0,6128 & 0,6085 & 0,6059 & \multicolumn{2}{|c|}{0,6056} & \multicolumn{2}{|c|}{0,6346} & 0,6124 \\
\hline $\operatorname{DP}\left(\hat{\beta}_{2}\right) / \sigma$ & 0,2268 & 0,2270 & 0,2269 & 0,2268 & 0,2271 & \multicolumn{2}{|c|}{0,2272} & \multicolumn{2}{|c|}{0,2326} & 0,2280 \\
\hline $\mathrm{DP}\left(\hat{\beta}_{3}\right) / \sigma$ & 0,2589 & 0,2628 & 0,2615 & 0,2598 & 0,2591 & \multicolumn{2}{|c|}{0,2590} & \multicolumn{2}{|c|}{0,2589} & 0,2612 \\
\hline Traço $\left(X^{T} X\right)^{-1}$ & 0,6256 & 0,6454 & 0,6433 & 0,6325 & 0,6265 & \multicolumn{2}{|c|}{0,6259} & \multicolumn{2}{|c|}{0,6802} & 0,6363 \\
\hline$\left|\left(X^{T} X\right)\right|$ & 119836,3 & 109211,4 & 111130,2 & 114744,4 & 115869,3 & \multicolumn{2}{|c|}{114705,5} & \multicolumn{2}{|c|}{ 105499,1 } & 111729,7 \\
\hline $\operatorname{VIF}\left(X_{1}\right)$ & 2,1 & 2,1 & 2,1 & 2,1 & 2,1 & 2,0 & & 2,2 & & 2,1 \\
\hline $\operatorname{VIF}\left(X_{2}\right)$ & 3,5 & 3,5 & 3,5 & 3,5 & 3,5 & 3,5 & & 3,7 & & 3,5 \\
\hline $\operatorname{VIF}\left(X_{3}\right)$ & 2,2 & 2,1 & 2,2 & 2,2 & 2,2 & 2,2 & & 2,2 & & 2,2 \\
\hline & $8^{\mathrm{a}}$ réplica & $9^{a}$ réplica & $10^{\mathrm{a}}$ réplica & a $\quad 11^{\mathrm{a}}$ réplic & $12^{\mathrm{a}}$ & lica & $13^{\mathrm{a}}$ ré & lica & $14^{\mathrm{a}} \mathrm{re}$ & plica \\
\hline $\operatorname{DP}\left(\hat{\beta}_{0}\right) / \sigma$ & 0,3756 & 0,3752 & 0,3750 & 0,3832 & & & 0,377 & & 0,37 & \\
\hline $\operatorname{DP}\left(\hat{\beta}_{1}\right) / \sigma$ & 0,6080 & 0,6091 & 0,6166 & 0,6105 & 0,6 & & 0,626 & & 0,64 & \\
\hline $\operatorname{DP}\left(\hat{\beta}_{2}\right) / \sigma$ & 0,2280 & 0,2295 & 0,2269 & 0,2298 & & & 0,24 & & 0,24 & \\
\hline $\operatorname{DP}\left(\hat{\beta}_{3}\right) / \sigma$ & 0,2604 & 0,2631 & 0,2590 & 0,2604 & & & 0,27 & & 0,26 & \\
\hline Traço $\left(X^{T} X\right)^{-1}$ & 0,6303 & 0,6337 & 0,6393 & 0,6402 & 0,6 & & 0,64 & & 0,68 & \\
\hline$\left|\left(X^{T} X\right)\right|$ & 111580,1 & 112472,2 & 109510,9 & $9 \quad 104931,5$ & 105 & 98,9 & 9321 & ,89 & 9812 & 5,87 \\
\hline $\operatorname{VIF}\left(X_{1}\right)$ & 2,0 & 2,1 & 2,0 & 2,1 & 2,0 & & 1,9 & & 2,2 & \\
\hline $\operatorname{VIF}\left(X_{2}\right)$ & 3,5 & 3,6 & 3,4 & 3,4 & 3,3 & & 3,6 & & 4,0 & \\
\hline $\operatorname{VIF}\left(X_{3}\right)$ & 2,2 & 2,2 & 2,2 & 2,2 & 2,1 & & 2,5 & & 2,3 & \\
\hline
\end{tabular}


Tabela 6.15: Variáveis SIGMA, LogPAPP, MR4 e B4, réplicas de tamanho três, retirado um ponto de cada réplica

\begin{tabular}{|c|c|c|c|c|c|c|c|c|c|}
\hline & 0 réplica & \multirow{2}{*}{$\begin{array}{l}1^{\mathrm{a}} \text { réplica } \\
0,7381\end{array}$} & $2^{\mathrm{a}}$ réplica & $3^{\mathrm{a}}$ réplica & \multicolumn{2}{|c|}{$4^{\mathrm{a}}$ réplica } & $5^{\mathrm{a}}$ réplica & \multirow{2}{*}{$\begin{array}{c}\text { 6 réplica } \\
0,7064\end{array}$} & \multirow{2}{*}{$\begin{array}{c}7^{\mathrm{a}} \text { réplica } \\
0,7056\end{array}$} \\
\hline $\operatorname{DP}\left(\hat{\beta}_{0}\right) / \sigma$ & 0,7056 & & 0,7143 & 0,7059 & 0,70 & & 0,7056 & & \\
\hline $\operatorname{DP}\left(\hat{\beta}_{1}\right) / \sigma$ & 0,5556 & 0,5650 & 0,5561 & 0,5564 & \multicolumn{2}{|c|}{0,5577} & 0,5556 & 0,5765 & 0,5560 \\
\hline $\operatorname{DP}\left(\hat{\beta}_{2}\right) / \sigma$ & 0,6076 & 0,6147 & 0,6151 & 0,6103 & \multicolumn{2}{|c|}{0,6081} & 0,6076 & 0,6346 & 0,6142 \\
\hline $\operatorname{DP}\left(\hat{\beta}_{3}\right) / \sigma$ & 0,2324 & 0,2324 & 0,2324 & 0,2324 & \multicolumn{2}{|c|}{0,2330} & 0,2328 & 0,2420 & 0,2338 \\
\hline $\operatorname{DP}\left(\hat{\beta}_{4}\right) / \sigma$ & 0,9044 & 0,9116 & 0,9044 & 0,9070 & \multicolumn{2}{|c|}{0,9068} & 0,9044 & 0,9351 & 0,9044 \\
\hline Traço $\left(X^{T} X\right)^{-1}$ & 2,0476 & 2,1269 & 2,0699 & 2,0569 & \multicolumn{2}{|c|}{2,0602} & 2,0479 & 2,1669 & 2,0567 \\
\hline$\left|\left(X^{T} X\right)\right|$ & 388195,8 & 342088,0 & 359359,8 & 370585,2 & 372 & 502,0 & 371572,9 & $9 \quad 317438,4$ & 361386,4 \\
\hline $\operatorname{VIF}\left(X_{1}\right)$ & 29,3 & 28,6 & 28,9 & 29,4 & 29 & & 28,9 & 31,5 & 28,6 \\
\hline $\operatorname{VIF}\left(X_{2}\right)$ & 2,1 & 2,1 & 2,1 & 2,1 & 2,1 & & 2,1 & 2,2 & 2,1 \\
\hline $\operatorname{VIF}\left(X_{3}\right)$ & 3,7 & 3,7 & 3,7 & 3,7 & 3,7 & & 3,6 & 4,0 & 3,7 \\
\hline $\operatorname{VIF}\left(X_{4}\right)$ & 26,7 & 25,9 & 26,2 & 26,8 & 26,8 & & 26,3 & 28,3 & 26,1 \\
\hline & $8^{\circ}$ ponto & $9^{\circ}$ ponto & $10^{\circ}$ pont & $11^{\circ} \mathrm{po}$ & & $12^{\circ} \mathrm{F}$ & onto & $13^{\circ}$ ponto & $14^{\circ}$ ponto \\
\hline $\operatorname{DP}\left(\hat{\beta}_{0}\right) / \sigma$ & 0,7057 & 0,7194 & 0,7264 & 0,70 & & 0,70 & 64 & 0,7057 & 0,7641 \\
\hline $\operatorname{DP}\left(\hat{\beta}_{1}\right) / \sigma$ & 0,5567 & 0,5668 & 0,5745 & 0,556 & & 0,55 & & 0,5567 & 0,6023 \\
\hline $\operatorname{DP}\left(\hat{\beta}_{2}\right) / \sigma$ & 0,6102 & 0,6103 & 0,6170 & 0,61 & & 0,60 & & 0,6084 & 0,6610 \\
\hline $\operatorname{DP}\left(\hat{\beta}_{3}\right) / \sigma$ & 0,2339 & 0,2369 & 0,2331 & 0,23 & & 0,23 & & 0,2476 & 0,2430 \\
\hline $\operatorname{DP}\left(\hat{\beta}_{4}\right) / \sigma$ & 0,9048 & 0,9132 & 0,9314 & 0,90 & & 0,90 & & 0,9053 & 1,0080 \\
\hline Traço $\left(X^{T} X\right)^{-1}$ & 2,053720 & 2,1013 & 2,1601 & 2,06 & & 2,05 & & 2,0588 & 2,4586 \\
\hline$\left|\left(X^{T} X\right)\right|$ & 359970,1 & 350118 & 331838, & 3389 & 99,4 & 340 & 588,4 & 300813,9 & 270487,3 \\
\hline $\operatorname{VIF}\left(X_{1}\right)$ & 29,4 & 29,8 & 30,4 & 27,2 & & 26,5 & & 29,4 & 34,3 \\
\hline $\operatorname{VIF}\left(X_{2}\right)$ & 2,0 & 2,1 & 2,0 & 2,1 & & 2,0 & & 1,9 & 2,4 \\
\hline $\operatorname{VIF}\left(X_{3}\right)$ & 3,7 & 3,9 & 3,6 & 3,5 & & 3,5 & & 3,8 & 4,1 \\
\hline $\operatorname{VIF}\left(X_{4}\right)$ & 26,7 & 26,8 & 27,9 & 24,7 & & 24,2 & & 26,7 & 32,5 \\
\hline
\end{tabular}

As Tabelas 6.16 a 6.22 apresentam as mesmas medidas para réplicas de tamanho três, sendo que o cálculo foi realizado retirando-se uma réplica de cada vez e utilizandose $n_{i}=3$ nas demais. Tal procedimento gerou ao todo 14 retiradas e foram analisados os modelos com uma variável independente, duas variáveis independentes (SIGMA e LogPAPP), três variáveis independentes (SIGMA, LogPAPP, MR4) e quatro variáveis independentes (SIGMA, LogPAPP, MR4 e B4). 
Tabela 6.16: Variável SIGMA, réplica de tamanho três, retirada uma réplica de cada vez

\begin{tabular}{|c|c|c|c|c|c|c|c|}
\hline & $1^{\text {a }}$ réplica & $2^{\mathrm{a}}$ réplica & $3^{\mathrm{a}}$ réplica & $4^{\mathrm{a}}$ réplica & $5^{a}$ réplica & $6^{a}$ réplica & $7^{\mathrm{a}}$ réplica \\
\hline $\operatorname{DP}\left(\hat{\beta}_{0}\right) / \sigma$ & 0,1631 & 0,1645 & 0,1643 & 0,1641 & 0,1644 & 0,1654 & 0,1660 \\
\hline $\operatorname{DP}\left(\hat{\beta}_{1}\right) / \sigma$ & 0,4218 & 0,4283 & 0,4272 & 0,4261 & 0,4277 & 0,4359 & 0,4408 \\
\hline Traço $\left(X^{T} X\right)^{-1}$ & 0,2046 & 0,2105 & 0,2095 & 0,2085 & 0,2099 & 0,2174 & 0,2219 \\
\hline$\left|\left(X^{T} X\right)\right|$ & 219,18 & 212,6 & 213,72 & 214,78 & 213,16 & 205,28 & 200,69 \\
\hline \multirow[t]{2}{*}{$\operatorname{VIF}\left(X_{1}\right)$} & 0 & 0 & 0 & 0 & 0 & 0 & 0 \\
\hline & $8^{\mathrm{a}}$ réplica & $9^{\mathrm{a}}$ réplica & $10^{\mathrm{a}}$ réplica & $11^{\mathrm{a}}$ réplica & $12^{\mathrm{a}}$ réplica & $13^{\mathrm{a}}$ réplica & $14^{\mathrm{a}}$ réplica \\
\hline $\operatorname{DP}\left(\hat{\beta}_{0}\right) / \sigma$ & 0,1609 & 0,1619 & 0,1605 & 0,1644 & 0,1660 & 0,1604 & 0,1608 \\
\hline $\operatorname{DP}\left(\hat{\beta}_{1}\right) / \sigma$ & 0,4456 & 0,4244 & 0,4709 & 0,4277 & 0,4408 & 0,4841 & 0,4509 \\
\hline $\operatorname{Traço}\left(X^{T} X\right)^{-1}$ & 0,2245 & 0,2063 & 0,2476 & 0,2099 & 0,2219 & 0,2601 & 0,2291 \\
\hline$\left|\left(X^{T} X\right)\right|$ & 196,41 & 216,53 & 175,82 & 213,16 & 200,69 & 166,43 & 191,87 \\
\hline $\operatorname{VIF}\left(X_{1}\right)$ & 0 & 0 & 0 & 0 & 0 & 0 & 0 \\
\hline
\end{tabular}

Tabela 6.17: Variável LogPAPP, réplica de tamanho três, retirada uma réplica de cada vez

\begin{tabular}{|c|c|c|c|c|c|c|c|}
\hline & $1^{\mathrm{a}}$ réplica & $2^{\mathrm{a}}$ réplica & $3^{\mathrm{a}}$ réplica & $4^{\mathrm{a}}$ réplica & $5^{\text {a }}$ réplica & $6^{a}$ réplica & $7^{\mathrm{a}}$ réplica \\
\hline $\mathrm{DP}\left(\hat{\beta}_{0}\right) / \sigma$ & 0,2776 & 0,2686 & 0,2655 & 0,2635 & 0,2634 & 0,2748 & 0,2633 \\
\hline $\mathrm{DP}\left(\hat{\beta}_{1}\right) / \sigma$ & 0,1233 & 0,1208 & 0,1208 & 0,1220 & 0,1245 & 0,1224 & 0,1228 \\
\hline Traço $\left(X^{T} X\right)^{-1}$ & 0,0922 & 0,0868 & 0,0851 & 0,0843 & 0,0849 & 0,0905 & 0,0844 \\
\hline$\left|\left(X^{T} X\right)\right|$ & 2566,2 & 2670,4 & 2672,7 & 2618,1 & 2518,0 & 2604,6 & 2583,1 \\
\hline \multirow[t]{2}{*}{$\operatorname{VIF}\left(X_{2}\right)$} & 0 & 0 & 0 & 0 & 0 & 0 & 0 \\
\hline & $8^{\mathrm{a}}$ réplica & $9^{\mathrm{a}}$ réplica & $10^{\mathrm{a}}$ réplica & $11^{\mathrm{a}}$ réplica & $12^{\mathrm{a}}$ réplica & $13^{\mathrm{a}}$ réplica & $14^{\mathrm{a}}$ réplica \\
\hline $\operatorname{DP}\left(\hat{\beta}_{0}\right) / \sigma$ & 0,2840 & 0,2678 & 0,2866 & 0,2722 & 0,2694 & 0,3222 & 0,2660 \\
\hline $\operatorname{DP}\left(\hat{\beta}_{1}\right) / \sigma$ & 0,1257 & 0,1208 & 0,1268 & 0,1268 & 0,1344 & 0,1429 & 0,1207 \\
\hline Traço $\left(X^{T} X\right)^{-1}$ & 0,0965 & 0,0863 & 0,0982 & 0,0931 & 0,0907 & 0,1243 & 0,0853 \\
\hline$\left|\left(X^{T} X\right)\right|$ & 2468,1 & 2674,5 & 2427,4 & 2048,7 & 2156,2 & 1909,9 & 2675,5 \\
\hline $\operatorname{VIF}\left(X_{2}\right)$ & 0 & 0 & 0 & 0 & 0 & 0 & 0 \\
\hline
\end{tabular}


Tabela 6.18: Variável MR4, réplica de tamanho três, retirada uma réplica de cada vez sendo que ao todo são 14 retiradas

\begin{tabular}{|c|c|c|c|c|c|c|c|}
\hline & $1^{\mathrm{a}}$ réplica & $2^{\mathrm{a}}$ réplica & $3^{\mathrm{a}}$ réplica & $4^{\mathrm{a}}$ réplica & $5^{a}$ réplica & 6a réplica & $7^{\mathrm{a}}$ réplica \\
\hline $\operatorname{DP}\left(\hat{\beta}_{0}\right) / \sigma$ & 0,3095 & 0,2932 & 0,2831 & 0,2776 & 0,2761 & 0,2878 & 0,2767 \\
\hline $\mathrm{DP}\left(\hat{\beta}_{1}\right) / \sigma$ & 0,1892 & 0,1801 & 0,1758 & 0,1754 & 0,1790 & 0,1775 & 0,1819 \\
\hline Traço $\left(X^{T} X\right)^{-1}$ & 0,1316 & 0,1184 & 0,1111 & 0,1078 & 0,1083 & 0,1143 & 0,1097 \\
\hline$\left|\left(X^{T} X\right)\right|$ & 1089,1 & 1202,4 & 1262,1 & 1267,3 & 1216,6 & 1237,7 & 1178,8 \\
\hline $\operatorname{VIF}\left(X_{3}\right)$ & 0 & 0 & 0 & 0 & 0 & 0 & 0 \\
\hline & $8^{\mathrm{a}}$ réplica & $9^{\mathrm{a}}$ réplica & $10^{\mathrm{a}}$ réplica & $11^{\mathrm{a}}$ réplica & $12^{\mathrm{a}}$ réplica & $13^{\mathrm{a}}$ réplica & $14^{\mathrm{a}}$ réplica \\
\hline $\operatorname{DP}\left(\hat{\beta}_{0}\right) / \sigma$ & 0,2818 & 0,2922 & 0,2914 & 0,2879 & 0,2948 & 0,2789 & 0,2950 \\
\hline $\mathrm{DP}\left(\hat{\beta}_{1}\right) / \sigma$ & 0,1754 & 0,1796 & 0,1792 & 0,2018 & 0,2116 & 0,1751 & 0,1810 \\
\hline Traço $\left(X^{T} X\right)^{-1}$ & 0,1102 & 0,1176 & 0,1170 & 0,1236 & 0,1317 & 0,1084 & 0,1198 \\
\hline$\left|\left(X^{T} X\right)\right|$ & 1267,3 & 1209,3 & 1214,6 & 957,25 & 871,23 & 1271,6 & 1190,1 \\
\hline $\operatorname{VIF}\left(X_{3}\right)$ & 0 & 0 & 0 & 0 & 0 & 0 & 0 \\
\hline
\end{tabular}

Tabela 6.19: Variável B4, réplica de tamanho três, retirada uma réplica de cada vez

\begin{tabular}{|c|c|c|c|c|c|c|c|}
\hline & $1^{\mathrm{a}}$ réplica & $2^{\mathrm{a}}$ réplica & $3^{\mathrm{a}}$ réplica & $4^{\mathrm{a}}$ réplica & $5^{\mathrm{a}}$ réplica & $6^{\mathrm{a}}$ réplica & $7^{\mathrm{a}}$ réplica \\
\hline $\operatorname{DP}\left(\hat{\beta}_{0}\right) / \sigma$ & 0,4209 & 0,3890 & 0,3744 & 0,3705 & 0,3705 & 0,3755 & 0,3732 \\
\hline $\operatorname{DP}\left(\hat{\beta}_{1}\right) / \sigma$ & 0,1130 & 0,1054 & 0,1028 & 0,1027 & 0,1050 & 0,1029 & 0,1069 \\
\hline $\operatorname{Traço}\left(X^{T} X\right)^{-1}$ & 0,1899 & 0,1624 & 0,1508 & 0,1478 & 0,1483 & 0,1516 & 0,1507 \\
\hline$\left|\left(X^{T} X\right)\right|$ & 3052,3 & 3510,8 & 3689,9 & 3695,0 & 3534,3 & 3681,1 & 3409,8 \\
\hline $\operatorname{VIF}\left(X_{4}\right)$ & 0 & 0 & 0 & 0 & 0 & 0 & 0 \\
\hline & $8^{\mathrm{a}}$ réplica & $9^{\mathrm{a}}$ réplica & $10^{\mathrm{a}}$ réplica & $11^{\mathrm{a}}$ réplica & $12^{\mathrm{a}}$ réplica & $13^{\mathrm{a}}$ réplica & $14^{\mathrm{a}}$ réplica \\
\hline $\operatorname{DP}\left(\hat{\beta}_{0}\right) / \sigma$ & 0,3748 & 0,3946 & 0,4000 & 0,3932 & 0,4057 & 0,3728 & 0,3789 \\
\hline $\operatorname{DP}\left(\hat{\beta}_{1}\right) / \sigma$ & 0,1029 & 0,1066 & 0,1079 & 0,1170 & 0,1226 & 0,1027 & 0,1034 \\
\hline Traço $\left(X^{T} X\right)^{-1}$ & 0,1511 & 0,1671 & 0,1717 & 0,1683 & 0,1796 & 0,1495 & 0,1542 \\
\hline$\left|\left(X^{T} X\right)\right|$ & 3686,7 & 3429,2 & 3350,1 & 2848,9 & 2596,7 & 3699,4 & 3646,4 \\
\hline $\operatorname{VIF}\left(X_{4}\right)$ & 0 & 0 & 0 & 0 & 0 & 0 & 0 \\
\hline
\end{tabular}


Tabela 6.20: Variáveis SIGMA e LogPAPP, réplicas de tamanho três, retirada uma réplica de cada vez

\begin{tabular}{|c|c|c|c|c|c|c|c|}
\hline & $1^{\mathrm{a}}$ réplica & $2^{\mathrm{a}}$ réplica & $3^{\mathrm{a}}$ réplica & $4^{\mathrm{a}}$ réplica & $5^{a}$ réplica & $6^{\mathrm{a}}$ réplica & $7^{\mathrm{a}}$ réplica \\
\hline $\operatorname{DP}\left(\hat{\beta}_{0}\right) / \sigma$ & 0,4048 & 0,3935 & 0,3781 & 0,3691 & 0,3681 & 0,4495 & 0,3737 \\
\hline $\operatorname{DP}\left(\hat{\beta}_{1}\right) / \sigma$ & 0,3909 & 0,6296 & 0,6109 & 0,6004 & 0,5991 & 0,7111 & 0,6162 \\
\hline $\operatorname{DP}\left(\hat{\beta}_{2}\right) / \sigma$ & 0,1827 & 0,1776 & 0,0298 & 0,1720 & 0,1743 & 0,1996 & 0,1718 \\
\hline Traço $\left(X^{T} X\right)^{-1}$ & 0,5882 & 0,5829 & 0,5460 & 0,5262 & 0,5248 & 0,7476 & 0,5488 \\
\hline$\left|\left(X^{T} X\right)\right|$ & 6565,0 & 6735,6 & 7160,7 & 7263,9 & 7016,3 & 5151,1 & 6803,4 \\
\hline $\operatorname{VIF}\left(X_{1}\right)$ & 2,2 & 2,2 & 2,0 & 2,0 & 2,0 & 2,7 & 2,0 \\
\hline $\operatorname{VIF}\left(X_{2}\right)$ & 2,2 & 2,2 & 2,0 & 2,0 & 2,0 & 2,7 & 2,0 \\
\hline
\end{tabular}

$8^{\mathrm{a}}$ réplica $9^{\mathrm{a}}$ réplica $10^{\mathrm{a}}$ réplica $11^{\mathrm{a}}$ réplica $12^{\mathrm{a}}$ réplica $13^{\mathrm{a}}$ réplica $14^{\mathrm{a}}$ réplica

\begin{tabular}{|c|c|c|c|c|c|c|c|}
\hline & $8^{\mathrm{a}}$ réplica & $9^{\mathrm{a}}$ réplica & $10^{\mathrm{a}}$ réplica & $11^{\mathrm{a}}$ réplica & $12^{\mathrm{a}}$ réplica & $13^{\mathrm{a}}$ réplica & $14^{\mathrm{a}}$ réplica \\
\hline $\mathrm{DP}\left(\hat{\beta}_{0}\right) / \sigma$ & 0,3727 & 0,3683 & 0,3690 & 0,3680 & 0,3553 & 0,3746 & 0,3653 \\
\hline $\operatorname{DP}\left(\hat{\beta}_{1}\right) / \sigma$ & 0,6101 & 0,6053 & 0,6380 & 0,5991 & 0,5870 & 0,6012 & 0,6785 \\
\hline $\mathrm{DP}\left(\hat{\beta}_{2}\right) / \sigma$ & 0,1721 & 0,1722 & 0,1717 & 0,1717 & 0,1606 & 0,1612 & 0,1673 \\
\hline Traço $\left(X^{T} X\right)^{-1}$ & 0,5407 & 0,5316 & 0,5726 & 0,5238 & 0,4965 & 0,5278 & 0,6218 \\
\hline$\left|\left(X^{T} X\right)\right|$ & 6631,8 & 7299,9 & 5964,4 & 8032,7 & 8679,9 & 7041,5 & 7535,0 \\
\hline $\operatorname{VIF}\left(X_{1}\right)$ & 1,9 & 2,0 & 1,8 & 2,1 & 1,8 & 1,6 & 2,5 \\
\hline $\operatorname{VIF}\left(X_{2}\right)$ & 1,9 & 2,0 & 1,8 & 2,1 & 1,8 & 1,6 & 2,5 \\
\hline
\end{tabular}


Tabela 6.21: Variáveis SIGMA, LogPAPP e MR4, réplicas de tamanho três, retirada uma réplica de cada vez

\begin{tabular}{|c|c|c|c|c|c|c|c|}
\hline & $1^{\mathrm{a}}$ réplica & $2^{\mathrm{a}}$ réplica & $3^{\mathrm{a}}$ réplica & $4^{\mathrm{a}}$ réplica & $5^{a}$ réplica & $6^{a}$ réplica & $7^{\mathrm{a}}$ réplica \\
\hline $\operatorname{DP}\left(\hat{\beta}_{0}\right) / \sigma$ & 0,4255 & 0,4086 & 0,3872 & 0,3761 & 0,3749 & 0,4543 & 0,3780 \\
\hline $\mathrm{DP}\left(\hat{\beta}_{1}\right) / \sigma$ & 0,6261 & 0,6310 & 0,6152 & 0,6065 & 0,6056 & 0,7174 & 0,6292 \\
\hline $\operatorname{DP}\left(\hat{\beta}_{2}\right) / \sigma$ & 0,2274 & 0,2270 & 0,2269 & 0,2277 & 0,2280 & 0,2497 & 0,2308 \\
\hline $\mathrm{DP}\left(\hat{\beta}_{3}\right) / \sigma$ & 0,2732 & 0,2681 & 0,2617 & 0,2594 & 0,2592 & 0,2589 & 0,2670 \\
\hline Traço $\left(X^{T} X\right)^{-1}$ & 0,6994 & 0,6884 & 0,6483 & 0,6284 & 0,6265 & 0,8505 & 0,6633 \\
\hline$\left|\left(X^{T} X\right)\right|$ & 87961,7 & 93717,9 & 104560,7 & 107935,4 & 104444,1 & 76824,9 & 95516,6 \\
\hline $\operatorname{VIF}\left(X_{1}\right)$ & 2,2 & 2,2 & 2,1 & 2,0 & 2,0 & 2,7 & 2,0 \\
\hline $\operatorname{VIF}\left(X_{2}\right)$ & 3,4 & 3,5 & 3,5 & 3,5 & 3,4 & 4,2 & 3,5 \\
\hline \multirow[t]{2}{*}{$\operatorname{VIF}\left(X_{3}\right)$} & 2,1 & 2,2 & 2,2 & 2,2 & 2,1 & 2,1 & 2,2 \\
\hline & $8^{\mathrm{a}}$ réplica & $9^{\mathrm{a}}$ réplica & $10^{\mathrm{a}}$ réplica & $11^{\mathrm{a}}$ réplica & $12^{\mathrm{a}}$ réplica & $13^{\mathrm{a}}$ réplica & $14^{\mathrm{a}}$ réplica \\
\hline $\operatorname{DP}\left(\hat{\beta}_{0}\right) / \sigma$ & 0,3775 & 0,3765 & 0,3758 & 0,4093 & 0,3878 & 0,3954 & 0,3858 \\
\hline $\operatorname{DP}\left(\hat{\beta}_{1}\right) / \sigma$ & 0,6137 & 0,6176 & 0,6452 & 0,6259 & 0,6059 & 0,6102 & 0,7935 \\
\hline $\operatorname{DP}\left(\hat{\beta}_{2}\right) / \sigma$ & 0,2308 & 0,2360 & 0,2270 & 0,2390 & 0,2270 & 0,3141 & 0,3004 \\
\hline $\operatorname{DP}\left(\hat{\beta}_{3}\right) / \sigma$ & 0,2641 & 0,2733 & 0,2591 & 0,2648 & 0,2812 & 0,3583 & 0,3132 \\
\hline Traço $\left(X^{T} X\right)^{-1}$ & 0,6422 & 0,6536 & 0,6762 & 0,6865 & 0,6480 & 0,7556 & 0,9668 \\
\hline$\left|\left(X^{T} X\right)\right|$ & 95067,7 & 97743,9 & 88860,2 & 75121,9 & 75924,3 & 39978,1 & 54705,1 \\
\hline $\operatorname{VIF}\left(X_{1}\right)$ & 1,9 & 2,1 & 1,9 & 2,1 & 1,9 & 1,6 & 3,1 \\
\hline $\operatorname{VIF}\left(X_{2}\right)$ & 3,4 & 3,8 & 3,2 & 3,0 & 2,8 & 4,8 & 6,2 \\
\hline $\operatorname{VIF}\left(X_{3}\right)$ & 2,3 & 2,3 & 2,1 & 1,7 & 1,8 & 4,2 & 3,0 \\
\hline
\end{tabular}


Tabela 6.22: Variáveis SIGMA, LogPAPP, MR4 e B4, réplicas de tamanho três, retirada uma réplica de cada vez

\begin{tabular}{|c|c|c|c|c|c|c|c|}
\hline & $1^{\mathrm{a}}$ réplica & $2^{\mathrm{a}}$ réplica & $3^{\mathrm{a}}$ réplica & $4^{\mathrm{a}}$ réplica & $5^{\mathrm{a}}$ réplica & 6a réplica & $7^{\mathrm{a}}$ réplica \\
\hline $\operatorname{DP}\left(\hat{\beta}_{0}\right) / \sigma$ & 0,8311 & 0,7365 & 0,7066 & 0,7170 & 0,7056 & 0,7100 & 0,7056 \\
\hline $\operatorname{DP}\left(\hat{\beta}_{1}\right) / \sigma$ & 0,5933 & 0,5574 & 0,5584 & 0,5625 & 0,5556 & 0,6608 & 0,5571 \\
\hline $\operatorname{DP}\left(\hat{\beta}_{2}\right) / \sigma$ & 0,6361 & 0,6341 & 0,6164 & 0,6091 & 0,6076 & 0,7418 & 0,6303 \\
\hline $\operatorname{DP}\left(\hat{\beta}_{3}\right) / \sigma$ & 0,2324 & 0,2324 & 0,2324 & 0,2341 & 0,2336 & 0,2804 & 0,2371 \\
\hline $\operatorname{DP}\left(\hat{\beta}_{4}\right) / \sigma$ & 0,9335 & 0,9044 & 0,9130 & 0,9124 & 0,9045 & 1,0599 & 0,9044 \\
\hline Traço $\left(X^{T} X\right)^{-1}$ & 2,3729 & 2,1271 & 2,0786 & 2,0887 & 2,0486 & 2,6932 & 2,0796 \\
\hline$\left|\left(X^{T} X\right)\right|$ & 249872,6 & 301688,0 & 335364,1 & 341114,3 & 338327,2 & 175923,7 & 307767,5 \\
\hline $\operatorname{VIF}\left(X_{1}\right)$ & 27,6 & 28,0 & 29,5 & 30,0 & 28,0 & 41,2 & 27,1 \\
\hline $\operatorname{VIF}\left(X_{2}\right)$ & 2,3 & 2,2 & 2,1 & 2,0 & 2,0 & 2,9 & 2,0 \\
\hline $\operatorname{VIF}\left(X_{3}\right)$ & 3,6 & 3,7 & 3,7 & 3,7 & 3,5 & 5,2 & 3,7 \\
\hline $\operatorname{VIF}\left(X_{4}\right)$ & 24,3 & 25,2 & 27,0 & 27,0 & 25,5 & 35,7 & 24,7 \\
\hline & $8^{\mathrm{a}}$ réplica & 9a réplica & $10^{\mathrm{a}}$ réplica & $11^{\mathrm{a}}$ réplica & $12^{\mathrm{a}}$ réplica & $13^{\mathrm{a}}$ réplica & ca $14^{\mathrm{a}}$ réplica \\
\hline $\operatorname{DP}\left(\hat{\beta}_{0}\right) / \sigma$ & 0,7060 & 0,7575 & 0,7959 & 0,7129 & 0,7092 & 0,7062 & 1,5775 \\
\hline $\operatorname{DP}\left(\hat{\beta}_{1}\right) / \sigma$ & 0,5597 & 0,5973 & 0,6368 & 0,5588 & 0,5563 & 0,5632 & 1,2489 \\
\hline $\operatorname{DP}\left(\hat{\beta}_{2}\right) / \sigma$ & 0,6169 & 0,6177 & 0,6488 & 0,6268 & 0,6080 & 0,6134 & 1,3918 \\
\hline $\operatorname{DP}\left(\hat{\beta}_{3}\right) / \sigma$ & 0,2375 & 0,2491 & 0,2356 & 0,2462 & 0,2326 & 0,3260 & 0,4124 \\
\hline $\operatorname{DP}\left(\hat{\beta}_{4}\right) / \sigma$ & 0,9059 & 0,9377 & 1,0213 & 0,9465 & 0,9170 & 0,9108 & 2,3237 \\
\hline $\operatorname{Traço}\left(X^{T} X\right)^{-1}$ & 2,069267 & 2,253514 & 2,5584 & 2,1138 & 2,0769 & 2,1278 & 11,55520 \\
\hline$\left|\left(X^{T} X\right)\right|$ & 303518,7 & 273962,4 & 219122,7 & 240606,7 & 245373,6 & 6126050,2 & $2 \quad 35070,23$ \\
\hline $\operatorname{VIF}\left(X_{1}\right)$ & 29,6 & 31,4 & 34,8 & 22,8 & 20,6 & 30,1 & 145,8 \\
\hline $\operatorname{VIF}\left(X_{2}\right)$ & 1,9 & 2,1 & 1,9 & 2,1 & 1,9 & 1,6 & 9,5 \\
\hline $\operatorname{VIF}\left(X_{3}\right)$ & 3,6 & 4,3 & 3,5 & 3,2 & 3,0 & 5,2 & 11,7 \\
\hline $\operatorname{VIF}\left(X_{4}\right)$ & 26,7 & 27,3 & 32,5 & 21,8 & 18,8 & 27,0 & 164,8 \\
\hline
\end{tabular}

Comparando-se as Tabelas 6.16 a 6.22 com suas correspondentes 6.9 a 6.15, observamos que a retirada da réplica completa produziu maior redução em $\left|X^{T} X\right|$ do que a retirada de um único ponto da mesma réplica. Com relação a influência de pontos extremos e pontos centrais, a análise após a remoção da réplica completa apresentou características similares às obtidas quando da remoção de um ponto único.

As Tabelas 6.23 e 6.24 apresentam os valores das alavancas para os modelos com quatro, três, duas e uma variável independente. As alavancas foram calculadas no Minitab. 
Tabela 6.23: Cálculo da Alavanca para réplica de tamanho 2

\begin{tabular}{lllllll}
\hline 4 variáveis & 2 variáveis & 3 variáveis & SIGMA & LogPAPP & MR4 & B4 \\
\hline 0,178162 & 0,091258 & 0,132992 & 0,036992 & 0,0549070 & 0,102394 & 0,117108 \\
0,111423 & 0,080740 & 0,108975 & 0,050955 & 0,036842 & 0,061039 & 0,059599 \\
0,068048 & 0,054282 & 0,063735 & 0,048513 & 0,036445 & 0,039244 & 0,037130 \\
0,060641 & 0,047853 & 0,049655 & 0,046285 & 0,045905 & 0,037357 & 0,036484 \\
0,064231 & 0,063268 & 0,064222 & 0,049707 & 0,063268 & 0,055873 & 0,056643 \\
0,273409 & 0,179369 & 0,179459 & 0,066354 & 0,048242 & 0,048152 & 0,038234 \\
0,103592 & 0,076521 & 0,101470 & 0,076051 & 0,051985 & 0,069655 & 0,072266 \\
0,109065 & 0,087200 & 0,103343 & 0,085093 & 0,071920 & 0,037357 & 0,037534 \\
0,147134 & 0,045615 & 0,092177 & 0,042589 & 0,036125 & 0,058512 & 0,069836 \\
0,217768 & 0,128745 & 0,129243 & 0,128593 & 0,078986 & 0,056610 & 0,079757 \\
0,190096 & 0,172074 & 0,186565 & 0,049707 & 0,144670 & 0,150544 & 0,142620 \\
0,183956 & 0,126359 & 0,183216 & 0,076051 & 0,126025 & 0,181946 & 0,174265 \\
0,337646 & 0,180536 & 0,333197 & 0,148419 & 0,168734 & 0,035795 & 0,035939 \\
0,454829 & 0,166079 & 0,271751 & 0,094690 & 0,035945 & 0,065522 & 0,042584 \\
\hline
\end{tabular}

Para réplicas de tamanho 2, comparando as alavancas com uma, duas, três e quatro variáveis independentes, pode-se dizer que para a variável SIGMA os valores variam menos, de 0,03 a 0,15, para a variável LogPAPP temos valores 0,03 a 0,17, para a variável MR4 temos valores 0,03 a 0,18 e para a variável B4, 0,03 a 0,17. Para duas variáveis independentes os valores variam de 0,04 até 0,18 , já para três variáveis independentes temos valores de 0,04 até 0,33 e para quatro variáveis independentes, de 0,06 até 0,45 . Observa-se então um acréscimo da variabilidade com o aumento do número de variáveis explicativas. 


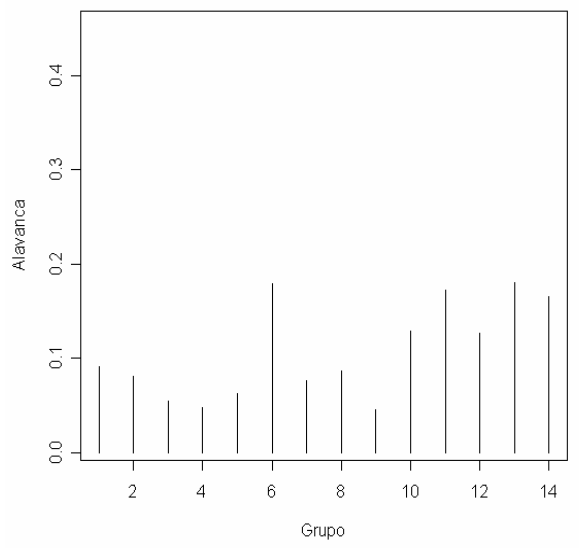

Gráfico1: Alavanca para duas variáveis independentes

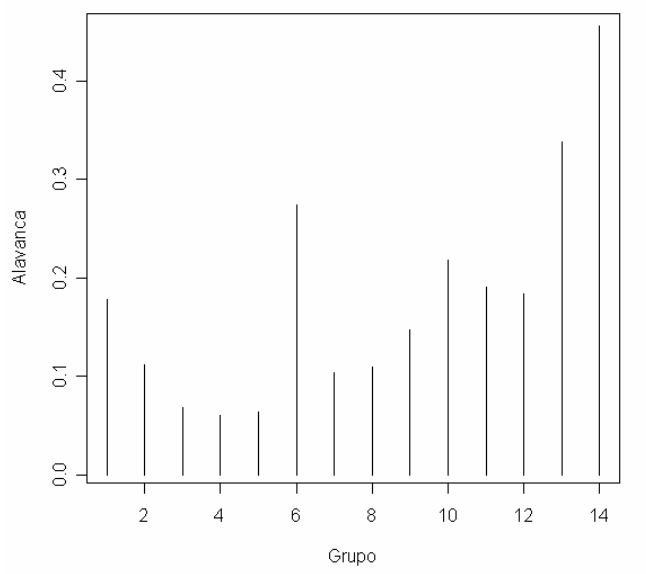

Gráfico3: Alavanca para quatro variáveis independentes

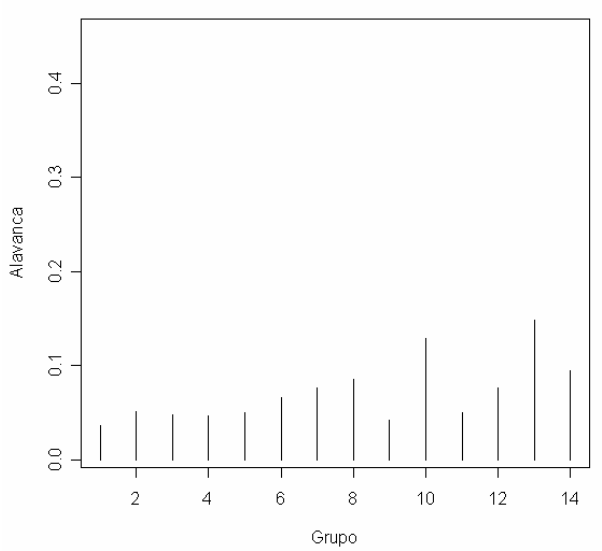

Gráfico4: Alavanca para uma variável independente (SIGMA)

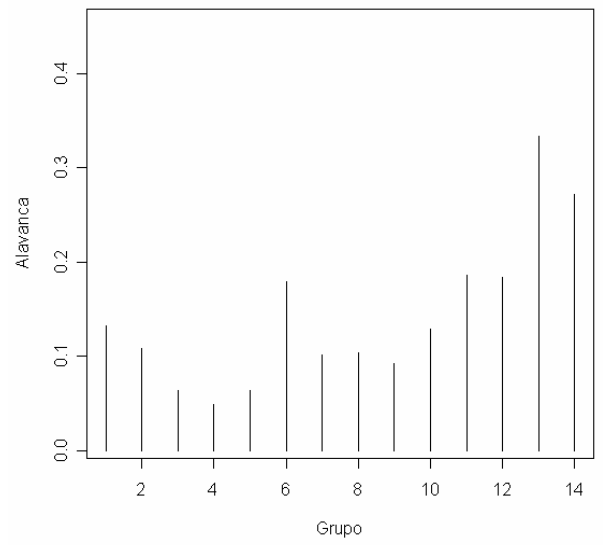

Gráfico2: Alavanca para três variáveis independentes

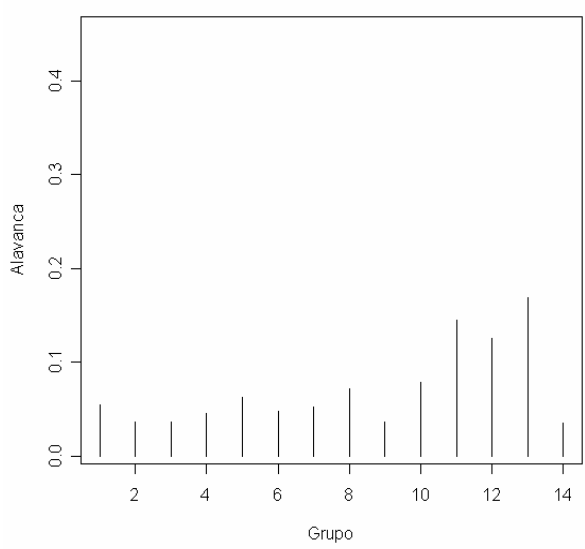

Gráfico5: Alavanca para uma variável independente (LogPAPP) 


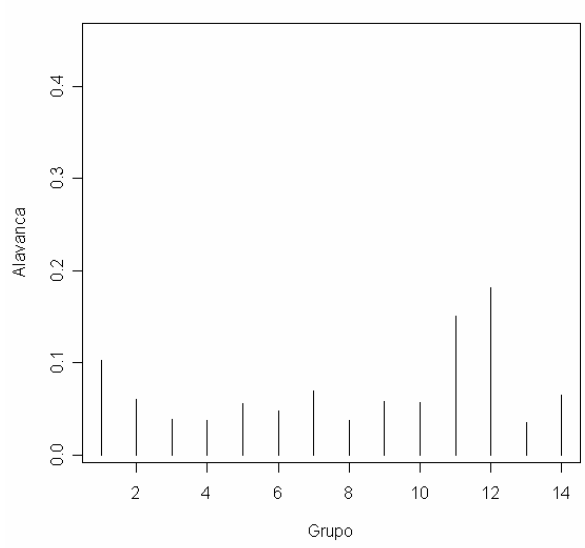

Gráfico6: Alavanca para uma variável independente (MR4)

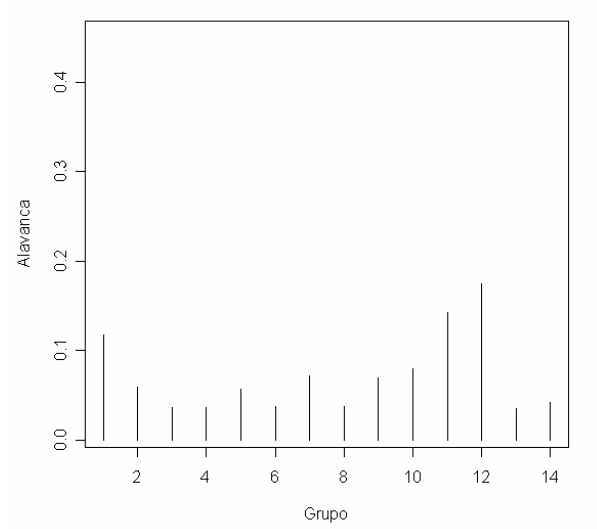

Gráfico7: Alavanca para uma variável independente (B4)

Analisando os Gráficos 1 a 6 podemos perceber que a variabilidade aumenta quando temos um número maior de variáveis independentes.

Tabela 6.24: Cálculo da Alavanca para réplica de tamanho três

\begin{tabular}{lllllll}
\hline 4 variáveis & 2 variáveis & 3 Variáveis & SIGMA & LogPAPP & MR4 & B4 \\
\hline 0,118774 & 0,060905 & 0,088661 & 0,0246614 & 0,036605 & 0,068262 & 0,078072 \\
0,074282 & 0,053827 & 0,072650 & 0,0339697 & 0,024561 & 0,040693 & 0,039733 \\
0,045365 & 0,036188 & 0,042490 & 0,0323423 & 0,024297 & 0,026162 & 0,024753 \\
0,040428 & 0,031902 & 0,033103 & 0,0308568 & 0,030603 & 0,024905 & 0,024323 \\
0,042821 & 0,042179 & 0,042815 & 0,0331383 & 0,042179 & 0,037248 & 0,037762 \\
0,182272 & 0,119579 & 0,119639 & 0,0442363 & 0,032162 & 0,032101 & 0,025489 \\
0,069062 & 0,051014 & 0,067647 & 0,0507005 & 0,034657 & 0,046437 & 0,048177 \\
0,072710 & 0,058134 & 0,068896 & 0,0567286 & 0,047947 & 0,024905 & 0,025023 \\
0,098089 & 0,030410 & 0,061451 & 0,0283928 & 0,024084 & 0,039008 & 0,046557 \\
0,145179 & 0,085830 & 0,086162 & 0,0857286 & 0,052657 & 0,037740 & 0,053171 \\
0,126731 & 0,114716 & 0,124376 & 0,0331383 & 0,096447 & 0,100362 & 0,095080 \\
0,122638 & 0,084239 & 0,122144 & 0,0507005 & 0,084017 & 0,121297 & 0,116176 \\
0,225097 & 0,120358 & 0,222131 & 0,0989458 & 0,112489 & 0,023864 & 0,023959 \\
0,303219 & 0,110719 & 0,181167 & 0,0631268 & 0,023964 & 0,043681 & 0,028390 \\
\hline
\end{tabular}


No caso de réplicas de tamanho 3, verifica-se que, para a variável SIGMA, os valores das alavancas variam menos, de 0,02 a 0,10, para a variável LogPAPP temos valores 0,02 a 0,11, para a variável MR4, 0,02 a 0,12 e para a variável B4, 0,02 a 0,11. Para duas variáveis independentes, os valores variam de 0,03 até 0,12 , para três variáveis independentes temos valores de 0,03 até 0,22 e para quatro variáveis independentes valores de 0,04 até 0,30. Observa-se então maior variabilidade nos modelos das alavancas, com maior quantidade de variáveis independentes, fato esse já constatado para réplicas de tamanho 2.

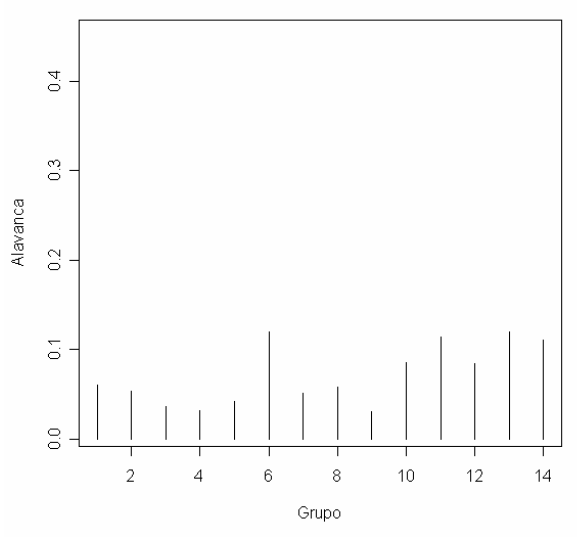

Gráfico8: Alavanca para duas variáveis independentes

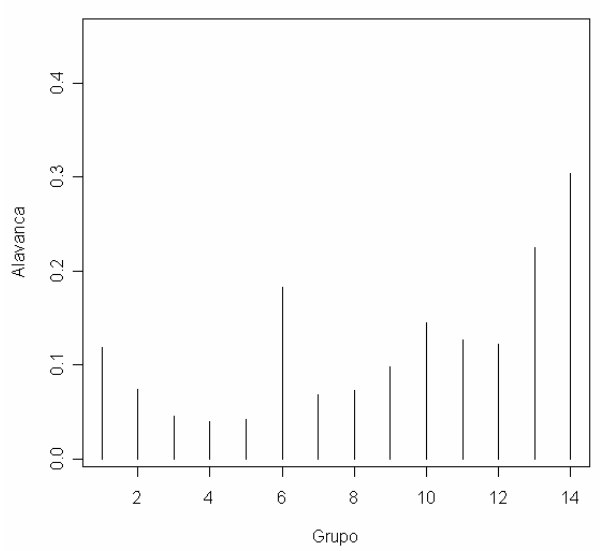

Gráfico10: Alavanca para quatro variáveis Independentes

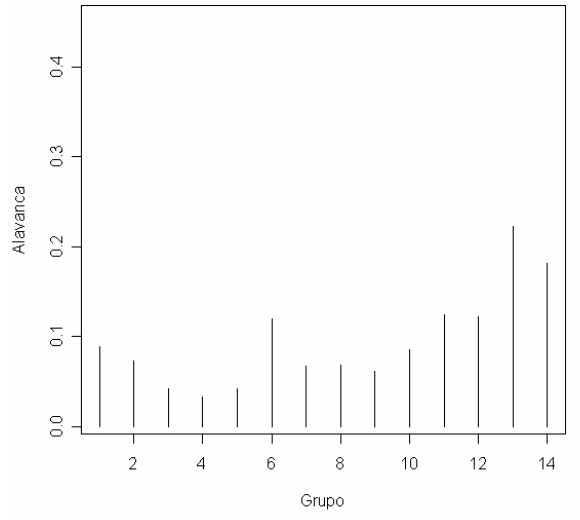

Gráfico9: Alavanca para três variáveis independentes 


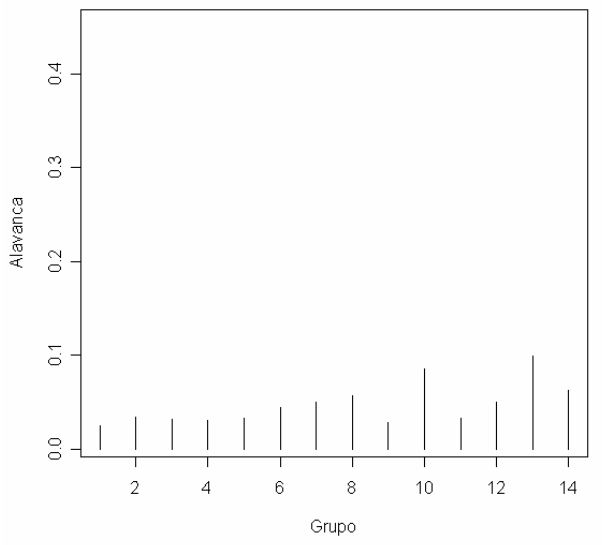

Gráfico11: Alavanca para uma variável independente(SIGMA)

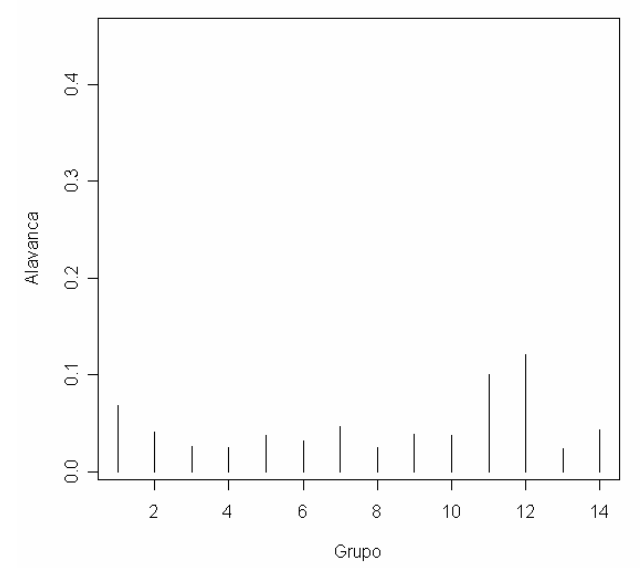

Gráfico13: Alavanca para uma variável independente(MR4)

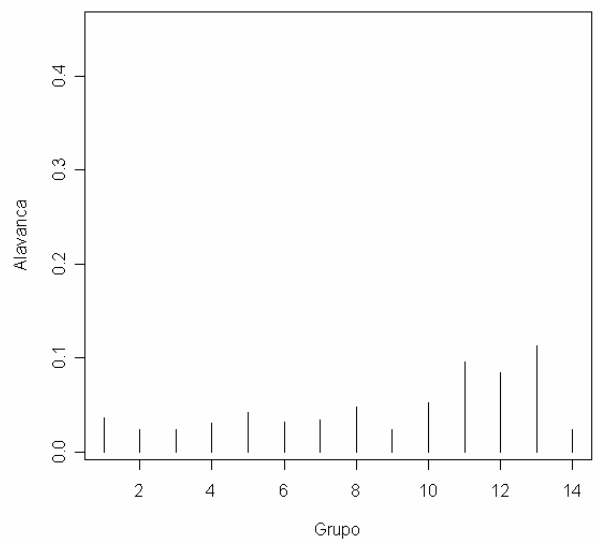

Gráfico12: Alavanca para uma variável independente(LogPAPP)

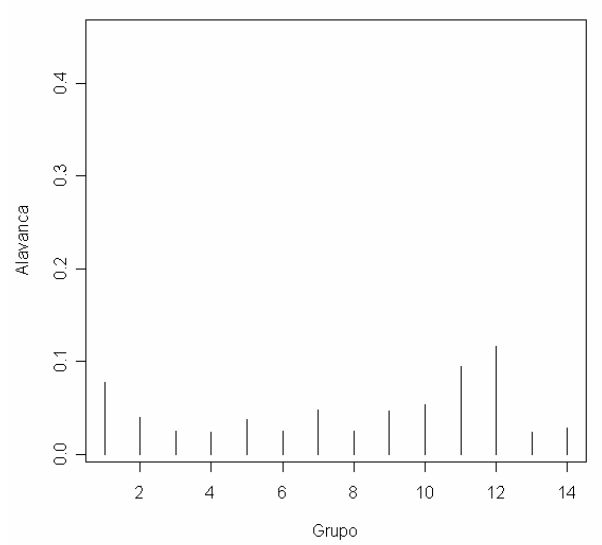

Gráfico14: Alavanca para uma variável independente(B4)

Analisando os Gráficos 8 a 14 percebemos que quanto maior o número de variáveis independentes maior será a variabilidade nos valores das Alavancas. Este fato também foi comentado para 2 réplicas já que tivemos comportamentos semelhantes.

Fazendo uma comparação dos Gráficos para 2 réplicas e 3 réplicas, observou-se que para réplicas de tamanho três, a variabilidade das alavancas diminui, o que era esperado, pois o tamanho da amostra $\mathrm{n}$ aumentou. Portanto, concluímos que para réplicas de tamanho três, o planejamento melhora segundo o critério de planejamentos com alavancagem constante. 


\section{Capítulo 7 Considerações Finais}

Conforme discutido no Capítulo 2, Box e Draper (1975) apresentaram 14 diferentes propriedades importantes para um planejamento experimental em modelos de regressão. Steinberg e Hunter (1984) apresentam um excelente levantamento sobre o assunto, destacando a necessidade de planejar experimentos considerando várias metas simultaneamente e não apenas uma ou duas. Este ponto é fundamental já que na análise de experimentos ótimos normalmente um único critério é empregado. Os autores apresentam ainda uma série de considerações práticas de extrema relevância. Segundo os mesmos, antes que qualquer experimento possa ser planejado, é essencial fixar claramente os objetivos para discutir possíveis fatores que possam substancialmente afetar os resultados. Embora possa haver uma coleção muito grande de fatores a influenciar nos resultados, o planejamento amostral em principio poderá controlar apenas um pequeno subconjunto deles.

Dessa forma, decisões devem ser tomadas sobre quais deles serão variáveis, quais serão mantidas constantes e quais não serão controlados.

O estatístico que espera que sua contribuição para o planejamento vá envolver algum tópico técnico em teoria estatística perceberá que pode dar uma contribuição muito mais valiosa se levar o investigador a explicar claramente porque está executando o experimento e justificar a forma como o está realizando de modo a alcançar os objetivos. Do ponto de vista de ensino, sugerem aos estatísticos lecionar disciplinas para 
outras áreas que abordem mais planejamento e menos análise do que tem feito até agora.

Pesquisadores freqüentemente consultam estatísticos somente depois que obtiveram seus dados e encontraram dificuldade para analisá-los. Em muitas dessas situações a aplicação dos princípios básicos de estatística de planejamento experimental teriam gerado dados muito mais informativos.

Estatísticos tornam suas contribuições mais valiosas quando são consultados nos estágios de planejamento de uma investigação. Um planejamento experimental apropriado é mais importante que a análise estatística sofisticada já que resultados de um experimento bem planejado são evidentes através de uma análise gráfica simples. Nem a melhor análise estatística pode resgatar um experimento pobremente planejado.

Planejar um experimento é mais uma arte que uma ciência exata e não há um "caminho correto", o estatístico deve servir como um catalisador para garantir que os objetivos, limitações e suposições da investigação sejam claramente entendidas e que o experimento produz a maior quantidade possível de resultados válidos.

Boa comunicação entre o investigador e o estatístico é essencial. O estatístico deve ser inquisitivo, investigador, ativamente envolvido na investigação e pronto para criar questões fundamentais. O investigador deve aceitar o estatístico como um membro da equipe e estar preparado para fornecer o máximo de informações sobre o problema.

Do ponto de vista de estudos futuros na área, temas importantes de pesquisa podem ser encontrados.

Modelos de regressão polinomial, embora sejam casos particulares do modelo de regressão linear múltipla, apresentam algumas características próprias. Nessa linha, existe extensa literatura em planejamentos experimentais, que não foi abordada no presente trabalho.

Sugerimos ainda o estudo de planejamentos experimentais na presença de dados correlacionados, em modelos não lineares e em modelos lineares generalizados. 


\section{Apêndice A}

Os programas abaixo foram feitos no software $\mathrm{R}$ para calcularmos toda a aplicação prática desenvolvida no decorrer do trabalho, como desvio padrão(DP $(\hat{\beta}) / \sigma)$, traço $\left(X^{T} X\right)^{-1}$, determinante $\left|X^{T} X\right|$, VIF, gráficos 1 a 14 das páginas 73, 74, 76 e 77 e construção da figura 2.1 da página 7.

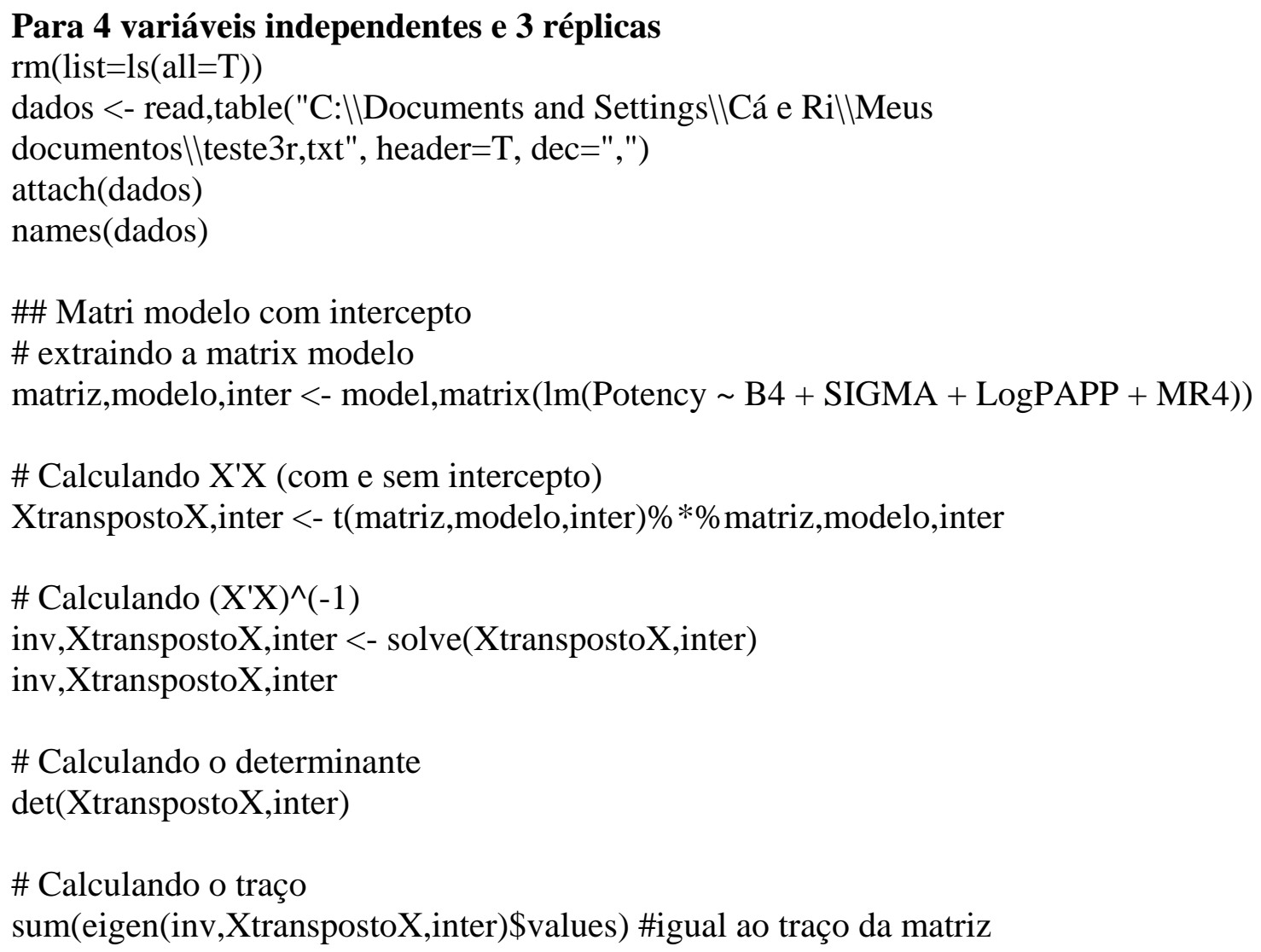




\section{Para 4 variáveis independentes e 2 réplicas}

rm(list=ls(all=T)

dados <- read,table("C: \\Documents and Settings \\Cá e Ri \Meus

documentos $\backslash$ teste2r,txt", header=T, dec=",")

attach(dados)

names(dados)

\#\# Matri modelo com intercepto

\# extraindo a matrix modelo

matriz,modelo,inter <- model,matrix(lm(Potency B4 + SIGMA + LogPAPP + MR4)

\# Calculando X'X

XtranspostoX,inter <- t(matriz,modelo,inter)\%*\%matriz,modelo,inter

\# Calculando o determinante

$\operatorname{det}($ XtranspostoX,inter)

Para 2 variáveis independentes e 2 réplicas

rm(list=ls(all=T)

dados <- read,table("C: \\Documents and Settings \\Cá e Ri \\Meus

documentos \\teste2r,txt", header=T, dec=",")

attach(dados)

names(dados)

\#\# Matri modelo com intercepto

\# extraindo a matrix modelo

matriz,modelo,inter <- model,matrix(lm(Potency SIGMA + LogPAPP))

\# Calculando X'X

XtranspostoX,inter <- t(matriz,modelo,inter)\%*\%matriz,modelo,inter

\# Calculando o determinante

$\operatorname{det}($ XtranspostoX,inter)

\# Calculando $\left(\mathrm{X}^{\prime} \mathrm{X}\right)^{\wedge}(-1)$

inv,XtranspostoX,inter <- solve(XtranspostoX,inter)

\# Calculando o traço

sum(eigen(inv,XtranspostoX,inter)\$values) \#igual ao traço da matriz 


\section{Para 2 variáveis independentes e 3 réplicas}

rm(list $=\mathrm{ls}($ all $=\mathrm{T}))$

dados <- read,table("C: \\Documents and Settings \\Cá e Ril\Meus

documentos $\backslash$ teste3r,txt", header=T, dec=",")

attach(dados)

names(dados)

\#\# Matri modelo com intercepto

\# extraindo a matrix modelo

matriz,modelo,inter <- model,matrix(lm(Potency SIGMA + LogPAPP))

\# Calculando X'X

XtranspostoX,inter <- t(matriz,modelo,inter)\%*\%matriz,modelo,inter

\# Calculando o determinante

$\operatorname{det}($ XtranspostoX,inter)

\# Calculando $\left(\mathrm{X}^{\prime} \mathrm{X}\right)^{\wedge}(-1)$

inv,XtranspostoX,inter <- solve(XtranspostoX,inter)

inv,XtranspostoX,inter

\# Calculando o traço

sum(eigen(inv,XtranspostoX,inter)\$values) \#igual ao traço da matriz

\section{Para 3 variáveis independentes e 2 réplicas}

rm(list=ls(all=T))

dados <- read,table("C: \\Documents and Settings \\Cá e Ri \\Meus

documentos \\teste2r,txt", header=T, dec=",")

attach(dados)

names(dados)

\#\# Matri modelo com intercepto

\# extraindo a matrix modelo

matriz,modelo,inter <- model,matrix(lm(Potency SIGMA + LogPAPP + MR4))

\# Calculando X'X

XtranspostoX,inter <- t(matriz,modelo,inter)\%*\%matriz,modelo,inter

\# Calculando o determinante

$\operatorname{det}($ XtranspostoX,inter)

\# Calculando $\left(\mathrm{X}^{\prime} \mathrm{X}\right)^{\wedge}(-1)$

inv,XtranspostoX,inter <- solve(XtranspostoX,inter)

\# Calculando o traço

sum(eigen(inv,XtranspostoX,inter)\$values) \#igual ao traço da matriz 


\section{Para 3 variáveis independentes e 3 réplicas}

rm(list=ls(all=T)

dados <- read,table("C: \\Documents and Settings \\Cá e Ril\Meus

documentos $\backslash$ teste3r,txt", header=T, dec=",")

attach(dados)

names(dados)

\#\# Matri modelo com intercepto

\# extraindo a matrix modelo

matriz,modelo,inter <- model,matrix(lm(Potency SIGMA + LogPAPP + MR4)

\# Calculando X'X

XtranspostoX,inter <- t(matriz,modelo,inter)\%*\%matriz,modelo,inter

\# Calculando o determinante

$\operatorname{det}($ XtranspostoX,inter)

\# Calculando $\left(\mathrm{X}^{\prime} \mathrm{X}\right)^{\wedge}(-1)$

inv,XtranspostoX,inter <- solve(XtranspostoX,inter)

inv,XtranspostoX,inter

\# Calculando o traço

sum(eigen(inv,XtranspostoX,inter)\$values) \#igual ao traço da matriz

\section{Para 1 variável independente e 2 réplicas}

rm(list $=\mathrm{ls}($ all $=\mathrm{T}))$

dados <- read,table("C: \\Documents and Settings \\Cá e Ril\Meus

documentos \\teste2r,txt", header=T, dec=",")

attach(dados)

names(dados)

\#\# Matriz modelo com intercepto

\# extraindo a matrix modelo

matriz,modelo,inter <- model,matrix $(\operatorname{lm}($ Potency $~$ SIGMA $))$

\# Calculando X'X

XtranspostoX,inter <- t(matriz,modelo,inter)\%*\%matriz,modelo,inter

\# Calculando o determinante

$\operatorname{det}($ XtranspostoX,inter)

\# Calculando $\left(\mathrm{X}^{\prime} \mathrm{X}\right)^{\wedge}(-1)$

inv,XtranspostoX,inter <- solve(XtranspostoX,inter)

inv,XtranspostoX,inter

\# Calculando o traço

sum(eigen(inv,XtranspostoX,inter)\$values) \#igual ao traço da matriz 


\section{Para 1 variável independente e 3 réplicas}

rm(list $=\mathrm{ls}($ all $=\mathrm{T}))$

dados <- read,table("C: \\Documents and Settings \\Cá e Ril\Meus

documentos $\backslash$ teste3r,txt", header=T, dec=",")

attach(dados)

names(dados)

\#\# Matri modelo com intercepto

\# extraindo a matrix modelo

matriz,modelo,inter <- model,matrix(lm(Potency SIGMA))

\# Calculando X'X

XtranspostoX,inter <- t(matriz,modelo,inter)\%*\%matriz,modelo,inter

\# Calculando o determinante

$\operatorname{det}($ XtranspostoX,inter)

\# Calculando $\left(\mathrm{X}^{\prime} \mathrm{X}\right)^{\wedge}(-1)$

inv,XtranspostoX,inter <- solve(XtranspostoX,inter)

inv,XtranspostoX,inter

\# Calculando o traço

sum(eigen(inv,XtranspostoX,inter)\$values) \#igual ao traço da matriz

\section{Para 1 variável independente e 2 réplicas}

rm(list $=\mathrm{ls}($ all $=\mathrm{T}))$

dados <- read,table("C: \\Documents and Settings \\Cá e Ril\Meus

documentos \\teste2r,txt", header=T, dec=",")

attach(dados)

names(dados)

\#\# Matri modelo com intercepto

\# extraindo a matrix modelo

matriz,modelo,inter <- model,matrix $(\operatorname{lm}($ Potency $~$ LogPAPP $))$

\# Calculando X'X

XtranspostoX,inter <- t(matriz,modelo,inter)\%*\%matriz,modelo,inter

\# Calculando o determinante

$\operatorname{det}($ XtranspostoX,inter)

\# Calculando $\left(\mathrm{X}^{\prime} \mathrm{X}\right)^{\wedge}(-1)$

inv,XtranspostoX,inter <- solve(XtranspostoX,inter)

inv,XtranspostoX,inter

\# Calculando o traço

sum(eigen(inv,XtranspostoX,inter)\$values) \#igual ao traço da matriz 


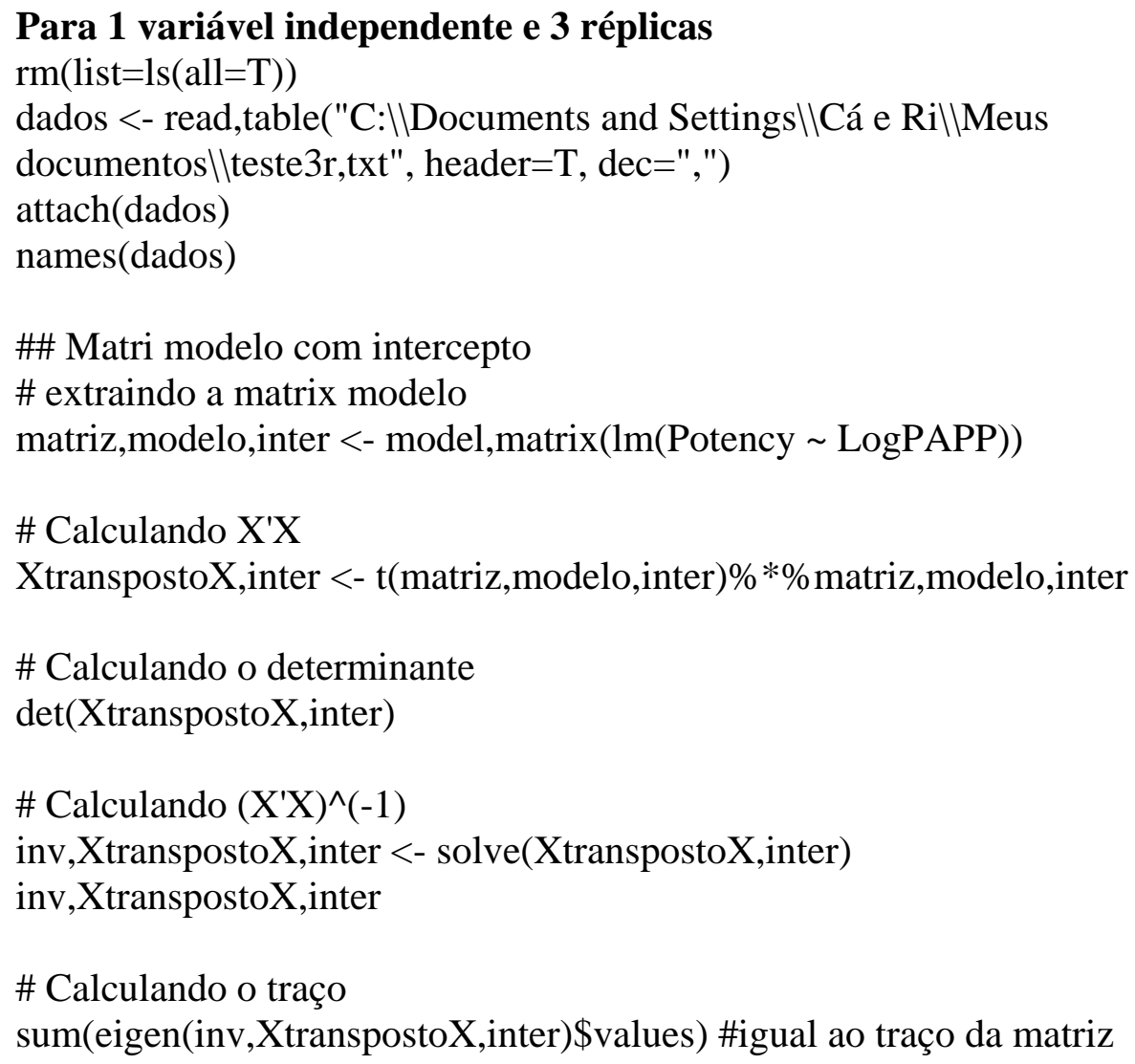

\section{Para 1 variável independente e 2 réplicas}

rm(list $=\mathrm{ls}($ all $=\mathrm{T}))$

dados <- read,table("C:\\Documents and Settings\\Cá e Ri \\Meus

documentos \\teste2r,txt", header=T, dec=",")

attach(dados)

names(dados)

\#\# Matri modelo com intercepto

\# extraindo a matrix modelo

matriz,modelo,inter <- model,matrix $(\operatorname{lm}($ Potency MR4)

\# Calculando X'X

XtranspostoX,inter <- t(matriz,modelo,inter)\%*\%matriz,modelo,inter

\# Calculando o determinante

$\operatorname{det}($ XtranspostoX,inter)

\# Calculando $\left(\mathrm{X}^{\prime} \mathrm{X}\right)^{\wedge}(-1)$

inv,XtranspostoX,inter <- solve(XtranspostoX,inter)

inv,XtranspostoX,inter

\# Calculando o traço

sum(eigen(inv,XtranspostoX,inter)\$values) \#igual ao traço da matriz 


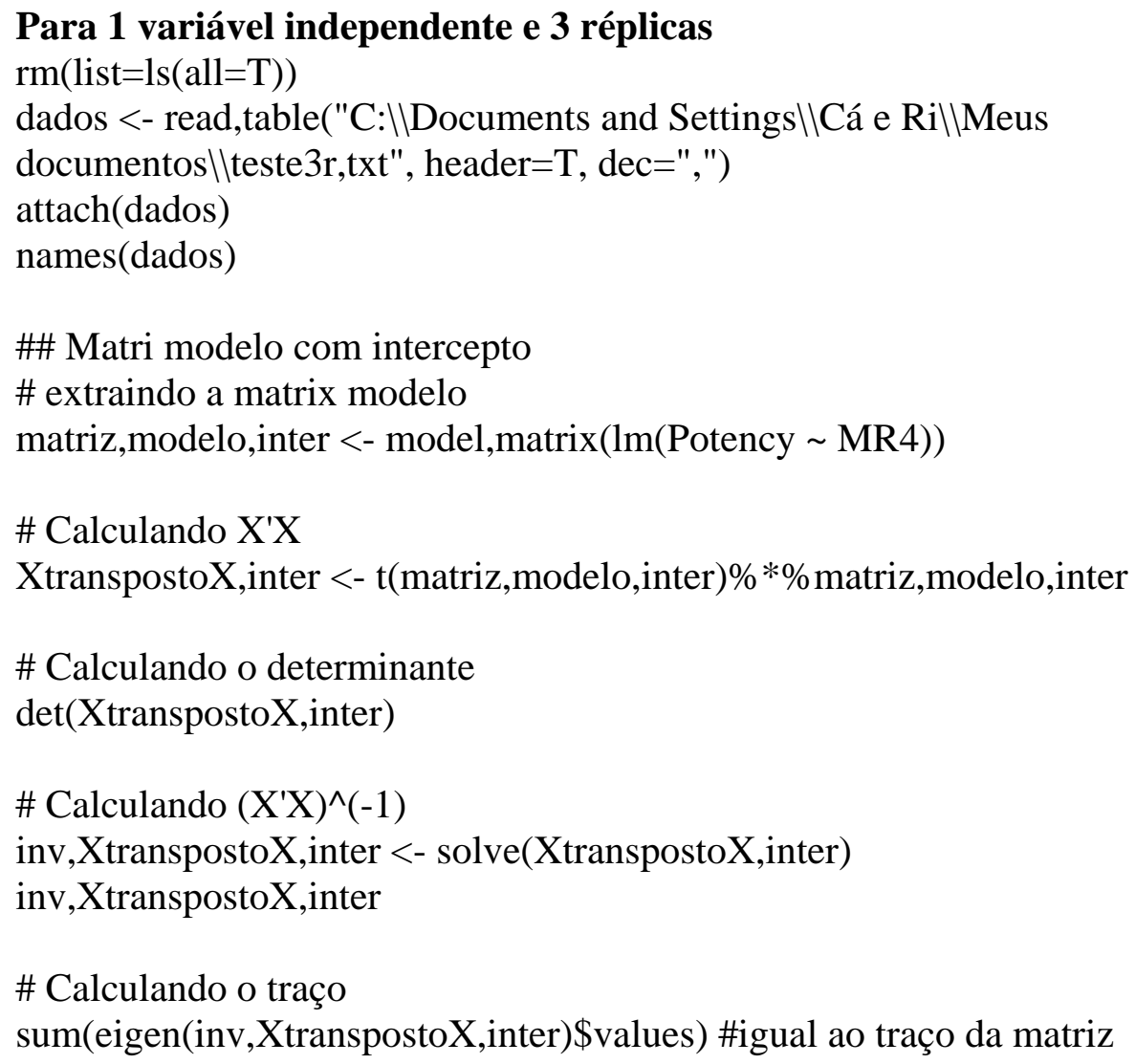

\section{Para 1 variável independente e 2 réplicas}

rm(list $=\mathrm{ls}($ all $=\mathrm{T}))$

dados <- read,table("C:\\Documents and Settings\\Cá e Ri \\Meus

documentos \\teste2r,txt", header=T, dec=",")

attach(dados)

names(dados)

\#\# Matri modelo com intercepto

\# extraindo a matrix modelo

matriz,modelo,inter <- model,matrix $(\operatorname{lm}($ Potency B4)

\# Calculando X'X

XtranspostoX,inter <- t(matriz,modelo,inter)\%*\%matriz,modelo,inter

\# Calculando o determinante

$\operatorname{det}($ XtranspostoX,inter)

\# Calculando $\left(\mathrm{X}^{\prime} \mathrm{X}\right)^{\wedge}(-1)$

inv,XtranspostoX,inter <- solve(XtranspostoX,inter)

inv,XtranspostoX,inter

\# Calculando o traço

sum(eigen(inv,XtranspostoX,inter)\$values) \#igual ao traço da matriz 


\section{Para 1 variável independente e 3 réplicas}

rm(list=ls(all=T))

dados <- read,table("C: \\Documents and Settings \\Cá e Ril\Meus

documentos \\teste3r,txt", header=T, dec=",")

attach(dados)

names(dados)

\#\# Matri modelo com intercepto

\# extraindo a matrix modelo

matriz,modelo,inter <- model,matrix $(\operatorname{lm}($ Potency $~ B 4))$

\# Calculando X'X

XtranspostoX,inter <- t(matriz,modelo,inter)\%*\%matriz,modelo,inter

\# Calculando o determinante

$\operatorname{det}($ XtranspostoX,inter)

\# Calculando $\left(\mathrm{X}^{\prime} \mathrm{X}\right)^{\wedge}(-1)$

inv, XtranspostoX,inter <- solve(XtranspostoX,inter)

inv,XtranspostoX,inter

\# Calculando o traço

sum(eigen(inv,XtranspostoX,inter)\$values) \#igual ao traço da matriz

Para calcular a Alavanca o caminho usado foi:

Stat $\rightarrow$ Regression $\rightarrow$ Storage $\rightarrow$ Leverages $\rightarrow$ ok.

\section{Calculando gráficos das páginas 73, 74, 76 e 77}

teste <- read.table("C: \\Documents and Settings $\backslash \backslash C a m i l a \backslash \backslash$ Meus documentos $\backslash \backslash$ teste.txt", header=T, dec=",")

attach(teste)

names(teste)

plot(obs=1:28, Alavanca,type="h",xlab="numero da observação" , ylab="Alavanca")

teste <- read.table("C: $\backslash \backslash$ Documents and Settings $\backslash \backslash C A \backslash \backslash$ Meus documentos $\backslash \backslash$ teste.txt", header=T, dec=",")

attach(teste)

names(teste)

plot(obs=1:42, alavanca,type="h",xlab="numero da observação" , ylab="alavanca") 


\section{Programação para construção dos gráficos da página 7.}

\# deletando arquivos pré-existentes no R

$r m($ list $=1 s(\operatorname{all}=\mathrm{T}))$

\# abrindo uma janela para 8 gráficos

$\operatorname{par}(\operatorname{mfrow}=\mathrm{c}(2,2))$

\# gráfico 1

$\# \operatorname{par}(\mathrm{fig}=\mathrm{c}(0.1,0.7,0.7,0.5))$

$x<-\operatorname{seq}(-1,1, b y=2 / 15)$

$y<-\operatorname{rep}(0, \operatorname{NROW}(x))$

plot $(x, y, p t y=" n ", y a x t=' n ', y l a b=" 1, \quad x l a b=" 1, \quad \operatorname{xaxp}=c(-1,1,1)$, $y \lim =c(\odot, \odot .1), \quad p c h=20, \operatorname{lwd}=3, \quad b t y=" n ", \operatorname{tck}=\odot)$

mtext ("a", 1, adj $=1$, line $=-\odot .8$ )

\# gráfico 2

$x<-\operatorname{seq}(-1,1, b y=2 / 6)$

$y<-\operatorname{rep}(0, \operatorname{NROW}(x))$

y1 <- $\operatorname{rep}(0.005, \operatorname{NROW}(x))$

plot $(x, y$, pty $=$ "n", yaxt='n', ylab="", $x l a b="$ la $x \operatorname{axp}=c(-1,1,2)$, $y \lim =c(\odot, \odot .1), p c h=2 \odot, \quad l w d=3, \quad b t y=" n "$, tck $=\odot)$

points $(x, y 1, p c h=20, l w d=3)$

mtext ("b", 1, adj $=1$, line $=-0.8$ )

\# gráfico 3

$x<-\operatorname{seq}(-1,1, b y=2 / 4)$

$y<-\operatorname{rep}(0, \operatorname{NROW}(x))$

y1 <- $\operatorname{rep}(0.005, \operatorname{NROW}(x))$

y2 <- $0.01 ; y 3<-0.015$

plot $\left(x, y, p t y=" n ", y a x t=n^{\prime}, y l a b="\right.$ ", $x \operatorname{lab}="$ ", $\operatorname{xaxp}=c(-1,1,2)$, $y \lim =c(\odot, \odot .1), p c h=2 \odot, \operatorname{lwd}=3$, bty $=" n "$, tck $=\odot)$

points $(x, y 1, p c h=20,1 w d=3)$

points $(x[1], y 2, p c h=20,1 w d=3)$

points $(x[1], y 3, \operatorname{pch}=20, \quad l w d=3)$

points $(x[5], y 2, p c h=20, l w d=3)$

points $(x[5], y 3, p c h=20, \quad l w d=3)$

mtext ("c", 1, adj $=1$, line $=-0.8$ )

\# gráfico 4

$x<-\operatorname{seq}(-1,1, b y=2 / 3)$

$y<-\operatorname{rep}(0, \operatorname{NROW}(x))$

y1 <- $\operatorname{rep}(0.005, \operatorname{NROW}(x))$

y2<- $0.010 ;$ y3<- $0.015 ;$ y4 <- 0.020

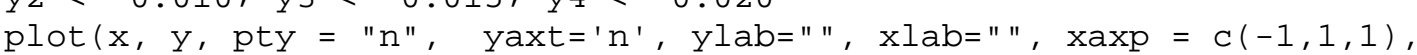
$y \lim =c(\odot, \odot .1), p c h=2 \odot, l w d=3$, bty $=" n "$, tck $=\odot)$

points $(x, y 1, p c h=20,1 w d=3)$

points $(x[1], y 2, p c h=20,1 w d=3)$

points $(x[1], y 3, p c h=20,1 w d=3)$

points $(x[1], y 4, p c h=20,1 w d=3)$

points $(x[4], y 2, p c h=20,1 w d=3)$

points $(x[4], y 3, \operatorname{pch}=20, \quad l w d=3)$

points $(x[4], y 4, p c h=20, \quad l w d=3)$

mtext ("d", 1, adj $=1$, line $=-\odot .8$ )

\# gráfico 5

$x<-\operatorname{seq}(-1,1, b y=1)$

$y<-\operatorname{rep}(0, \operatorname{NROW}(x))$

y1 <- $\operatorname{rep}(0.005, \operatorname{NROW}(x))$

y2 <- $\operatorname{rep}(0.010, \operatorname{NROW}(x))$

y3 <- $\operatorname{rep}(0.015, \operatorname{NROW}(x))$

y4 <- 0.020

plot $\left(x, y, p t y=" n ", y a x t=' n^{\prime}, y l a b=" ", \quad x l a b=" ", \quad x a x p=c(-1,1,2)\right.$, $y \lim =c(\odot, \odot .1), p c h=2 \odot, \quad l w d=3$, bty $=" n "$, tck $=0)$

$\operatorname{points}(x, y 1, p c h=20, \quad l w d=3)$

points $(x, y 2, p c h=20, \quad l w d=3)$

points $(x, y 3, \operatorname{pch}=20,1 w d=3)$

points $(x[1], y 4, p c h=20, \quad l w d=3)$ 


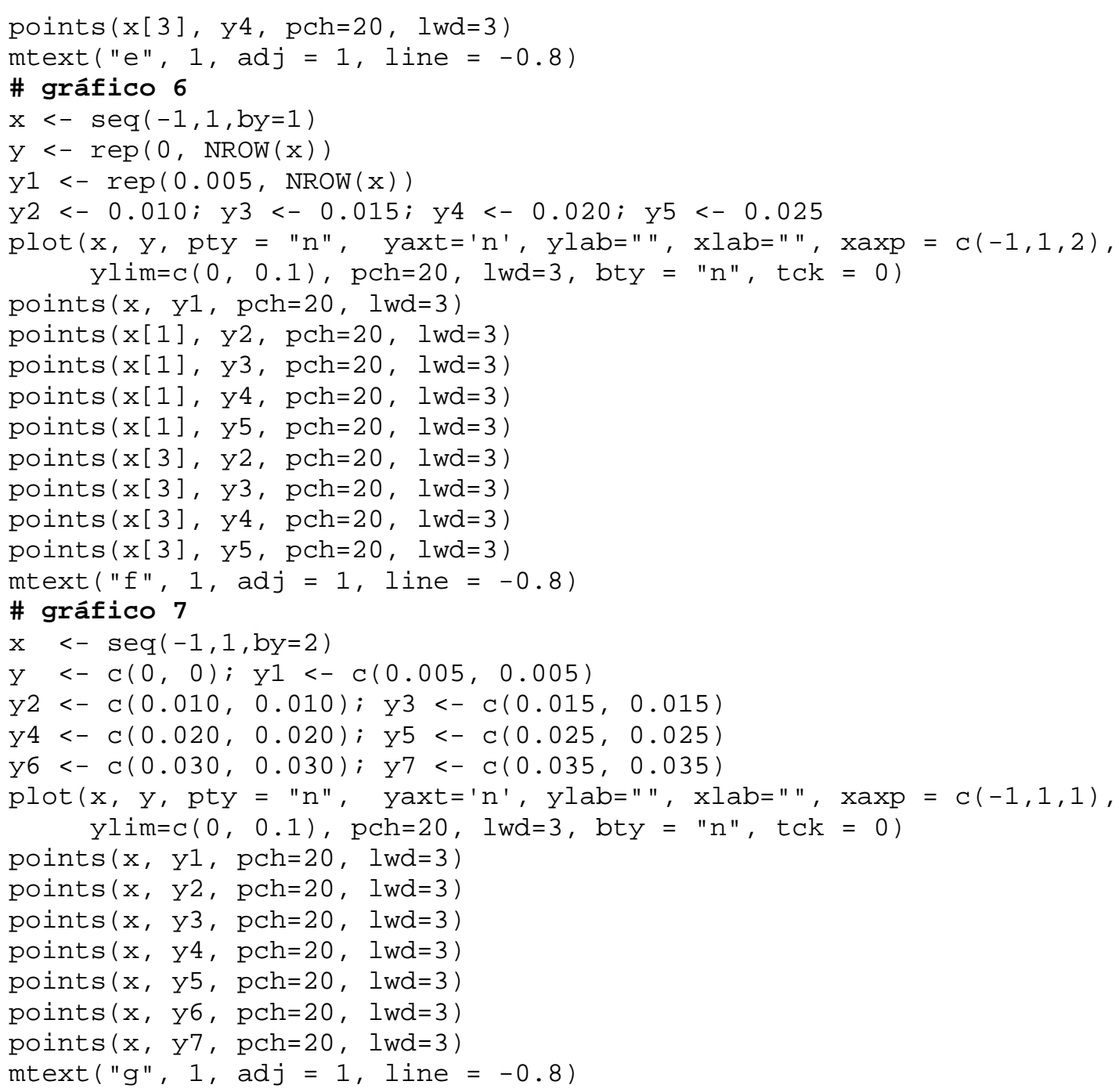




\section{Apêndice B}

\section{Teorema 3.1}

Prova:

i) Seja $Z^{T} Z=k I$. Então a i-ésima alavanca é $z_{i}{ }^{T}(k I)^{-1} z_{i}=k^{-1}\left\|z_{i}\right\|^{2}$. Portanto, segue que Z é um planejamento de alavancagem constante se e somente se todas as linhas de Z têm mesmo comprimento. Além disso, se cada linha tem comprimento um então as alavancagems são todas iguais a $\frac{1}{k}$ e como conseqüência, da Seção 3.2, temos que $k=\frac{n}{p}$

ii) Como Z é um planejamento de alavancagem constante, os pontos de $\mathrm{Z}$ encontram-se no elipsóide $\xi_{Z}\left(\frac{p}{n}\right)$. Pela suposição do item (i), este elipsóide coincide com uma esfera centrada e com isso a forma quadrática $\mathrm{q}(\mathrm{z})=Z^{T}\left(Z^{T} Z\right)^{-1} Z$ em $\mathfrak{R}^{p}$ define contornos esféricos. Este fato pode ocorrer somente se $\left(Z^{T} Z\right)^{-1}$ e, portanto $Z^{T} Z$ é uma matriz escalar. 
iii) Se $\mathrm{U}$ é uma matriz ortogonal então $\mathrm{U}^{T} \mathrm{U}=\mathrm{I}$ e assim, $(Z U)^{T} Z U=U^{T} Z^{T} Z U=U^{T} m I U=m U^{T} U=m I$. Portanto ZU é escalar.

vi) Como cada linha de $\mathrm{Z}$ é $\mathrm{Z}^{T}=\left[w_{i}{ }^{T}, \pm c_{i}{ }^{\frac{1}{2}}\right]$, então seu comprimento é $\left[\left\|w_{i}^{T}\right\|+\left(c_{i}^{\frac{1}{2}}\right)^{2}\right]^{\frac{1}{2}}=\left[\left\|w_{i}^{T}\right\|+\frac{p k}{m}-\left\|w_{i}^{T}\right\|^{2}\right]^{\frac{1}{2}}=\left(\frac{p k}{m}\right)^{\frac{1}{2}}$. Portanto, pelo item (i), basta provar que Z é um planejamento escalar.

Sejam $W_{j}$ e $Z_{j}$ respectivamente as colunas de $\mathrm{W}$ e $\mathrm{Z}$. Por construção, as p-1 primeiras colunas de $Z$ são tais que $\left\|Z_{j}\right\|^{2}=2\left\|W_{j}\right\|^{2}$ e devido à hipótese $W^{T} W=k I_{p-1}$, segue que $\left\|W_{j}\right\|^{2}=k \quad e\left\|Z_{j}\right\|^{2}=2 k$ para $\mathrm{j}=1,2, \ldots, \mathrm{p}-1$.

Para j=p, $\left\|Z_{p}\right\|^{2}=2 \sum_{i=1}^{m} c_{i}=2\left[m\left(\frac{p k}{m}\right)-\sum_{i=1}^{m}\left\|w_{i}^{T}\right\|^{2}\right]$ e como $2 \sum_{i=1}^{m}\left\|w_{i}^{T}\right\|^{2}$ é a soma dos quadrados de todos os elementos das $\mathrm{p}-1$ primeiras colunas de $\mathrm{Z}$, essa quantidade se reduz a $2 \sum_{j=1}^{p-1}\left\|W_{j}\right\|^{2}$.

Além disso, $\left\|\mathrm{W}_{j}\right\|^{2}=\mathrm{k}$ pela hipótese de que $W^{T} W=k I_{p-1}$. Portanto temos que $\left\|Z_{p}\right\|^{2}=2 k$, o que prova que todas as colunas de $Z$ têm mesmo comprimento.

A ortogonalidade das colunas de $\mathrm{Z}$ é conseqüência da ortogonalidade das colunas de W e pela forma de construção $\left( \pm c_{i}^{\frac{1}{2}}\right)$ da p-ésima coluna de Z.

Portanto, Z é uma matriz de planejamento escalar de alavancagem constante de ordem $2 \mathrm{~m} x$ p. Como o comprimento de cada linha de $\mathrm{Z}$ é $\left(\frac{p k}{m}\right)^{\frac{1}{2}}$, os vetores $\mathrm{Z}^{T}$ pertencem à esfera de raio $\left(\frac{p k}{m}\right)^{\frac{1}{2}}$. 


\section{Apêndice C}

\section{Referências Bibliográficas}

Atkinon, A.C. (1972), Planning Experiments to Detect Inadequate Regression Models, Biometrika, 59, 275-293.

Box, G.E.P. (1954), The Exploration and Exploitation of Response Surfaces: Some General Considerations and Examples, Biometrics, 10, 16 - 60.

Box, G.E.P. (1982), Choice of Response Surface Design and Alphabetic Optimality, Utilitas Mathematica, 213, 11 - 55.

Box, G.E.P. and N. R. Draper (1959). A Basic for the Selection of a Response Surface Design. Journal of the American Statistical Association, 54, 622-654.

Box, G.E.P. and N.R.Draper (1975). Robust Designs. Biometrika, 62, 347-352.

Box G.E.P. and N.R.Draper (1987). Empirical Model Building and Response Surfaces. New York: John Wiley. 
Box, G.E.P. and Hunter, J.S. (1957). Multifactor Experimental Designs for Exploring Response Surfaces. Annals of Mathematical Statistics 28, p195.

Box, G.E.P., and Wilson, K.B.(1951), On the Experimental Attainment of Optimum Conditions, Journal of the Royal Statistical Society, Ser.B, 13, 1-45 (with discussion).

Box, G.E.P, and Youle, P.V. (1975), The Exploration and Exploitation of Response Surfaces: An Example of the link Between the Fitted Surface and the Basic Mechanism of the Sistem, Biometrics, 11, 287 - 323.

Cook, R.D. and Weiberg, S. (1982). Residuals and Influence in Regression. New York: Chapman and Hall.

Draper, N.R. (1982) “Center Points in Second - order Response Surface Designs," Technometrics, 24, $127-133$.

Draper, N.R., Smith, H. (1981) Applied Regression Analyses. 2nd ed. New York: John Wiley.

Dollinger, M. B. and R.G. Staudte (1990). The construction of Equileverage Designs for Multiple Linear Regression. Australian Journal of Statistics, 32(1), 99-118.

Dykstra, O. (1971). The Augmentation of Experimental Data to Maximize $\left|X^{T} X\right|$, Technometrics, 13, 682-688.

Evans, J. W. (1979). Computer Augmentation of Experimental Designs to Maximize $\left|X^{T} X\right|$. Technometrics 21, pp. 321-330.

Fedorov, V.V. (1969a). Properties and Methods for Construction of Point Optimal Designs in Regression Experiments. Peprint No.5 LSM, Izd - vo - Moscow State University, Moscow, USSR. 
Fedorov, V.V. (1969b). Theory of Optimal Experiments. Preprint No. 7 LSM, Izd - vo Moscow State Universty, Moscow, USSR.

Fedorov, V.V.(1972). Theory of Optimal Experiments. Translated and edited by W.J.Studden, and E.M. Klimko. New York: Academic Press.

Fedorov, V.V., and Dubova, I.S. (1968). Methods for Constructing Optimal Designs in Regression Experiments. Preprint No.4, LSM, Izd- vo - Moscow State University, Moscow, USSR.

Fisher, R.A. (1922), On the Mathematical Foundations of Theoretical Statistics, Philosophical Transactions of the Royal Society of London, Ser. A, 222, 309 - 368.

Fisher, R.A. (1926), The Arrangement of Field Experiments, Journal of the Ministry of Agriculture, 33, $503-513$.

Galil, Z., and Kiefer, J. (1977a), Comparison of Rotatable Designs for Regression on Balls, I (Quadratic), Journal of Statistical Planning and Inference, 1, 27 - 40.

Galil, Z., and Kiefer, J. (1977b), Comparison of Designs for Quadratic Regression on Cubes, Journal of Statistical Planning and Inference, 1, 121 - 132.

Galil, Z., and Kiefer, J. (1979), Extrapolation Designs and $\phi_{p}$-optimum Designs for Cubic Regression on the q-ball, Journal of Statistical Planning and Inference, 3, 27 - 38.

Gaylor, D.W. and Merrill, J.A.(1968). Augmenting Existing Data in Multiple Regression. Technometriscs, 10, $73-81$.

Hahn, G. J., Dershowitz, A.F. (1974), Evolutionary Operation Today - Some Survey Results and Observations. Apllied Statistics, 23, 214-218.

Kiefer, J. and J. Wolfowitz (1959). Optimum Designs in Regression Problems. Annals of Mathematical Statistics, 30, 271-294. 
Lauter, E. (1974), Experimental Design in a Class of Models, Mathematische Operationforschung und Statistik, 5, 379 - 398.

Mitchel, T. J. (1974). Computer Construction of "D-optimal” First-order Designs. Technometrics, 16, $211-220$.

Mitchel, T. J. (1974). An Algorithm for the Construction on "D-optimal” Experimental Design. Technometrics, 16, $203-210$.

Montgomery, Douglas C., Design and Analysis of Experiments 2nd (1984) New York: John Wiley.

Ryan, Thomas P. , Modern Regression Methods (1997) New York: John Wiley.

Smith, k. (1918). On the Standard Deviations of Adjusted and Interpolated Values of an Observed Polynomial Function and its Constants and the Guidance they Give Towards Proper Choice of the Distribution of Observations, Biometrika, 12, 1-85.

Snee, R.D.(1985). Computer-aided designs of experiments: Some Practical Experiences. Journal of Quality Technology, 17, 222-236.

Spendley, W., Hext, G.R., and Himsworth, F.R. (1962). Sequential Application of Simplex Designs in Optimization and EVOP. Technometrics, 4, 441-461.

St, John, R.C and N.R. Draper (1975). D-optimality for Regression Designs: A review. Technometrics, 17, 15-24.

Steinberg, D.M. and W.G. Hunter (1984). Experimental Design: Review and Comment. Technometrics, 26, $71-130$.

Wald, A. (1943). On the Efficient Designs Statistical Investigations. Ann. Math. Statist., $14,134-140$. 
Wynn, H.P (1970). The Sequential Generation of D-optimum Experimental Designs. Ann. Math. Statist., 41, 1655-1664.

Yates, F. (1964), Sir Ronald Fisher and the Design of Experiments, Biometrics, 20, $307-321$. 